ANL-5219

Physics

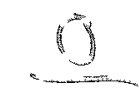

ARGONNE NATIONAL LABORATORY

P. O. Box 299

Lemont, Illinois

\title{
A TABULATION OF NEUTRON ENERGIES FROM MONOERGIC PROTONS ON LITHIUM
}

by

A. S. Langsdorf, Jr., J. E. Monahan, W. A. Reardon

PHYSICS DIVISION

January 1954

Operated by The Univer sity of Chicago

under

Contract $W-31-109-e n g-38$ 


\section{DISCLAIMER}

This report was prepared as an account of work sponsored by an agency of the United States Government. Neither the United States Government nor any agency Thereof, nor any of their employees, makes any warranty, express or implied, or assumes any legal liability or responsibility for the accuracy, completeness, or usefulness of any information, apparatus, product, or process disclosed, or represents that its use would not infringe privately owned rights. Reference herein to any specific commercial product, process, or service by trade name, trademark, manufacturer, or otherwise does not necessarily constitute or imply its endorsement, recommendation, or favoring by the United States Government or any agency thereof. The views and opinions of authors expressed herein do not necessarily state or reflect those of the United States Government or any agency thereof. 


\section{DISCLAIMER}

Portions of this document may be illegible in electronic image products. Images are produced from the best available original document. 
1.

\section{A TABULATION OF NEUTRON ENERGIES FROM MONOERGIC PROTONS ON LITHIUM}

by

A. S. Langsdorf, Jr., J. E. Monahan, W. A. Reardon

I. Introduction

The high energy voltage scale in the vicinity of one to three million volts has been calibrated to an accuracy of about $0.1 \%$.(1) The ability to control voltages of electrostatic generators in this region is now such that a relative precision of a few hundredths per cent can sometimes be claimed. Hence at times calculation of neutron energy from the $\mathrm{Li}^{7}(\mathrm{p}, \mathrm{n}) \mathrm{Be}^{7}$ reaction demands calculation to an accuracy exceeding $0.1 \%$, if loss of precision is to be avoided. Such calculations made repeatedly are tedious. The accompanying tables are intended to give neutron energies from the $\mathrm{Li}^{7}(\mathrm{p}, \mathrm{n}) \mathrm{Be}^{7} \mathrm{re}-$ action to about $0.01 \%$ or $10 \mathrm{ev}$, whichever is larger, in terms of the input data considered as numerically exact.

In connection with preparation for calculation of these tables, considerable work has been done to develop a convenient form of relativistic equation. Also a number of sources of shift, spread or error in neutron energies have been studied. The results may be of use in refined measurements or analysis not only of the $\mathrm{Li}^{7}(\mathrm{p}, \mathrm{n}) \mathrm{Be}^{7}$ reaction, but also of other two-body reactions, whether they yield neutrons or charged particles. The results of these studies are summarized in the following sections.

In case users of these tables discover errors, it will be appreciated if they notify the authors. Send the correction to A. Langsdorf, D203-G113, Argonne National Laboratory, Lemont, Illinois.

II. Theory

The completely relativistic expression for the energy of an outgoing particle in a two-body reaction may be derived in several ways. See, for example, Chapters I and II of Landau and Lifshitz.(2) The result may be written

$$
T_{3}=\frac{4 m_{3} D-A B \pm 2 \sqrt{D\left(B^{2}-2 m_{3} A B+4 m_{3}^{2} D\right)}}{A^{2}-4 D}
$$

in which

$$
\begin{aligned}
& A=2\left[m_{3}+m_{4}+T_{1}+Q\right] \\
& B=2 T_{1}\left[m_{1}-m_{4}-Q\right]-\left(2 m_{4} Q+Q^{2}\right)
\end{aligned}
$$


$\mathrm{D}=\mathrm{T}_{1}\left(\mathrm{~T}_{1}+2 \mathrm{~m}_{1}\right) \cos ^{2} \theta$

$m_{1}$ is the rest mass of the incident particle (proton)

$m_{2}$ is the rest mass of the stationary target atom (lithium -7)

$\mathrm{m}_{3}$ is the rest mass of outgoing particle of interest (neutron)

$m_{4}$ is the rest mass of the other outgoing or recoil atom (beryllium -7)

$T_{1}$ is the kinetic energy, in mass units, of the particle of mass $m_{1}$ at the moment of collision

$T_{3}$ is the kinetic energy in mass units of the particle of mass $m_{3}$

$\theta$ is the angle between the direction of motion of $m_{1}$ and $m_{3}$ in the laboratory frame of reference.

$Q=\left(m_{1}+m_{2}-m_{3}-m_{4}\right)$ is the reaction energy in the center of mass system.

When $Q$ is negative, as in the case of interest here, a threshold energy exists below which no reaction can occur. This will be called $\mathrm{T}_{\mathrm{ft}}$, or the "forward threshold," because it is the minimum value of $T_{1}$ which can give a real value of $T_{3}$ from equation (1). We find

$$
T_{f t}=-Q\left[1+\frac{m_{1}}{m_{2}}-\frac{Q}{2 m_{2}}\right]
$$

$\mathrm{T}_{\mathrm{ft}}$ is the threshold which Herb, et al.,(1) measured to be $1.882 \mathrm{Mev}$ and which in the tabulation has been assumed to be 1.88200 exactly.

Another threshold we make use of is the "back-threshold," represented by $T_{b t}$. This is the value of $T_{1}$ above which neutrons are emitted at angles $\theta \geqslant 90^{\circ}$. We find

$$
T_{b t}=-Q\left[1+\frac{m_{1}}{m_{2}-m_{3}}-\frac{Q}{2\left(m_{2}-m_{3}\right)}\right]
$$

The relativistic equation (1) can be made to appear almost like the classical expression as given by Hanson, et al., (3) if in equations ( 1 ) through (4) we substitute according to these defining equations:

$$
\begin{aligned}
& \mathrm{m}_{4}^{\prime}=\mathrm{m}_{4}+\mathrm{Q}=\mathrm{m}_{1}+\mathrm{m}_{2}-\mathrm{m}_{3} \\
& \mathrm{Q}^{N}=\mathrm{Q}\left[1-\left(\mathrm{Q} / 2 \mathrm{~m}_{4}^{\prime}\right)\right] \\
& \mu=\cos \theta \\
& \mathrm{z}=\frac{\mathrm{m}_{4}^{\prime}\left(\mathrm{m}_{4}^{\prime}+\mathrm{m}_{3}\right)}{\mathrm{m}_{1} \mathrm{~m}_{3}}\left(1-\frac{\mathrm{m}_{1}}{\mathrm{~m}_{4}^{\prime}}+\frac{\mathrm{Q}^{\circ}}{\mathrm{T}_{1}}\right)
\end{aligned}
$$

$$
\text { P.t." }
$$


with the result:

$$
T_{3}=\frac{T_{1} m_{1} m_{3} \beta_{1}}{\left(m_{3}+m_{4}^{\prime}\right)^{2}}\left[2 \mu^{2}+z \beta_{2} \pm 2 \mu \sqrt{\mu^{2}+z \beta_{3}}\right]
$$

where $\beta_{1}, \beta_{2}$, and $\beta_{3}$ are correction factors close to unity given by

$$
\begin{aligned}
& \beta_{1}=\frac{1+\left(T_{1} / 2 m_{1}\right)}{1+\frac{2 T_{1}}{m_{1}+m_{2}}\left(1-\frac{2 m_{1} \cos ^{2} \theta}{m_{1}+m_{2}}\right)+\frac{T_{1}^{2}\left(1-\cos ^{2} \theta\right)}{\left(m_{1}+m_{2}\right)^{2}}} \\
& \beta_{2}=\left[1+\left\{T_{1} /\left(m_{1}+m_{2}\right)\right\}\right] /\left[1+\left(T_{1} / 2 m_{1}\right)\right] \\
& \beta_{3}=\frac{1+\left[T_{1} /\left(m_{1}+m_{2}\right)\right]\left[1+\frac{m_{4}^{\prime}}{2 m_{3}}\left(1-\frac{m_{1}}{m_{4}^{\prime}}+\frac{Q^{\prime \prime}}{T_{1}}\right)\right]}{1+\left(T_{1} / 2 m_{1}\right)}
\end{aligned}
$$

Expression (12), with $\mu$ and $z$ given by (10) and (11), becomes just Hanson's expression if one identifies our $m_{4}$ ' and $Q$ " with his $m_{4}$ and $Q$, respectively, and makes the approximation that $\beta_{1}=\beta_{2}=\beta_{3}=1$.

It is desirable to eliminate $\mathrm{m}_{\dot{q}}^{\mathfrak{j}}$; then

$$
T_{3}=T_{1} \frac{m_{1} m_{3} \beta_{1}}{\left(m_{1}+m_{2}\right)^{2}}\left[2 \mu^{2}+z \beta_{2} \pm 2 \mu \sqrt{\mu^{2}+z \beta_{3}}\right]
$$

which may also be usefully written as

$$
T_{3}=T_{1} \frac{m_{1} m_{3} \beta_{1}}{\left(m_{1}+m_{2}\right)^{2}}\left[\left( \pm \mu+\sqrt{\mu^{2}+z \beta_{3}}\right)^{2}-\frac{z^{2} m_{1} T_{1}}{2\left(1+\frac{T_{1}}{2 m_{1}}\right)\left(m_{1}+m_{2}\right)^{2}}\right] \text { (16 }
$$

From equations (7) and (9) we obtain

$$
\frac{Q^{\prime \prime}}{T_{1}}=-\frac{T_{b t}}{T_{1}} \frac{m_{2}-m_{3}}{m_{1}+m_{2}-m_{3}}
$$

by aid of which, from (11) and (15), one obtains

$$
\begin{aligned}
& z=\frac{\left(m_{1}+m_{2}\right)\left(m_{2}-m_{3}\right)}{m_{1} m_{3}}\left(1-\frac{T_{b t}}{T_{1}}\right) \\
& \beta_{3}=\frac{1+\left[T_{1} /\left(m_{1}+m_{2}\right)\right]\left[1+\frac{m_{2}-m_{3}}{2 m_{3}}\left(1-\frac{T b t}{T_{1}}\right)\right]}{1+\left(T_{1} / 2 m_{1}\right)}
\end{aligned}
$$

Expressions (13), (14), (16a), (18), and (19) were the ones actually used in calculation of the tables in this report. The independent parameters in the equations were $m_{1}, m_{2}, m_{3}$, and $T_{f t}$. The value of $T_{b t}$ was calculated from equations (6) and (7). It is also at times convenient in such calculation of $\mathrm{T}_{\mathrm{bt}}$ to use

$$
\text { botion } 11 \text { ? }
$$




$$
\frac{T_{b t}-T_{f t}}{T_{f t}}=\frac{m_{1} m_{3}}{\left(m_{1}+m_{2}\right)\left(m_{2}-m_{3}\right)} \frac{1-\left(Q / 2 m_{1}\right)}{1-\left[Q / 2\left(m_{1}+m_{2}\right)\right]}
$$

in which expression only a rough value of $Q$ suffices.

After the actual tables were computed, it was observed that $\beta_{3}$, equation (19), is constant to within 4 parts per million for the $\mathrm{Li}^{7}(\mathrm{p}, n) \mathrm{Be}^{7}$ reaction up to $T_{1}=10 \mathrm{Mev}$. This occurs because $m_{1}$ and $m_{3}$ are nearly equal; even their slight difference is in a direction to make $\beta_{3}$ more nearly constant. One obtains very closely,

$$
\beta_{3} \cong 1-\left[T_{b t}\left(m_{2}-m_{3}\right) / 2 m_{3}\left(m_{1}+m_{2}\right)\right] \text {. }
$$

For the masses adopted in the calculation, $\beta_{3}$ is equal to 0.999234 . (At $T_{1}=10 \mathrm{Mev}$, the exact value of $\beta_{3}$ is 0.99923196. )

A useful approximation for $\beta_{1}$, accurate to a few parts in $10^{5}$ up to $10 \mathrm{Mev}$ proton energy, is the linear expansion

$$
\beta_{1}=1+\frac{T_{1}}{m_{1}+m_{2}}\left(\frac{m_{2}-3 m_{1}}{2 m_{1}}+\frac{4 m_{1} \cos ^{2} \theta}{m_{1}+n_{12}}\right)
$$

III. Investigation of Shift, Spread. or Error in Neutron Energy

A. A preliminary calculation of errors resulting from the classical formulation showed that they might sometimes be of the order of $0.1 \%$. The amount of error in the classical case depends on just what degree of approximation is employed. Rather than to exhaustively analyze the problem to find just when the calculation could be made classically and when it should be made relativistically, it was simpler to make the I.B.M. machine instructions everywhere fit the relativistic equation.

In the following analysis, the classical expression obtained from (16) by setting $\beta_{1}=\beta_{2}=\beta_{3}=1$ will be employed, ${ }^{*}$ i.e.,

*We retain equation (18) as the definition of $z$, classically, since this is most convenient for determination of energies near zero at "backangles." If, inaddition, we retain equation (7) in the calculation of $E_{b t}$, then $E_{f t}$ is not correctly given by equation (6). However, the difference is only about one part in $10^{5}$, and is not worth further consideration. One may also be consistent if one defines:

$$
E_{b t}=-Q\left(m_{1}+m_{2}-m_{3}\right) /\left(m_{2}-m_{3}\right) \text { and } E_{f t}=-Q\left(m_{1}+m_{2}\right) / m_{2}
$$

for purposes of classical calculation.

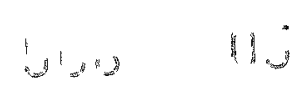




$$
E_{3}=\frac{m_{1} m_{3}}{\left(m_{1}+m_{2}\right)^{2}} E_{1}\left(2 \mu^{2}+z \pm 2 \mu \sqrt{\mu^{2}+z}\right)
$$

or

$$
E_{3}=\frac{m_{1} m_{3}}{\left(m_{1}+m_{2}\right)^{2}} E_{1}\left(t \mu+\sqrt{\mu^{2}+z}\right)^{2}
$$

The second form, (21a), is convenient to use, because of the circumstance that the bracket in (21) is a perfect square. The symbol $\mathrm{E}$ is used for energy calculated classically or only approximately relativistically, while $T$ is reserved for the fully relativistic kinetic energy. Subscripts have the same meaning as when applied to $T$. The minus sign of the $\pm \mu$ term only applies in the "double energy" region, that is, with $\mu$ positive and $z$ negative. For all $z$ positive cases, $\mu$ is taken with the + sign choice so the $\mu$ is positive when $\theta<90^{\circ}$ and negative when $\theta>90^{\circ}$.

B. Doppler Effect - This effect is the largest correction considered and is quite important.

For this case equation (21) is modified by considering the target atom to have a thermal motion energy $E_{2}$, with this motion at an angle $\alpha$ to the axis provided by the direction of motion of the incident projectile of mass $\mathrm{m}_{1}$. We obtain

$$
E_{3}=\frac{m_{1} m_{3}}{\left(m_{1}+m_{2}\right)^{2}} E_{1}\left(\mu_{1}+\sqrt{\mu_{1}^{2}+z_{1}}\right)^{2}
$$

in which we ignore the lower energy group in the "double energy" region, Here

$$
\begin{aligned}
& \mu_{1}=\cos \theta+\sqrt{\frac{m_{2} E_{2}}{m_{1} E_{1}}} \cos (\theta-\alpha) \\
& z_{1}=z+\frac{m_{1}+m_{2}}{m_{3}}\left[\frac{\left(m_{1}-m_{3}\right) E_{2}}{m_{1} E_{1}}-2 \sqrt{\frac{m_{2} E_{2}}{m_{1} E_{1}}} \cos \alpha\right]
\end{aligned}
$$

On differentiating (22) with respect to $\alpha$ and setting $\left(\delta E_{3} / \delta \alpha\right)=0$ one obtains the angle for which the change in $E_{3}$ is greatest. It is given by

$$
\tan \alpha_{\mathrm{m}}=\sin \theta /\left[\cos \theta-\sqrt{\frac{m_{1} E_{1}}{m_{3} E_{3}}}\right]
$$

On inserting this value of $\alpha_{m}$ into (22) one obtains $E_{3 m}$. If then $E_{30}$ is the value of $E_{3}$ for $E_{2}=0$, we define $\Delta E_{3}=2\left(E_{3 m}-E_{30}\right)$ to be the full spread in $E_{3}$ for the specified value of $E_{2}$, and consider $\Delta E_{3}$ as a convenient measure of the Doppler effect. (A better measure would be obtained by a suitable integration of $\Delta E_{3}$ considered as a function of both $E_{2}$ and $\alpha$ over all $\alpha$ and over a. Maxwellian distribution of $\mathrm{E}_{2 .}$.) 
The value of $\Delta E_{3}$ as defined above is found to be given to a close approximation, neglecting some (always small) higher order terms, by

$$
\frac{\Delta E_{3}}{E_{3}}=\frac{4}{\sqrt{\mu^{2}+z}} \sqrt{\frac{m_{2} E_{2}}{m_{1} E_{1}}+\frac{m_{2} E_{2}}{m_{3} E_{3}}-2 \mu \sqrt{\frac{m_{2} E_{2}}{m_{1} E_{1}} \cdot \frac{m_{2} E_{2}}{m_{3} E_{3}}}}
$$

It is to be noted that the Doppler spread is considerably less for forward directions than backward. The above expression for the fractional spread, of course, diverges as $\mathrm{E}_{3} \rightarrow 0$. By aid of (22), equation (26) may be changed to give

$$
\Delta E_{3}=4\left(1+\frac{\mu}{\sqrt{\mu^{2}+z}}\right) \sqrt{m_{2} E_{2}\left\{m_{1} E_{1}+m_{3} E_{3}-2 \mu \sqrt{m_{1} E_{1} m_{3} E_{3}}\right\}}
$$

so that as $z \rightarrow 0$ and $E_{3} \rightarrow 0$, we find $\Delta E_{3}$ is given by $\sqrt{m_{1} E_{1} m_{2} E_{2}}$ multiplied by $8 /\left(m_{1}+m_{2}\right)$ if $\mu$ is positive, $4 /\left(m_{1}+m_{2}\right)$ if $\mu$ is zero, and 0 if $\mu$ is negative.

Some calculated values of $\Delta E_{3}$ and $\Delta E_{3} / E_{3}$ are given in the table below to show the order of magnitude of the effect. In these calculations $E_{2}=1 / 40$ ev was used, and $m_{1} \cong m_{3} \cong 1, m_{2} \cong 7$.

It may be noted that the Doppler motion makes a slight shift in the mean value of $E_{3}$. The shift in the mean is much smaller than the spread,

\begin{tabular}{|c|c|c|c|c|c|}
\hline $\begin{array}{c}E_{1} \\
\text { Mev }\end{array}$ & $\mathrm{E}_{3}$ & $\mathrm{z}$ & $\theta$ & $\Delta E_{3} / E_{3}$ & $\begin{array}{c}\Delta E_{3} \\
\mathrm{ev}\end{array}$ \\
\hline 1.9217 & 0 & 0 & $90^{\circ}$ & & 290 \\
\hline 1.924 & $90 \mathrm{ev}$ & .056 & $120^{\circ}$ & .36 & 33 \\
\hline 1.931 & $1120 \mathrm{ev}$ & .228 & $120^{\circ}$ & .073 & 82 \\
\hline 3.58 & $1.003 \mathrm{MeV}$ & 21.94 & $120^{\circ}$ & $4.76 \times 10^{-4}$ & 476 \\
\hline 2.71 & $1.005 \mathrm{Mev}$ & 13.78 & $0^{\circ}$ & $1.7 \times 10^{-4}$ & 170 \\
\hline
\end{tabular}
and is generally negligible.

The Doppler effect also causes the threshold $E_{f t}$ to spread out. Specifically, if the target atoms move toward the projectiles, a reaction can occur below the theoretical threshold for stationary target atoms. Quantitatively, we find, using equations (22) to (24), that for $E_{2}=0.025 \mathrm{ev}$, threshold will begin about $190 \mathrm{ev}$ lower than if $\mathrm{E}_{2}=0$ for $\mathrm{Li}^{7}(\mathrm{p}, \mathrm{n}) \mathrm{Be}^{7}$. An appreciable part of the low energy "tail" of the nearly linear rise of the neutron counting rate curve just above threshold, as actually observed with a well stabilized. electrostatic generator, may be ascribed to this Doppler effect. I! . 
C. Mass Uncertainty - As will be discussed below, an appreciable uncertainty exists concerning the proper mass of the target nucleus that should be applied. Most of this uncertainty, within the limitation that the reaction is still described as a two-body type, may be considered to be due to the variability in the number of electrons taking part in the collision and recoil process.

To study the problem analytically, differentiate equation (21a) with respect to $m_{2}$ with the result.

$$
\frac{1}{E_{3}} \frac{d E_{3}}{d m_{2}}=\frac{-2}{m_{1}+m_{2}}+\frac{1}{\left(\mu+\sqrt{\mu^{2}+z}\right) \sqrt{\mu^{2}+z} \frac{d z}{d m_{2}}} \text {. }
$$

Now $\mathrm{dz} / \mathrm{dm}_{2}$ takes on three values, depending on whether one takes Ebt, $Q$, or $\mathrm{E}_{\mathrm{ft}}$ independent of $\mathrm{m}_{2}$. The three derivatives are:

$$
\begin{aligned}
& \left(\begin{array}{c}
\delta z \\
\delta m_{2}
\end{array}\right)_{E_{b t}}=\left(\frac{1}{m_{2}-m_{3}}+\frac{1}{m_{1}+m_{2}}\right) z \\
& \left(\frac{\delta z}{\delta m_{2}}\right)_{Q}=\left(\frac{\delta z}{\delta m_{2}}\right)_{E_{b t}}-\frac{\left(m_{1}+m_{2}\right)\left[m_{1}-(Q / 2)\right] Q}{m_{1} m_{3}\left(m_{2}-m_{3}\right) E_{1}} \\
& \left(\frac{\delta z}{\delta m_{2}}\right)_{E_{f t}}=\left(\frac{\delta z}{\delta m_{2}}\right)_{Q}+\frac{\left(m_{1}+m_{2}\right)\left[m_{1}-(Q / 2)\right]\left(m_{1}+m_{2}-m_{3}-Q\right) Q}{m_{1} m_{2} m_{3}\left(m_{1}+m_{2}-Q\right) E_{1}}
\end{aligned}
$$

approximately,

If we put $m_{1}=m_{3}=1, m_{2}=7, Q=1.65 \mathrm{Mev}$, we find,

$$
\begin{aligned}
& \left(\frac{\delta z}{\delta m_{2}}\right)_{E_{b t}}=0.29 z ;\left(\frac{\delta z}{\delta m_{2}}\right)_{Q}=0.29 z+\left(2.2 / E_{1}\right), \text { and } \\
& \left(\frac{\delta z}{\delta m_{2}}\right)_{E_{f t}}=0.29 z+\left(0.55 / E_{1}\right)
\end{aligned}
$$

where $E_{1}$ is given in Mev.

In cases where equation (27) diverges, we may replace it by

$$
\frac{d E_{3}}{d m_{2}}=\frac{1}{m_{1}+m_{2}}\left\{-2 E_{3}+\frac{\left(d z / d m_{2}\right)}{\left(\frac{m_{1}+m_{2}}{m_{1} m_{3} E_{1}}-\frac{\mu}{1 m_{1} E_{1} m_{3} \overline{E_{3}}}\right)}\right\}
$$

which does not diverge at $E_{3} \rightarrow 0$. 
The uncertainty in the atomic mass of lithium as given by Li, Whaling, Fowler, and Lauritsen $(4)$ is 0.000026 mass unit. This is so much smaller than an uncertainty of one electron mass, which is 0.00055 mass unit, that we will concentrate attention on effects possibly ascribable to the number of electrons carried by the recoil berylluim.

A complete treatment of the electron problem undoubtedly would remove the reaction from the category of two-body reactions. We will assume the reaction remains a two-body type. This means we insist on retaining equation (5), $Q=m_{1}+m_{2}-m_{3}-m_{4}$, no matter how the number of electrons carried by recoil particles of mass $\mathrm{m}_{4}$ may vary. In turn this means that for a recoil of a given ionization, say $\mathrm{Be}^{+++}$, the target atom must be considered always to have one less unit of charge, e.g., Litt, in order that charge and mass be conserved when the recoil occurs with any particular state of ionization.

We assume that the threshold for loss of an electron by a recoil atom of mass $m_{4}$, velocity $v_{4}$, energv $E_{4}$ is at that velocity for which $v_{4}=v_{e}$, if $\mathrm{v}_{\mathrm{e}}$ is the velocity of the electron, (6) Then, if $\mathrm{E}_{\mathrm{e}}$ is the ionization potential for loss of an electron, we find that an electron will be lost if

$$
E_{4}>\frac{m_{4}}{m_{e}} E_{e}
$$

Since $E_{1}$ and $E_{3}$ are given in the tables, it is convenient to define

$$
E_{13}=E_{1}-E_{3}=E_{4}-Q
$$

In the following tabulation, states of ionization of Be are tabulated together with corresponding ionizations for the $L_{i}$, and the ranges of $E_{4}$ and $E_{13}$ within which these ionization states should apply on the basis of the above assumption:

$\begin{array}{llll}\mathrm{Be}^{+} & \mathrm{Li}^{0} & 0<\mathrm{E}_{4}<0.23 & 1.65<\mathrm{E}_{13}<1.88 \\ \mathrm{Be}^{++} & \mathrm{Li}^{+} & 0.23<\mathrm{E}_{4}<1.96 & 1.88<\mathrm{E}_{13}<3.60 \\ \mathrm{Be}^{+++} & \mathrm{Li}^{++} & 1.96<\mathrm{E}_{4}<2.77 & 3.60<\mathrm{E}_{13}<4.42 \\ \mathrm{Be}^{++++} & \mathrm{Li}^{+++} & 2.77<\mathrm{E}_{4} & 4.42<\mathrm{E}_{13}\end{array}$

A survey of the tables will show that the zero degree data (for which only the higher energy group is tabulated in the double-energy region below $1.9217 \mathrm{Mev}$ ) should use the mass of neutral lithium, Li ${ }^{0}$, the $60^{\circ}$ data that for $\mathrm{Li}^{+}$, and the $120^{\circ}$ data that for $\mathrm{Li}+$ up to $6.5 \mathrm{Mev}$, then $\mathrm{Li}++$ up to $8.75 \mathrm{Mev}$, and finally $\mathrm{Li}++$ above $8.75 \mathrm{Mev}$ proton energy ${ }^{*}$

* The values of $\mathrm{m}_{2}$ actually used in computation are discussed in Section VI on numerical values and results. 
To how much error does a change of one electron mass in the mass $m_{2}$ correspond? If the error were made in mis-assigning $m_{2}$ in determining threshold, then $\left(\mathrm{dz} / \mathrm{dm}_{2}\right)_{\text {Eft }}$ the derivative in equation (30) should be used because the fixed value $E_{f t}$ applies and $Q$ is a function of $m_{2}$. If the error were due to a change in the value of $m_{2}$ that should be used from that which applies at threshold calibration, then the derivative $(\mathrm{dz} / \mathrm{dm})_{Q}$ should be used from equation (29), because once established, $Q$ is not varied.

The following tabulation presents results of some calculations of $\Delta \mathrm{E}_{3}$ (for $\Delta \mathrm{m}_{2}=0.00055$ for $\mathrm{Li}^{7}(\mathrm{p}, \mathrm{n}) \mathrm{Be}^{7}$ ), representative of the magnitude of errors to be expected. Usually they are less than 10 ev or $0.01 \%$. They are considerably less than the Doppler broadening.

It is certain that the above mechanical interpretation of the meaning of a change of number of electrons carried by the recoil is not strictly correct. It is probable however, that the results of this calculation give an order of magnitude estimate of the spreading in neutron energy resulting from sharing of recoil momentum in the reaction by the electrons in the atoms with the recoil nucleus. If this is true, then the results may be interpreted, at least, as meaning that this type of phenomenon is an order of magnitude less important than the Doppler effect.

\begin{tabular}{|c|c|c|c|c|c|c|c|c|}
\hline \multicolumn{3}{|c|}{$\theta=0^{\circ}$} & \multicolumn{3}{|c|}{$\theta=60^{\circ}$} & \multicolumn{3}{|c|}{$\theta=120^{\circ}$} \\
\hline $\mathrm{E}_{3}$ & $\Delta \mathrm{E}_{3 \mathrm{Q}}$ & $\Delta E_{3 \mathrm{ft}}$ & $E_{3}$ & $\Delta \mathrm{E}_{3 Q}$ & $\Delta \mathbb{E}_{3 f t}$ & $E_{3}$ & $\Delta \mathrm{E}_{3 \mathrm{Q}}$ & $\Delta \mathrm{E}_{3 \mathrm{ft}}$ \\
\hline $121,400 \mathrm{ev}$ & $+21 \mathrm{ev}$ & $-7 \mathrm{ev}$ & & & & & & \\
\hline 135.560 & +19 & -8 & $43,290 \mathrm{ev}$ & $+28 \mathrm{ev}$ & $+4 \mathrm{ev}$ & $1,120 \mathrm{ev}$ & $+5 \mathrm{ev}$ & $+2 \mathrm{ev}$ \\
\hline 181,900 & +16 & -8 & 82,130 & +23 & +3 & 12,200 & +12 & +4 \\
\hline 348,520 & +10 & -11 & 218,610 & +20 & +1 & 81.470 & +19 & +8 \\
\hline $1,005,020$ & +4 & -14 & 771,820 & +21 & +4 & 451,040 & +35 & +23 \\
\hline 2.018 Mev & $-2 \mathrm{ev}$ & $-19 \mathrm{ev}$ & $1.641 \mathrm{Mev}$ & $+20 \mathrm{ev}$ & $+11 \mathrm{ev}$ & $1.0795 \mathrm{MeV}$ & $+58 \mathrm{ev}$ & $+44 \mathrm{ev}$ \\
\hline 4.035 & -2 & -19 & 3.379 & +47 & +30 & 2.365 & +77 & +64 \\
\hline 8.346 & -3 & -48 & 7.103 & +68 & +55 & 5.138 & +185 & +165 \\
\hline
\end{tabular}

In the above tabulation, $\triangle \mathrm{E}_{3 Q}$ represents $\Delta \mathrm{E}_{3}$ calculated by equation (29) for $Q$ constant and $\Delta E_{3 f t}$ the same for equation (30) where $E_{f t}$ constant.

The above classical calculations agree only approximately with the results of a completely relativistic exact calculation made at $T_{1}=10 \mathrm{Mev}$, 
where the deviations, on the whole, are the largest. The following tabulation gives the results of this exact calculation made using equations (6), (7), (13), (14), (16a), (18), and (19).

\begin{tabular}{|c|c|c|c|c|c|}
\hline & & \multicolumn{4}{|c|}{ State of Ionization Determining Mass of Target } \\
\hline$\theta$ & & $\mathrm{Li}_{\mathrm{i}}^{0}$ & $\mathrm{Lit}$ & $\mathrm{Li}++$ & $\mathrm{Li}+++$ \\
\hline \multirow{2}{*}{$0^{\circ}$} & $\mathrm{Li}^{0}$ & 8.346481 & 8.346501 & 8.346522 & 8.346542 \\
\hline & $\mathrm{Li}^{+}$ & 8.346475 & 8.346496 & 8.346516 & 8.346536 \\
\hline \multirow{2}{*}{$60^{\circ}$} & $\mathrm{Li}^{0}$ & 7.103224 & 7.103153 & 7.103081 & 7.103009 \\
\hline & $\mathrm{Li}^{+}$ & 7.103218 & 7.103148 & 7.103076 & 7.103004 \\
\hline \multirow{2}{*}{$120^{\circ}$} & $\mathrm{Li}^{0}$ & 5.137981 & 5.137798 & 5.137613 & 5.137429 \\
\hline & $\mathrm{Li}^{+}$ & 5.137977 & 5.137793 & 5.137609 & 5.137425 \\
\hline
\end{tabular}

The first column gives the angle, $\theta$, at which the neutrons are observed. The second column gives the two choices used in determining the effective mass $m_{2}$ at threshold by which in turn $Q$ is determined. The next four columns give the neutron energies for the four possible choices of ionization determining $m_{2}$ for the reaction at $T_{1}=10 \mathrm{Mev}$. It will be seen that the greatest possible change, percentagewise, is for the reaction at $120^{\circ}$, and is just about $0.01 \%$.

It may be of interest to compare values of $z, \beta_{1}, \beta_{2}$, and $\beta_{3}$, etco, computed for the four possible values of lithium mass. The values, which were obtained for $\mathrm{T}_{1}=10 \mathrm{Mev}$, are given in this tabulation.

\begin{tabular}{|c|c|c|c|c|c|}
\hline \multicolumn{2}{|c|}{} & $\mathrm{Li}^{0}$ & $\mathrm{Li}^{+}$ & $\mathrm{Li}++$ & $\mathrm{Li}+++$ \\
\hline & $\mathrm{Li}^{0}$ & 38.323022 & 38.316911 & 38.310799 & 38.304690 \\
$\beta_{2}$ & $\mathrm{Li}^{+}$ & 38.322992 & 38.316881 & 38.310770 & 38.304660 \\
$\beta_{3}$ & & 0.99603004 & 0.99603013 & 0.99603022 & 0.99603031 \\
$\beta_{1}$ & $0^{\circ}$ & 0.9992319 & 0.9992320 & 0.9992320 & 0.9992320 \\
$\beta_{1}$ & $60^{\circ}, 120^{\circ}$ & 1.0033165 & 1.0033164 & 1.0033163 & 1.0033163 \\
\hline
\end{tabular}




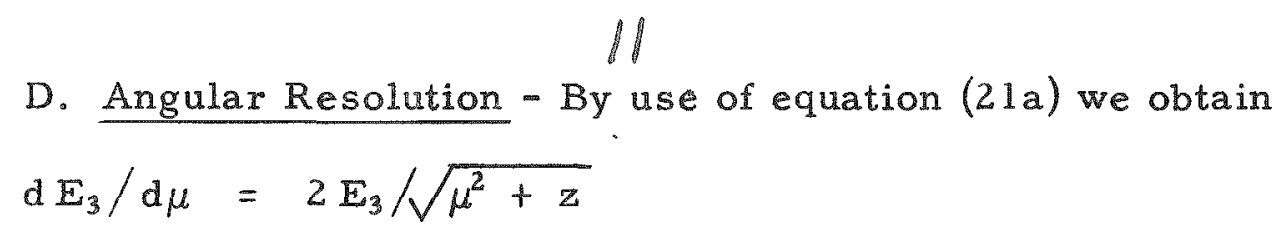

It is simple to calculate the stringency of angular resolution demanded for any desired resolution at a given angle and energy. [Values of $\Delta \mathrm{E}_{3}$ for $\Delta \theta=1^{\circ}$ are given in the tables for $0^{\circ}, 60^{\circ}$, and $120^{\circ}$. They were not, in fact, calculated by equation (32) but by calculating $E_{3}$ for one degree more and less than the given angle and tabulating one half the difference. The result agrees closely with equation (32).]

E. Target Thickness and Beam Energy Spread - Analytically, these two effects enter in the same way, since they determine the range of values of $E_{1}$ at the moment when the neutron producing reaction occurs. Normally the energy spread in the beam may be held in the range of $0.1 \%$ to $0.01 \%$ by a high resolution beam analyzer and a very stable accelerating machine. Lithium targets may be prepared which are as thin as may be warranted. The thinnest that may justifiably be used, presuming that the neutron flux produced is not the limiting factor, is such a thickness that the spread in neutron energy thereby resulting is about the same as that resulting from the combined effects of Doppler broadening and energy spread in the proton beam itself.

Expressions for $d E_{3} / d E_{1}$ may be written in a number of forms by suitable substitutions after differentiation of equation (2la). Some of these are:

$$
\begin{aligned}
\frac{d E_{3}}{d E_{1}} & =\frac{E_{3}}{E_{1}}+\frac{E_{3} E_{b t}\left(m_{1}+m_{2}\right)\left(m_{2}-m_{3}\right)}{E_{1}^{2}\left(\mu+\sqrt{\mu^{2}+z}\right) \sqrt{\mu^{2}+z}} \\
& =\frac{E_{3}}{E_{1}}+\sqrt{\frac{E_{3}}{E_{1}}} \frac{E_{b t}}{E_{1}} \frac{\left(m_{2}-m_{3}\right)}{\sqrt{m_{1} m_{3}} \sqrt{\mu^{2}+z}} \\
& =\frac{\sqrt{E_{3} / E_{1}}}{\sqrt{\mu^{2}+z}}\left\{\mu \sqrt{E_{3} / E_{1}}+\left(m_{2}-m_{3}\right) / \sqrt{m_{1} m_{3}}\right\}
\end{aligned}
$$

The form (33c) is particularly suited to show that the resolution is in general better at back-angles than forward, and that at low energy in the back direction, better resolution is attainable than a naive view suggests. As $E_{3} \rightarrow 0$ at $\mu=-1 / 2$, for example, one finds $\Delta E_{3} / E_{3}-12 \Delta E_{1} / \sqrt{E_{1} E_{3}}$. If, for example, $\Delta E_{1}=2000 \mathrm{ev}$ and $E_{3}=300$, one finds $\Delta E_{3} / E_{3} \cong 1$. Hence one may make measurements almost down to $300 \mathrm{ev}$ neutron energy before the resolution width is as wide as the distance from zero to the energy setting desired for $E_{3}$, with a spread in energy $E_{1}$ due to target and beam control of only this $2000 \mathrm{ev}$. 


$$
l_{i \rightarrow \infty}
$$

F. Considerations with Respect to $Q$ - If, instead of using $\mathrm{T}_{\mathrm{ft}}=1.882$ as the basic input energy, one wishes to use a $Q$ value obtained, for example, by adjustment from other nuclear data, confusion will be avoided if, from this $Q$ value, new values of $T_{f t}$ and $T_{b t}$ are calculated by equations (6) and (7), and these values used in the neutron energy calculation and in the proton energy calibration.

G. Uncertainty in Neutron Energy Resulting from Limited Accuracy of the Threshold Energy; Correction to a New Value of $\mathrm{T}_{\mathrm{ft} .}-$ In equation (18), the value of $\mathrm{z}$ is determined (aside from mass values used) only by the ratio $\mathrm{T}_{\mathrm{bt}} / \mathrm{T}_{1}$, and hence the value of $\mathrm{z}$ is practically independent of the absolute scale of energy, but experimentally $\mathrm{z}$ is limited in accuracy of determination only by the sensitivity and linearity of the voltage measuring system.* In equation (16) the relativity corrections are not very sensitive to small changes in $T_{1}$. However, $T_{3}$ is linearly related to the value of $T_{1}$ which is the leading term on the right side of equation (16). If, then, as is the normal practice, one calibrates the voltage scale for $\mathrm{Li}_{i}^{7}(\mathrm{p}, \mathrm{n}) \mathrm{Be}^{7}$ neutron work against the forward threshold measurements, this value of $T_{1}$ is linearly dependent on the value of $\mathrm{T}_{\mathrm{ft}}$ used.

It is apparent, therefore, that if a new value of $T_{f t}$ is adopted, the present tables can be used by looking up $\mathrm{T}_{3}$ for a value of $\mathrm{T}_{1}$, calculated assuming that $T_{f t}=1.88200$, then multiplying the value of $T_{3}$ so found by the ratio of the new $\mathrm{T}_{\mathrm{ft}}$ to 1.882 .

H. Solid Angle Relations Between Intensity of Neutrons in the Laboratory and Center of Mass System - The relativistic relation for this ratio probably is not simply related to the relativistic values of $T_{1}, T_{3}$, etc. However, a simple relation may be found in the classical calculation of this ratio. It is:

$$
\frac{I_{\ell}}{I_{c m}}=\frac{\left(m_{1}+m_{2}\right)\left[m_{1} m_{3}(z+1)-m_{2} m_{4}\right] E_{3}}{m_{1} m_{3} m_{4} Q \sqrt{z+1} \sqrt{\mu^{2}+z}}
$$

which may conveniently be calculated by aid of values of $z$ and $E_{3}$ from the tables. The above equation is derived from the relations given by Hanson et al. (3) Here $I_{\ell}$ is the intensity per unit solid angle in the laboratory at an angle $\theta$, and $I_{\mathrm{cm}}$ is the intensity per unit solid angle in the center of mass system at angle $\theta_{\mathrm{cm}}$.

* Absolute voltage calculations for both electrostatic and magnetic beam energy analyzers may be expected to require relativistic corrections for accuracies approaching $0.01 \%$, since this is a nonlinear correction. 
It may be of interest to perform activation experiments at the lowest possible energies. At low enough energies, $I_{\mathrm{cm}}$ is probably nearly a constant for $\mathrm{Li}^{7}(\mathrm{p}, \mathrm{n}) \mathrm{Be}^{7}$. If, in addition, one specifies the resolution $\triangle \mathrm{E}_{3}$ desired, one may use equation (32) to find $\Delta E_{3}=-2 \sin \theta \cdot \Delta \theta / \sqrt{\mu^{2}+z}$, by aid of which we obtain:

$$
I_{\ell} \Delta \Omega_{\ell}=\frac{\left(m_{1}+m_{2}\right)\left[m_{2} m_{4}-m_{1} m_{3}(z+1)\right] \Delta E_{3} \Delta \phi}{2 m_{1} m_{3} m_{4} Q \sqrt{z+1}}
$$

Qualitative consideration of this relation will show that if a foil be made in the shape of a ribbon wrapped around the full azimuth angle, the maximum intensity will be obtained at the smallest value of $z$ that can be used, which means $\theta$ should be near $90^{\circ}$ rather than near $180^{\circ}$. On the other hand, if a simple round foil is preferred, it should be used near $180^{\circ}$ so that the flux can be a maximum consistent with the desired $\Delta \mathrm{E}_{3}$. This problem has not been analyzed quantitatively. (See reference (7) for other useful solid angle equations.)

IV. The Excited State in $\mathrm{Be}^{7}$ and the Second Group of Neutrons from $\mathrm{Li}^{7}(p, n) B e^{7} * *$

Neutron energies from the reaction in which berylluim is left in its excited state were also calculated for $0^{\circ}, 60^{\circ}$, and $120^{\circ}$, and appear in the tables after the data for the reaction to the ground state. This calculation was set up on the basis of a back-threshold $E_{\mathrm{bt}}=2.4234 \mathrm{Mev}$ and assuming the mass of lithium corresponding to Lit. The corresponding $\mathrm{E}_{\mathrm{ft}}=2.3733 \mathrm{Mev}$ and $Q=2.0751$, which correspond to the excited state in $\mathrm{Be}^{7}$ being $0.4296 \mathrm{Mev}$ above the ground state. It was intended to choose something a bit higher for $E_{f t}$ and $Q$, but the above figures correspond to those actually adopted. The results are nevertheless probably accurate to three figures throughout most of the table. The tables are not as complete as the main tables, interpolation figures are not given, and not all data is so spaced that linear interpolation can always be correct. The general method of computation was the same as for the main tables. That is, the fully relativistic equation was employed.

V. Description of the Tables

Table I gives neutron energies for the $\mathrm{Li}^{7}(p, n) \mathrm{Be}^{7}$ reaction to the ground state of $\mathrm{Be}^{7}$. Table II gives similar data for the reaction to the excited state of $\mathrm{Be}^{7}$ at $430 \mathrm{kev}$. Both tables also give values of $\mathrm{z} \beta_{3}$ and $\mathrm{z} \beta_{2}$, as well as the neutron energies at $\theta=0^{\circ}, 60^{\circ}$, and $120^{\circ}$.

Column 1. Proton energies, $T_{p}\left(=T_{1}\right.$ in theory). Between values of $T_{p}$ lie values of the increment, $\Delta T_{p}$, as an aid to interpolation. 


\section{4}

Column 2. Neutron energies, $T_{n}\left(0^{\circ}\right)\left(=T_{3}\right.$ in theory). Between values of $\mathrm{T}_{\mathrm{n}}\left(0^{\circ}\right)$ lie values of the increment $\Delta \mathrm{T}_{\mathrm{n}}\left(0^{\circ}\right)$.

Column 3. The decrease in neutron energy on changing from $0^{\circ}$ to $1^{\circ}$, $\Delta T_{n}\left(0^{\circ}, 1^{\circ}\right)=\operatorname{Tn}\left(0^{\circ}\right)-T_{n}\left(1^{\circ}\right)$.

Column 4. The neutron energy $T_{n}\left(60^{\circ}\right)$ at $60^{\circ}$ and the increments.

Column 5. The quantity $\frac{1}{2}\left[T_{n}\left(59^{\circ}\right)-T_{n}\left(61^{\circ}\right)\right]=\frac{1}{2} \Delta T_{n}\left(59^{\circ}, 61^{\circ}\right)$ is the mean differential of neutron energy for a change in angle of one degree at $60^{\circ}$.

Column 6. As columns 2 and 4 , but for neutrons at $120^{\circ}$; thus, $T_{n}\left(120^{\circ}\right)$.

Column 7. Similarly to column 5 , this gives $\frac{1}{2}\left[T_{\mathrm{n}}\left(119^{\circ}\right)-\mathrm{T}_{\mathrm{n}}\left(121^{\circ}\right)\right]$ $=\frac{1}{2} \Delta T_{\mathrm{n}}\left(119^{\circ}, 121^{\circ}\right)$.

Column 8. Values of $z \beta_{2}$.

Column 9. Values of $z \beta_{3}$.

In Table II, columns 3, 5, and 7 are omitted. In Table I, the tabular values are so spaced that linear interpolation is accurate throughout. This is not always true for Table II.

For negative values of $z$, there are two neutron groups (at $0^{\circ}$ and at $60^{\circ}$ when neutrons appear at $60^{\circ}$ ). The tables only give the energy of the higher energy group.

The values of $z \beta_{2}$ and $z \beta_{3}$ are useful in calculations of $T_{n}$ for angles not tabulated. Since $\beta_{3}$ is almost constant with the value 0.999233 ( \pm 1 in the last figure between threshold and $10 \mathrm{Mev}$ ), z may easily be obtained from the tabulated values of $z \beta_{3}$, if desired.

The angular increment data in columns 3, 5, and 7 permits simple estimate of the energy resolution of experimental detection methods subtending angles up to a few degrees, and correction of mean energy for a setting deviating slightly from an intended setting of an even value of $60^{\circ}$ or $120^{\circ}$.

Details concerning the values of $\mathrm{m}_{2}$ (corresponding to the lithium target being $\mathrm{Li}^{0}, \mathrm{Li}^{+}, \mathrm{Li}^{+}+$, or $\mathrm{Li}+++$ ) which were actually used for the tabulated values in the tables are given in Section VI below. (See also Section III C above.)

Table $\mathrm{I}$ is intended only to be accurate to $0.01 \%$ or $10 \mathrm{ev}$, whichever is larger. Table II is not warranted to be more accurate than about $0.1 \%$. The tables are not, however, rounded off to the number of significant 


\section{5}

figures the above accuracy implies. The extra figures may be used with caution as a significant indication of the small difference in neutron energy for closely spaced values of $T_{1}$, but not otherwise.

Values of $T_{n}\left(60^{\circ}\right)$ in Table I are not tabulated quite all the way down to the $60^{\circ}$ threshold. In Table II, $T_{n}\left(0^{\circ}\right)$ is not tabulated quite down to threshold which is $2.3733 \mathrm{Mev}$, nor is $\mathrm{T}_{\mathrm{n}}\left(60^{\circ}\right)$ tabulated below the threshold for $T_{n}\left(120^{\circ}\right)$.

VI. Numerical Values Used in the Computation and Some Numerical Results

Basic input data is:

$\mathrm{m}_{1}$, proton mass $=1.007594$ mass units

$\mathrm{m}_{3}$, neutron mass $=1.008982$

$\mathrm{T}_{\mathrm{ft}}$, main group forward threshold $=1.88200$

Tbt, second group back-threshold $=2.4234$

$\mathrm{m}_{\mathrm{e}}$, mass of electron $=0.000548$ mass unit

Conversion factor, mass units to $\mathrm{Mev}=931.152$

$\mathrm{m}_{2}$, mass of neutral lithium $=7.018223$

Some derived quantities* are:

$$
\begin{aligned}
& \mathrm{m}_{2} \text { for } \mathrm{Li}^{+}=7.017675 \\
& \mathrm{~m}_{2} \text { for } \mathrm{Li}^{+}=7.017127
\end{aligned}
$$

\begin{tabular}{|l|c|c|}
\hline & $\begin{array}{c}\text { Calculated with } \\
\mathrm{m}_{2} \text { for } \mathrm{Li}^{+}\end{array}$ & $\begin{array}{c}\text { Calculated with } \\
\mathrm{m}_{2} \text { for } \mathrm{Li}^{+}\end{array}$ \\
$\mathrm{Q}^{\prime}$ for main group & $\begin{array}{l}1.645529 \\
2.07505\end{array}$ & 1.645512 \\
$\mathrm{~T}_{\mathrm{bt} \text { for main group }}$ & 1.9217082 & 1.9217145 \\
$\mathrm{~T}_{\text {ft }}^{\text {for second group }}$ & 2.3733 & \\
$\beta_{3}$ for main group & 0.9992343 & 0.9992343 \\
(calc. by equation (19a)) & & \\
\hline
\end{tabular}

The tabulated values of $\mathrm{z}_{2}$ and $\mathrm{z} \beta_{3}$ were calculated for a threshold $\mathrm{m}_{2}$ of $\mathrm{Li}+$ and an $\mathrm{m}_{2}$ of $\mathrm{Li}^{+}$up through $\mathrm{T}_{1}=6.45 \mathrm{Mev}$. At $6.5 \mathrm{Mev}$ for $\mathrm{T}_{1}$ and above, the threshold $\mathrm{m}_{2}$ seems to be still that of $\mathrm{Li}+$ and the $\mathrm{m}_{2}$ for the energy concerned, that of $\mathrm{Li}++$. The value of $z \beta_{2}$ or $z \beta_{3}$ above $6.45 \mathrm{Mev}$ and for a mass $m_{2}$ of Lit may be obtained to the third decimal place by adding 0.006 to the tabulated values.

* In some cases more figures are given than are significant. This is done to show how slight an effect a change in $m_{2}$ has in the computed result. 
In the actual I.B.M. calculations all the neutron energies were calculated using the above values of $z \beta_{2}$ and $z \beta_{3}$ for $\mathrm{m}_{2}$ of $\mathrm{Li}$ t up through $6.45 \mathrm{Mev}$ for $\mathrm{T}_{1}$, and $\mathrm{m}_{2}$ of $\mathrm{Li}+t$ at and above $6.50 \mathrm{Mev}$. This is not consistent with the theory of Section III C, but will be accurate to the intended $0.01 \%$. 


\section{$1 /$}

VII. References

1. R. G. Herb, S. C. Snowdon, O. Sala, "Absolute Voltage Determination of Three Nuclear Reactions," Phys. Rev., 75, 246 (1949)

2. L. Landau and E. Lifshitz, "The Classical Theory of Fields," AddisonWesley Press, Inc., 1951

3. A. O. Hanson, R. F. Taschek, J.H. Williams, "Monoenergetic Neutrons from Charged Particle Reactions," Rev. Mod. Phys., 21, 635 (1949)

4. C. W. Li, W. Whaling, W. A. Fowler, C. C. Lauritsen, "Masses of Light Nuclei from Nuclear Disintegration Energies," Phys. Rev., 83, 512 (1951)

5. F. Ajzenberg and T. Lauritsen, "Energy Levels of Light Nuclei. IV," Rev. Mod. Phys., 24, 321 (1952)

6. N. Bohr, Kgl. Dansk.Vid.Selsk., Math.-fys. Med., 18, 8 (1948)

7. T. W. Bonner and J.W. Butler, Phys. Rev. 83, 1096 (1951)

VIII. Acknowledgements

The authors are indebted to $M x$. Elwin L. Dershem for his expert calculation of the tables on the IBM machines. 
Table I

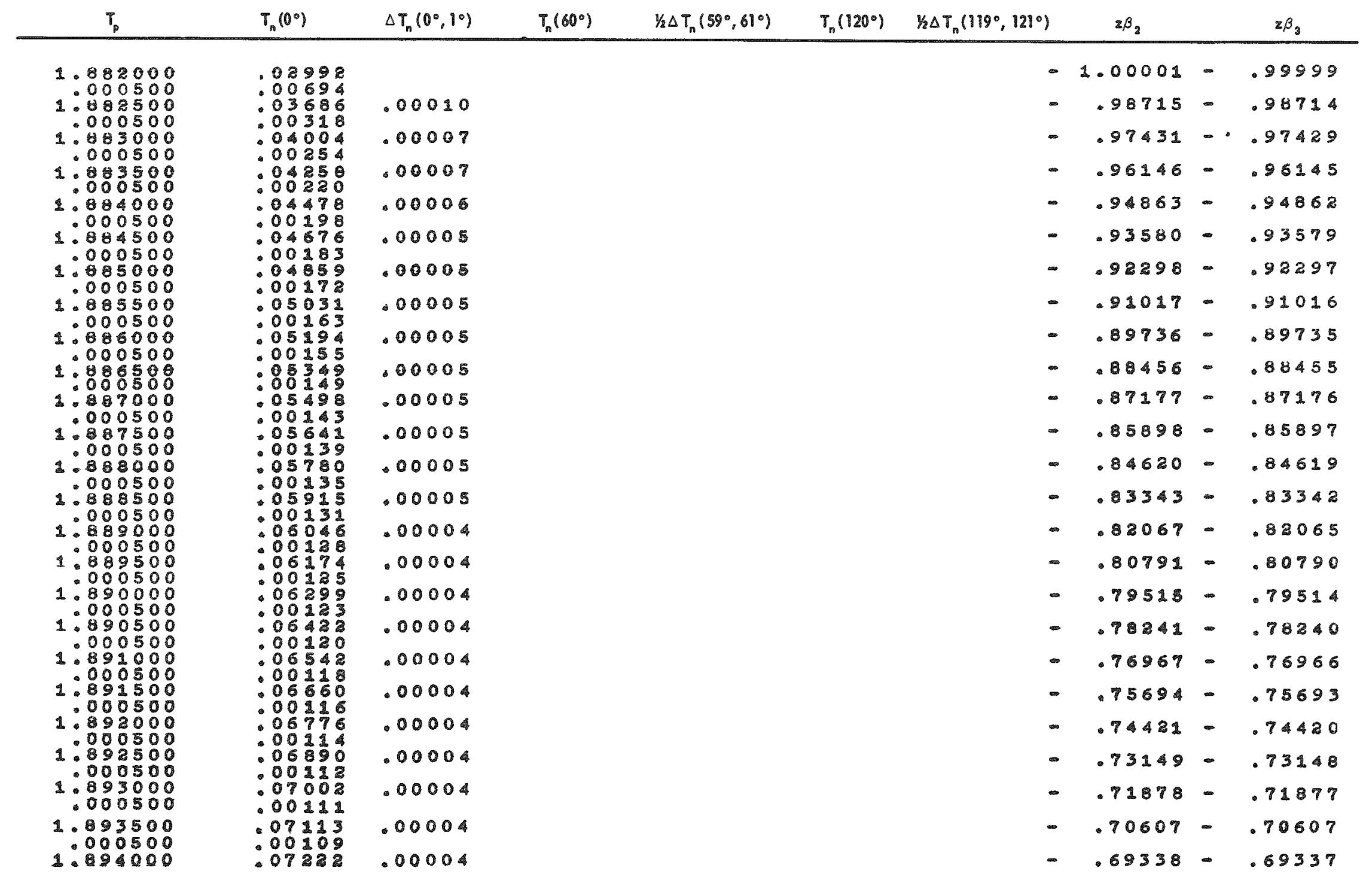




\begin{tabular}{|c|c|c|}
\hline 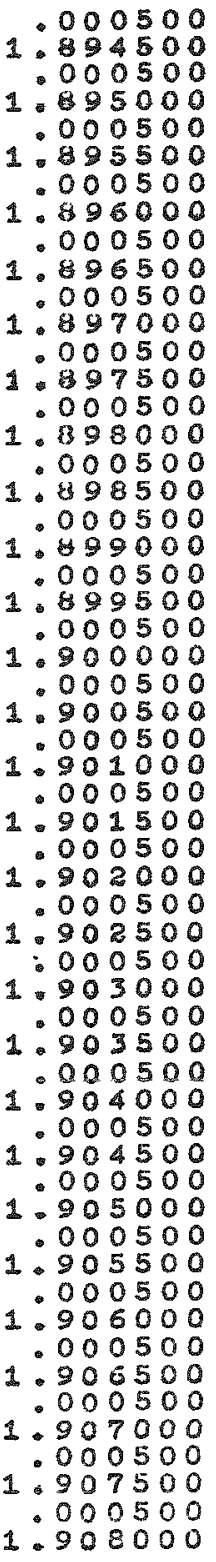 & 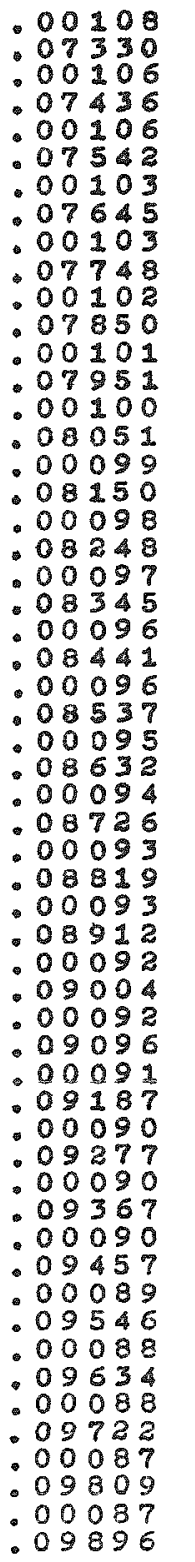 & 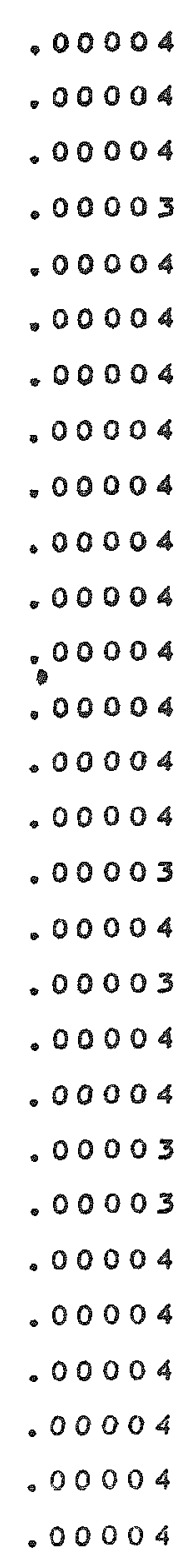 \\
\hline
\end{tabular}

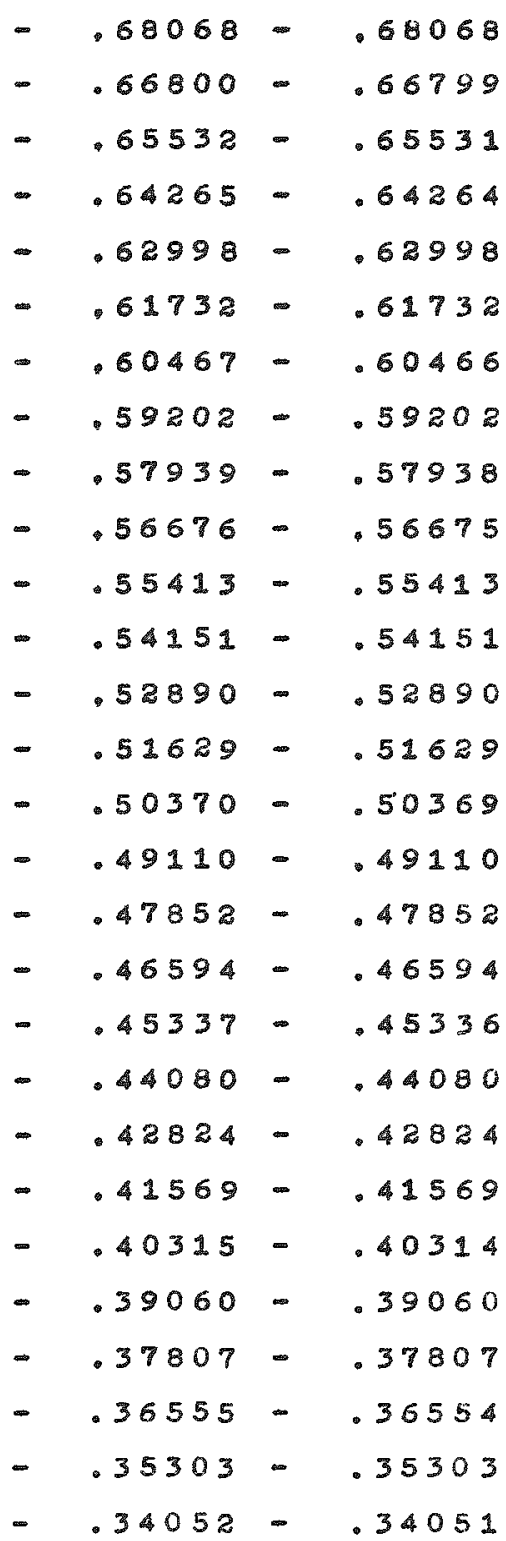




\begin{tabular}{|c|c|c|c|c|c|c|c|c|c|}
\hline \multicolumn{10}{|c|}{$\frac{2}{\text { Table I (Cont'd) }}$} \\
\hline$T_{p}$ & $T_{n}\left(0^{\circ}\right)$ & $\Delta T_{n}\left(0^{\circ}, 1^{\circ}\right)$ & $T_{n}\left(60^{\circ}\right)$ & $1 / 2 \Delta T_{n}\left(59^{\circ}, 61^{\circ}\right)$ & $T_{n}\left(120^{\circ}\right)$ & $1 / 2 \Delta T_{n}\left(119^{\circ}, 121^{\circ}\right)$ & $2 \beta_{2}$ & & $2 \beta_{3}$ \\
\hline \multirow{28}{*}{ 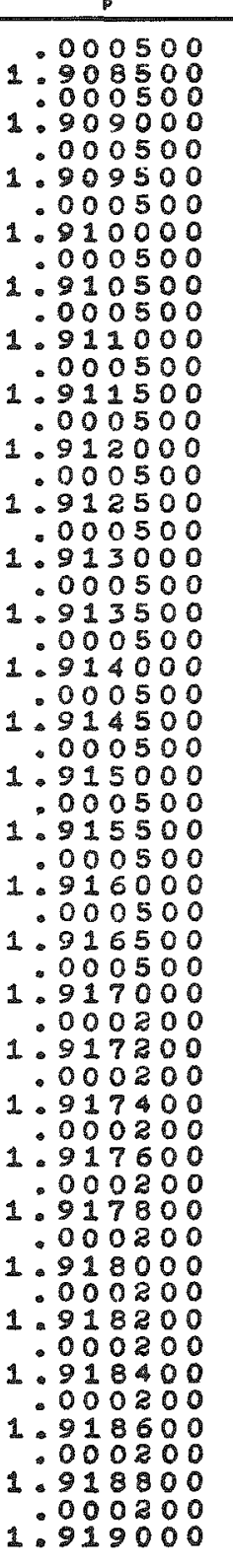 } & \multirow{28}{*}{ 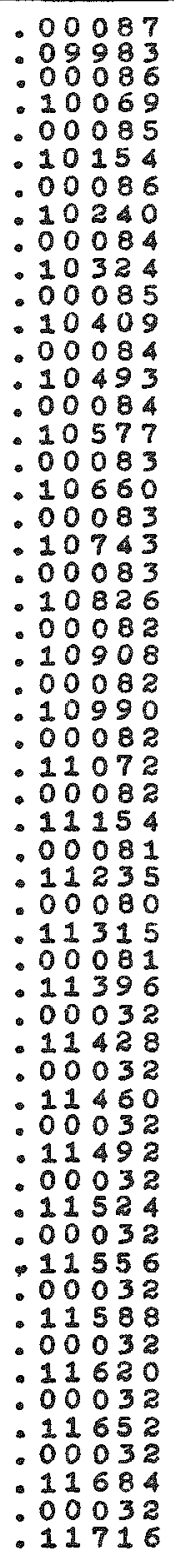 } & .00004 & \multirow{28}{*}{ 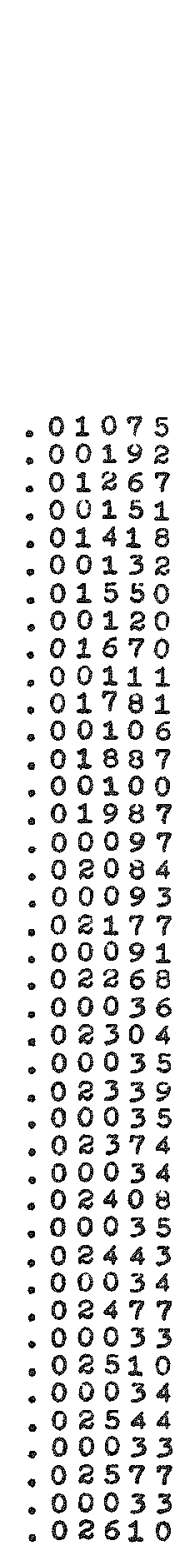 } & & & - & .32801 & - & .32801 \\
\hline & & .00004 & & & & - & .31551 & - & .31501 \\
\hline & & .00003 & & & & - & .30302 & - & .30301 \\
\hline & & .00004 & & & & - & .29053 & - & .29053 \\
\hline & & .00003 & & & & - & .27805 & - & .27805 \\
\hline & & .00004 & & & & - & .26558 & - & .26558 \\
\hline & & .00004 & & & & - & .25311 & - & .25311 \\
\hline & & .00004 & & & & - & .24065 & - & .24065 \\
\hline & & .00004 & & .00270 & & - & .22819 & - & .22819 \\
\hline & & .00003 & & .00235 & & - & .21575 & - & .21575 \\
\hline & & .00004 & & .00218 & & - & .20330 & - & .20330 \\
\hline & & .00003 & & .00208 & & - & .19087 & - & .19087 \\
\hline & & .00003 & & .00202 & & - & .17845 & - & .17844 \\
\hline & & .00004 & & .00197 & & - & .16602 & - & .16602 \\
\hline & & .00004 & & .00194 & & - & .15361 & - & .15360 \\
\hline & & .00004 & & .00191 & & - & .14120 & - & .14120 \\
\hline & & .00003 & & .00189 & & - & .12880 & - & .12860 \\
\hline & & .00004 & & .00188 & & - & .11640 & - & .11640 \\
\hline & & .00004 & & .00187 & & - & .11145 & - & .11145 \\
\hline & & .00003 & & .00187 & & - & .10649 & - & .10649 \\
\hline & & .00003 & & .00187 & & - & .10154 & - & $.101 \mathrm{~b} 4$ \\
\hline & & .00003 & & .00186 & & - & .09658 & - & .09658 \\
\hline & & .00003 & & .00186 & & - & .09163 & - & .09163 \\
\hline & & .00003 & & .00186 & & - & .08668 & - & .08668 \\
\hline & & .00004 & & .00185 & & - & .08173 & - & .08173 \\
\hline & & .00004 & & .00185 & & - & .07678 & - & .07678 \\
\hline & & .00004 & & .00185 & & - & .07183 & - & .07183 \\
\hline & & .00004 & & .00185 & & - & .06689 & - & .06689 \\
\hline
\end{tabular}




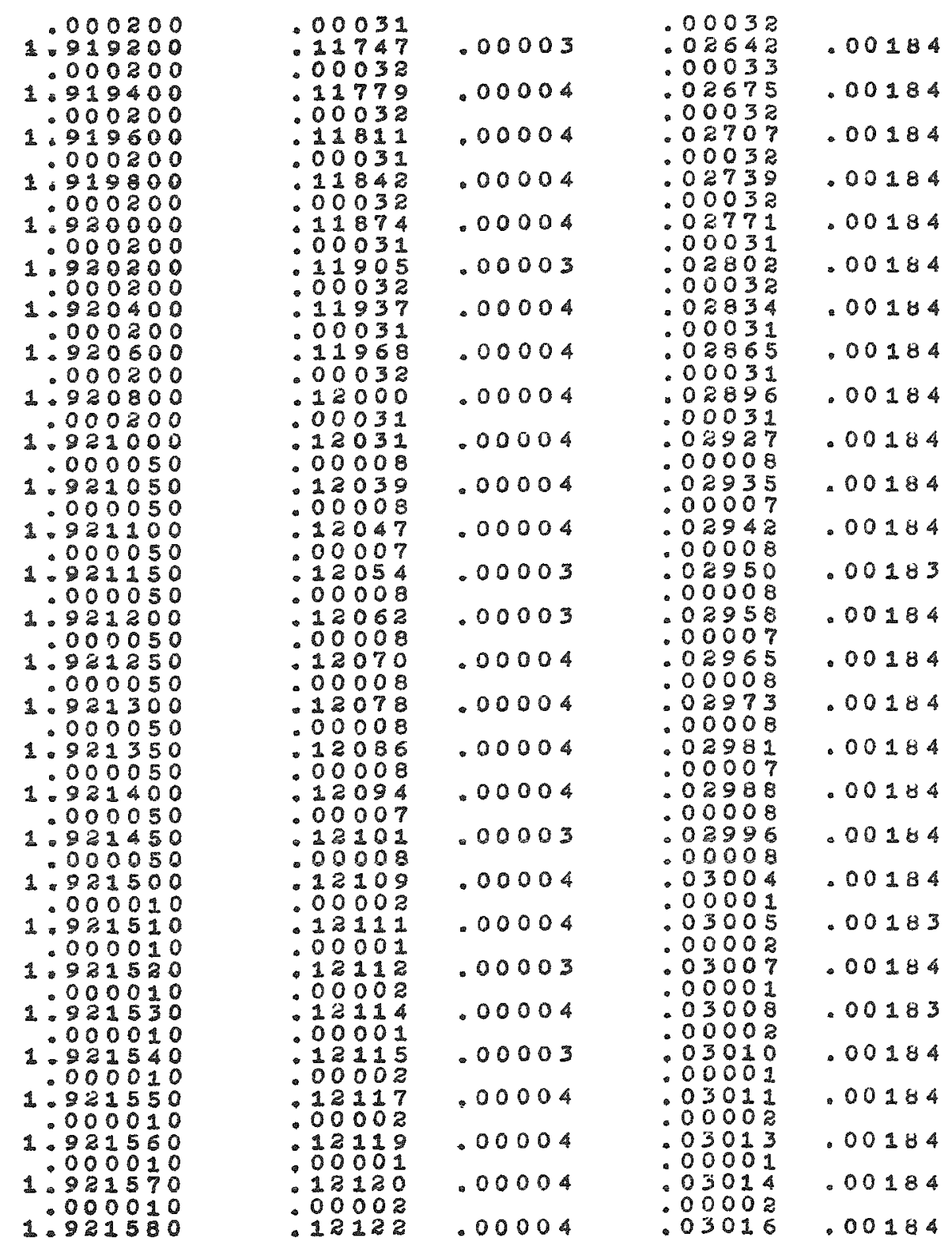

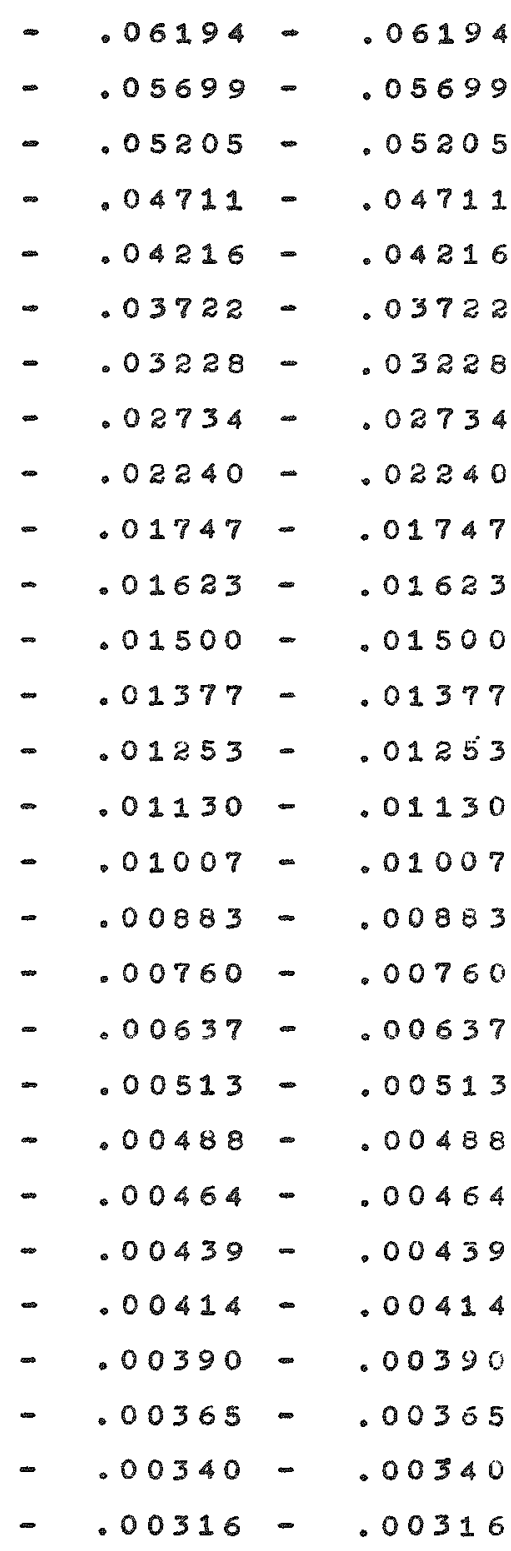


2

Table I (Cont'd)

\begin{tabular}{|c|c|c|c|c|c|c|c|c|}
\hline$T_{p}$ & $T_{n}\left(0^{\circ}\right)$ & $\Delta T_{n}\left(0^{\circ}, 1^{\circ}\right)$ & $T_{n}\left(60^{\circ}\right)$ & $1 / 2 \Delta T_{n}\left(59^{\circ}, 61^{\circ}\right)$ & $T_{n}\left(120^{\circ}\right)$ & $1 / 2 \Delta T_{n}\left(119^{\circ}, 121^{\circ}\right)$ & $z \beta_{2}$ & $z \beta_{3}$ \\
\hline \multirow{28}{*}{ 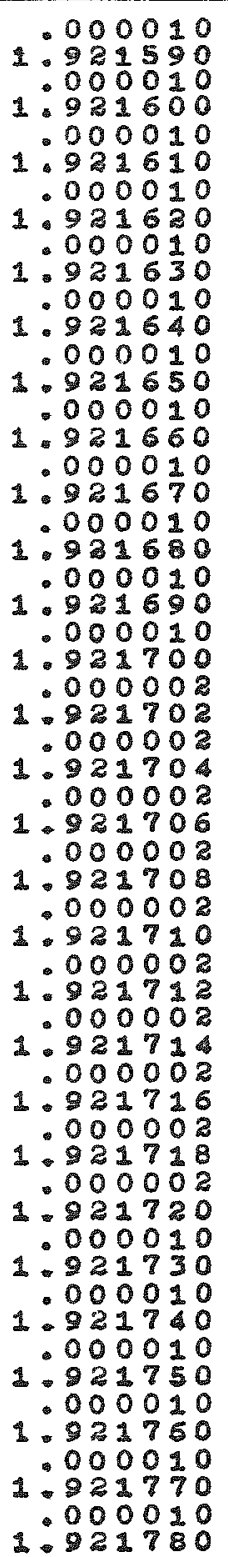 } & \multirow{28}{*}{ 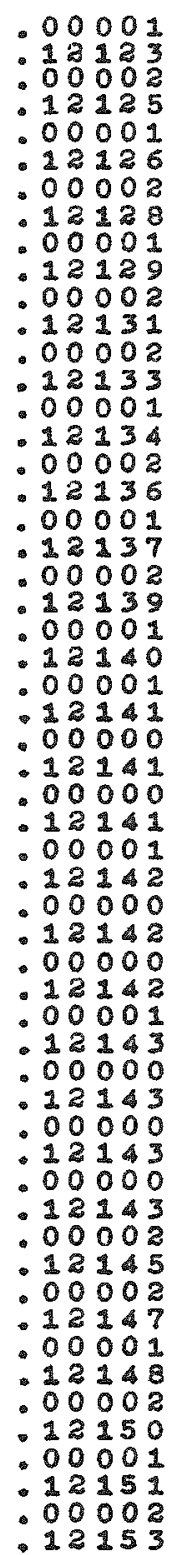 } & .00004 & \multirow{28}{*}{ 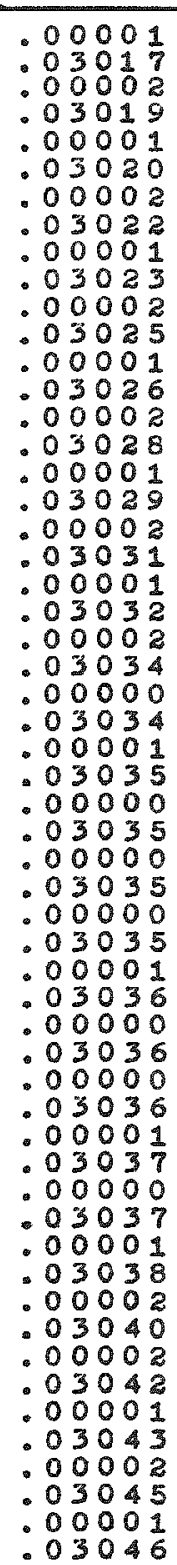 } & .00184 & & & .00291 & .00291 \\
\hline & & .00004 & & .00184 & & & .00266 & .00266 \\
\hline & & .00003 & & .00184 & & & .00242 & .00242 \\
\hline & & .00004 & & .00184 & & & .00217 & .00217 \\
\hline & & .00003 & & .00184 & & & .00192 & .00192 \\
\hline & & .00004 & & .00184 & & & .00168 & .00168 \\
\hline & & .00004 & & .00184 & & & .00143 & .00143 \\
\hline & & .00004 & & .00184 & & & .00119 & .00119 \\
\hline & & .00004 & & .00184 & & & .00094 & .00094 \\
\hline & & .00003 & & .00184 & & & .00069 & .00069 \\
\hline & & .00004 & & .00184 & & & .00045 & .00045 \\
\hline & & .00003 & & .00184 & & & .00020 & .00020 \\
\hline & & .00004 & & .00184 & & & .00015 & .00015 \\
\hline & & .00004 & & .00184 & & & .00010 & .00010 \\
\hline & & .00003 & & .00184 & & & .00005 & .00005 \\
\hline & & .00004 & & .00183 & .00000 & & .00000 & .00000 \\
\hline & & .00004 & & .00184 & .00000 & .00000 & .00005 & .00005 \\
\hline & & .00003 & & .00184 & $\therefore 0$ & .00000 & .00010 & .00010 \\
\hline & & .00004 & & .00184 & $\therefore 00000$ & .00000 & .00015 & .00015 \\
\hline & & .00004 & & .00184 & .00000 & .00000 & .00030 & .00020 \\
\hline & & .00004 & & .00184 & .00000 & .00000 & .00025 & .00025 \\
\hline & & .00003 & & .00184 & .00000 & .00000 & .00029 & .00029 \\
\hline & & .00004 & & .00184 & .00000 & .00000 & .00054 & .00054 \\
\hline & & .00004 & & .00184 & .00000 & .00000 & .00079 & .00079 \\
\hline & & .00004 & & .00184 & .00000 & .00000 & .00104 & .00104 \\
\hline & & .00004 & & .00184 & .00000 & .00000 & .00128 & .00128 \\
\hline & & .00003 & & .00184 & .00000 & .00000 & .00153 & .00153 \\
\hline & & .00004 & & .00184 & .00000 & .00000 & .00178 & .00178 \\
\hline
\end{tabular}




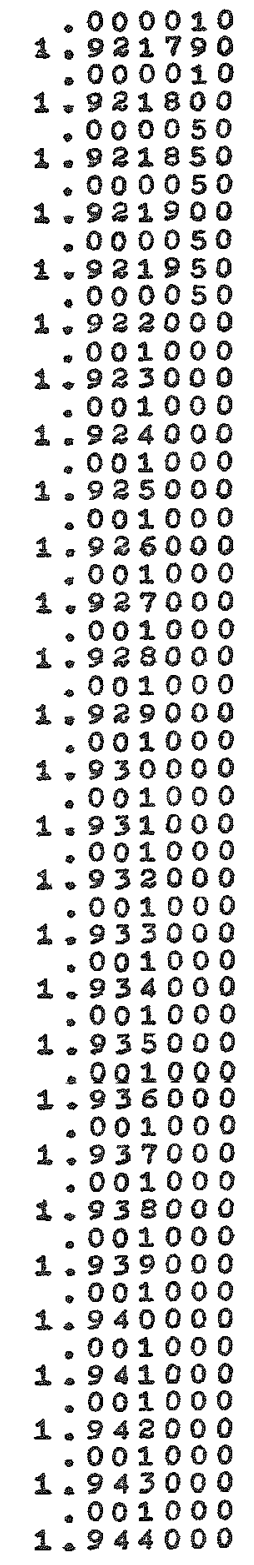

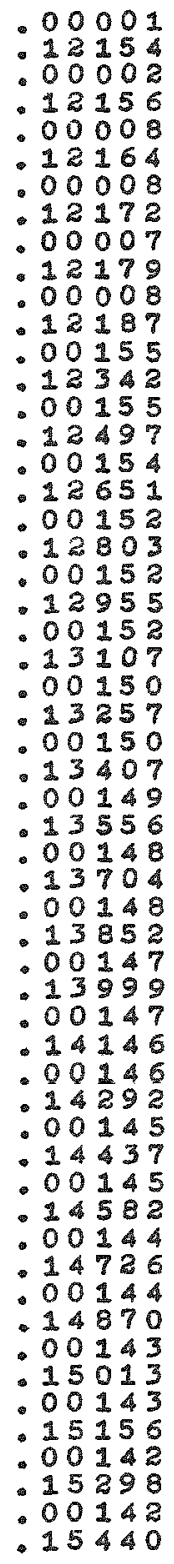

\begin{tabular}{|c|c|}
\hline .00003 & $\begin{array}{r}03048 \\
-030\end{array}$ \\
\hline .00004 & .03049 \\
\hline .00004 & $\begin{array}{r}03057 \\
.00007\end{array}$ \\
\hline .00004 & $\begin{array}{l}.03064 \\
.00008\end{array}$ \\
\hline .00003 & $\begin{array}{l}03072 \\
.00007\end{array}$ \\
\hline .00004 & $\begin{array}{r}03079 \\
00149\end{array}$ \\
\hline .00003 & $\begin{array}{l}.03228 \\
.00145\end{array}$ \\
\hline .00004 & $\begin{array}{l}03373 \\
.00143\end{array}$ \\
\hline .00004 & $\begin{array}{l}03516 \\
00140\end{array}$ \\
\hline .00003 & $\begin{array}{r}.03656 \\
.00138\end{array}$ \\
\hline .00003 & $\begin{array}{r}03794 \\
000137\end{array}$ \\
\hline .00004 & $\begin{array}{r}03931 \\
00134\end{array}$ \\
\hline .00004 & $\begin{array}{r}04065 \\
00133\end{array}$ \\
\hline .00004 & $\begin{array}{l}.04198 \\
.00131\end{array}$ \\
\hline .00004 & $\begin{array}{r}04329 \\
.00130\end{array}$ \\
\hline .00003 & $\begin{array}{r}04459 \\
0 \\
0\end{array} 0129$ \\
\hline .00004 & $\begin{array}{r}04588 \\
: 00127\end{array}$ \\
\hline .00003 & $\begin{array}{r}04715 \\
.00127\end{array}$ \\
\hline .00004 & $\begin{array}{r}04842 \\
.00125\end{array}$ \\
\hline .00004 & $\begin{array}{r}04967 \\
00124 \\
0\end{array}$ \\
\hline .00004 & $\begin{array}{r}05091 \\
00124\end{array}$ \\
\hline .00004 & $\begin{array}{l}05215 \\
.0012\end{array}$ \\
\hline .00004 & $\begin{array}{r}.05337 \\
000122\end{array}$ \\
\hline .00004 & $\begin{array}{r}05459 \\
0 \\
00121\end{array}$ \\
\hline .00004 & $\begin{array}{l}05580 \\
00120\end{array}$ \\
\hline .00004 & $\begin{array}{r}.05700 \\
.00120\end{array}$ \\
\hline .00004 & 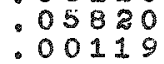 \\
\hline .00004 & 1007 \\
\hline
\end{tabular}

.00184

.00184

.00184

.00184

.00184

.00184

.00184

.00184

.00185

.00185

.00186

.00187

.00188

.00189

.00189

.00190

.00191

.00192

.00193

.00194

.00195

.00196

.00197

.00198

.00199

.00200

.00201

.00202

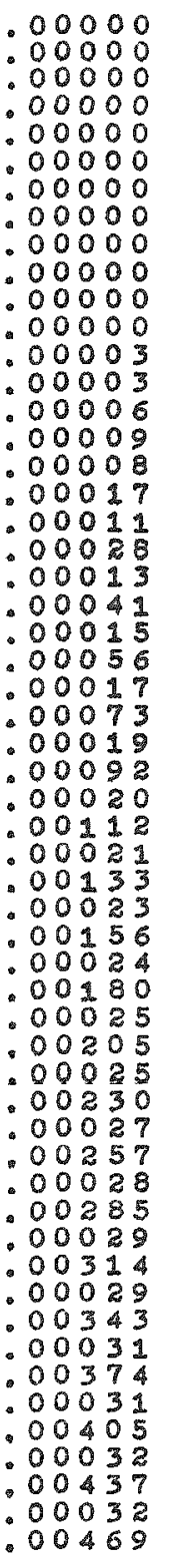

.00000

.00000

.00202

.00202

.00000

.00227

.00237

.00000

.00350

.00350

.00000

.00474

.00474

.00000

.00597

.00597

.00720

.00720

.00000

.03185

.03185

.00001

.05646

.05646

.00001

.08105

.08105

.00002

.10562

.10562

.00003

.13016

.13016

.00003

.15468

.15468

.00004

.17916

.17917

.00004

.20363

.20363

.22807

.25248

.27687

.30123

.32557

.34988

.37417

.39844

.42267

.00012

.00013

.00013

.00014

.00015

.00016
.44689

.47107

.49524

.51938

.54349 
24

Table I (Cont'd)

\begin{tabular}{|c|c|c|c|c|c|c|c|c|}
\hline$T_{p}$ & $T_{n}\left(0^{\circ}\right)$ & $\Delta T_{n}\left(0^{\circ}, 1^{\circ}\right)$ & $T_{n}\left(60^{\circ}\right)$ & $1 / 3 \Delta T_{n}\left(59^{\circ}, 61^{\circ}\right)$ & $T_{n}\left(120^{\circ}\right)$ & $Y / 2 \Delta T_{n}\left(119^{\circ}, 121^{\circ}\right)$ & $\mathbf{z} \beta_{2}$ & $2 \beta_{3}$ \\
\hline \multirow{28}{*}{ 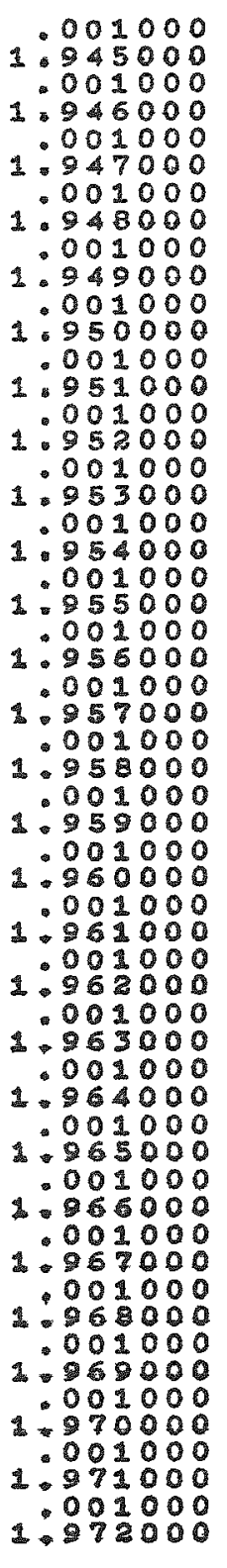 } & \multirow{28}{*}{ 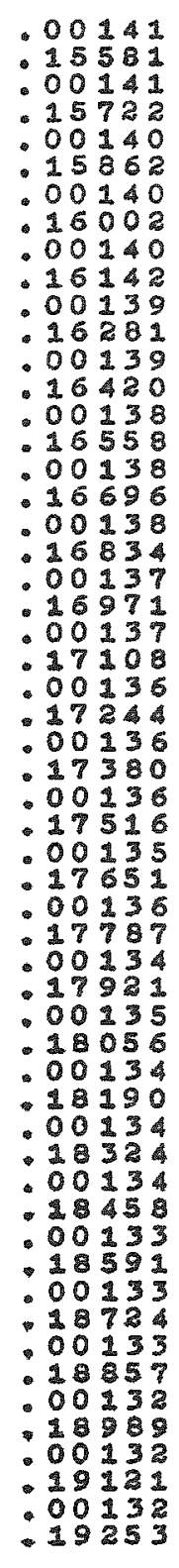 } & .00004 & \multirow{28}{*}{ 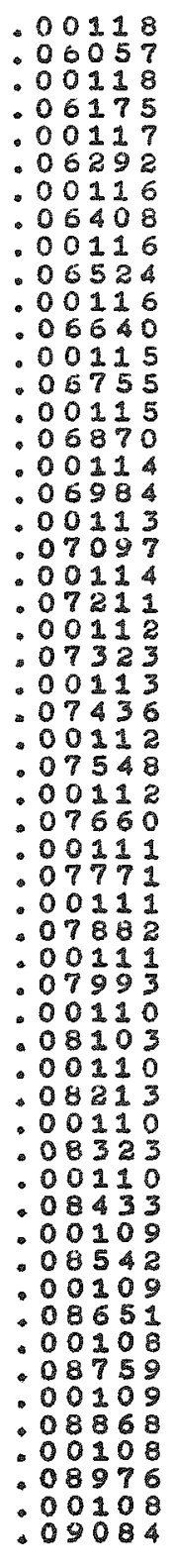 } & .00203 & \multirow{28}{*}{ 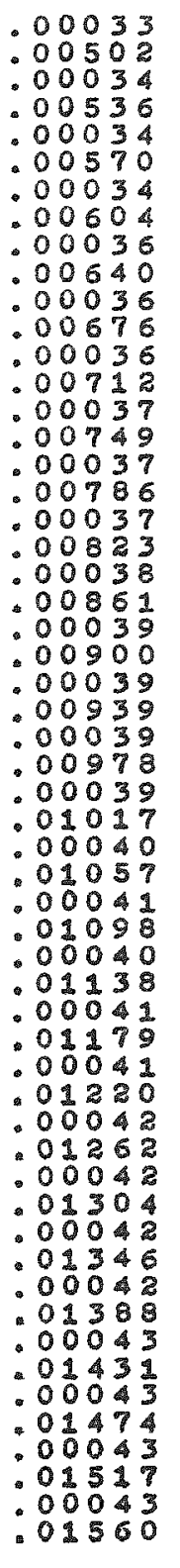 } & .00017 & .56757 & .56758 \\
\hline & & .00004 & & .00204 & & .00018 & .59163 & .59164 \\
\hline & & .00003 & & .00205 & & .00019 & .61567 & .61568 \\
\hline & & .00003 & & .00206 & & .00019 & .63969 & .63969 \\
\hline & & .00004 & & .00206 & & .00020 & .66368 & .66369 \\
\hline & & .00004 & & .00208 & & .00021 & .68764 & .68765 \\
\hline & & .00004 & & .00209 & & .00022 & .71158 & .71159 \\
\hline & & .00004 & & .00209 & & .00023 & .73550 & .73550 \\
\hline & & .00004 & & .00210 & & .00024 & .75939 & .75940 \\
\hline & & .00004 & & .00211 & & .00025 & .78325 & .78326 \\
\hline & & .00004 & & .00213 & & .00025 & .80710 & .80711 \\
\hline & & .00004 & & .00213 & & .00027 & .83091 & .83093 \\
\hline & & .00004 & & .00214 & & .00027 & .85471 & .85472 \\
\hline & & .00004 & & .00215 & & .00028 & .87847 & .87849 \\
\hline & & .00004 & & .00216 & & .00029 & .90222 & .90223 \\
\hline & & .00003 & & .00217 & & .00030 & .92594 & .92595 \\
\hline & & .00004 & & .00218 & & .00031 & .94964 & .94965 \\
\hline & & .00003 & & .00219 & & .00031 & .97331 & .97333 \\
\hline & & .00004 & & .00220 & & .00032 & .99695 & .99697 \\
\hline & & .00004 & & .00221 & & .00033 & 1.02058 & 1.02060 \\
\hline & & .00004 & & .00221 & & .00034 & 1.04418 & 1.04420 \\
\hline & & .00004 & & .00222 & & .00035 & 1.06776 & 1.06778 \\
\hline & & .00004 & & .00223 & & .00036 & 1.09131 & 1.09133 \\
\hline & & .00004 & & .00224 & & .00036 & 1.11484 & 1.11486 \\
\hline & & .00004 & & .00225 & & .00037 & 1.13834 & 1.13836 \\
\hline & & .00004 & & .00226 & & .00038 & 1.16182 & 1.16184 \\
\hline & & .00004 & & .00227 & & .00039 & 1.18527 & 1.18530 \\
\hline & & .00004 & & .00228 & & .00039 & 1.20871 & 1.20873 \\
\hline
\end{tabular}



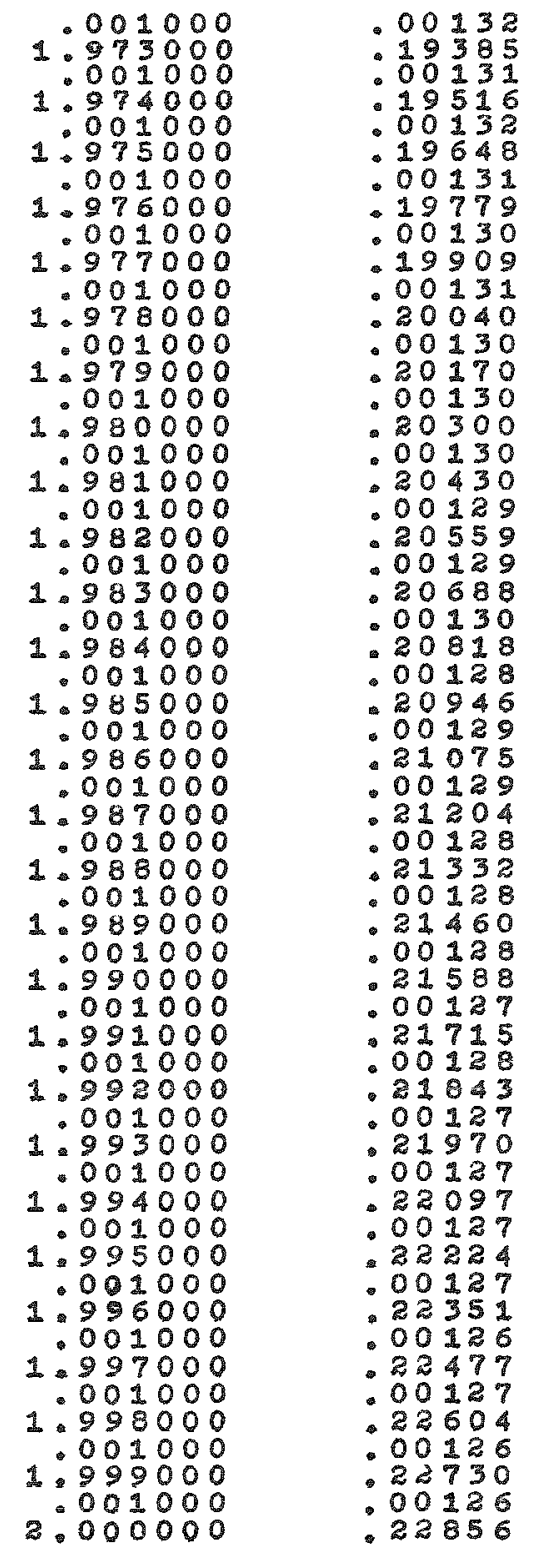

\begin{tabular}{|c|c|c|}
\hline .00004 & $\begin{array}{r}00197 \\
.09191\end{array}$ & .002 \\
\hline .00004 & $\begin{array}{l}299 \\
107\end{array}$ & .00229 \\
\hline .00004 & .09406 & .00230 \\
\hline .00004 & .09513 & .00231 \\
\hline .00004 & - 09620 & .00232 \\
\hline .00004 & $: 0$ & .00233 \\
\hline .00004 & .09832 & .00234 \\
\hline .00004 & .09938 & .00235 \\
\hline .00004 & $: 10044$ & .00235 \\
\hline .00004 & $\begin{array}{r}10150 \\
00105\end{array}$ & .00236 \\
\hline .00004 & $\begin{array}{r}10255 \\
.00106\end{array}$ & .00237 \\
\hline .00004 & .10361 & .00238 \\
\hline .00004 & $\begin{array}{r}10466 \\
.00105\end{array}$ & .00238 \\
\hline .00004 & .10571 & .00239 \\
\hline .00005 & .10676 & .00240 \\
\hline .00004 & $\begin{array}{r}10780 \\
.00105\end{array}$ & .00241 \\
\hline .00004 & .10885 & .00242 \\
\hline .00004 & $\begin{array}{r}10989 \\
.00104\end{array}$ & .00243 \\
\hline .00004 & $\begin{array}{r}11093 \\
.00104\end{array}$ & .00243 \\
\hline .00004 & .11197 & .00244 \\
\hline .00004 & .11301 & .00245 \\
\hline .00004 & $\begin{array}{r}11405 \\
.00103\end{array}$ & .00246 \\
\hline .0000 & 08 & .00247 \\
\hline .00004 & .116101 & .00248 \\
\hline .00004 & .11715 & .00249 \\
\hline .00004 & $\begin{array}{r}11818 \\
.00103\end{array}$ & .00249 \\
\hline .00004 & $\frac{1}{2}$ & .00250 \\
\hline .00004 & 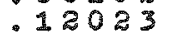 & .00251 \\
\hline
\end{tabular}

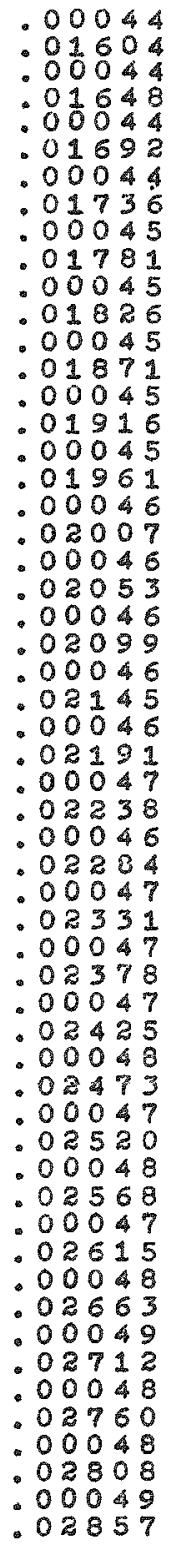

$\begin{array}{lll}.00040 & 1.23212 & 1.23214 \\ .00041 & 1.25550 & 1.25553 \\ .00042 & 1.27886 & 1.27889 \\ .00042 & 1.30220 & 1.30223 \\ .00043 & 1.32551 & 1.32554 \\ .00044 & 1.34880 & 1.34883 \\ .00045 & 1.37207 & 1.37210 \\ .00046 & 1.39531 & 1.39535 \\ .00046 & 1.41853 & 1.41856 \\ .00047 & 1.44173 & 1.44176 \\ .00048 & 1.46490 & 1.46494 \\ .00049 & 1.48805 & 1.48309 \\ .00049 & 1.51117 & 1.51121 \\ .00050 & 1.53428 & 1.53432 \\ .00051 & 1.55736 & 1.55740 \\ .00051 & 1.58042 & 1.58046 \\ .00052 & 1.60345 & 1.60349 \\ .00053 & 1.62646 & 1.62650 \\ .00053 & 1.64944 & 1.64949 \\ .00054 & 1.67241 & 1.67245 \\ .00055 & 1.69535 & 1.69540 \\ .00056 & 1.71827 & 1.71832 \\ .00057 & 1.74116 & 1.74121 \\ .0058 & 1.80971 & 1.80976 \\ .0058 & 1.85529 & 1.85535\end{array}$


Table I (Cont'd)

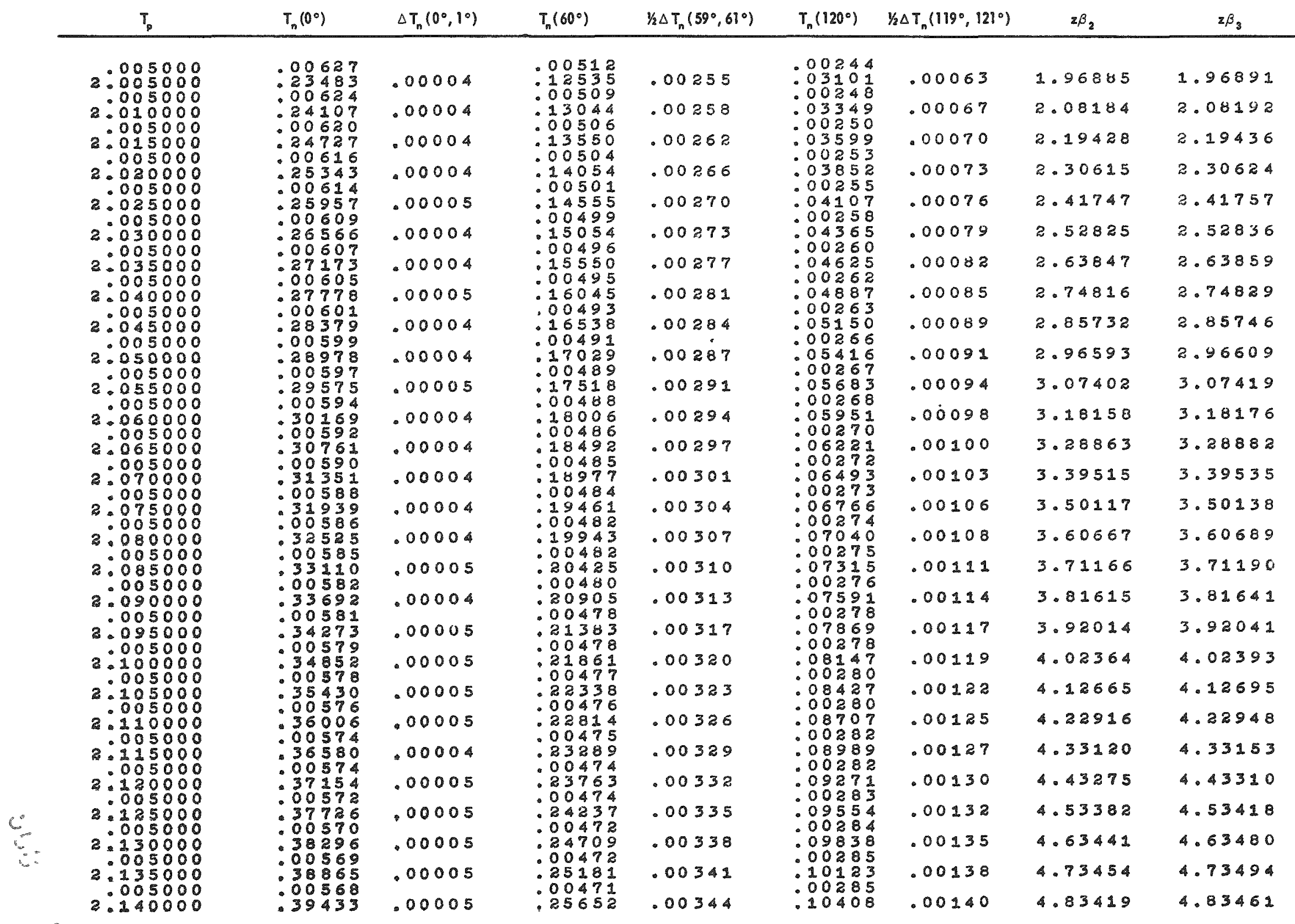




\begin{tabular}{|c|c|}
\hline 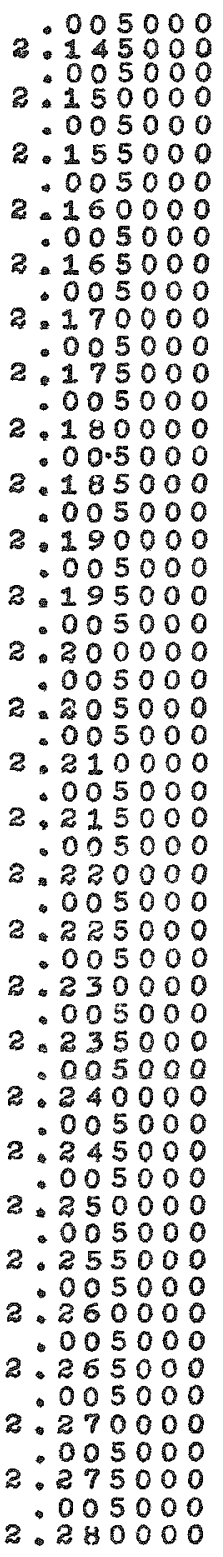 & 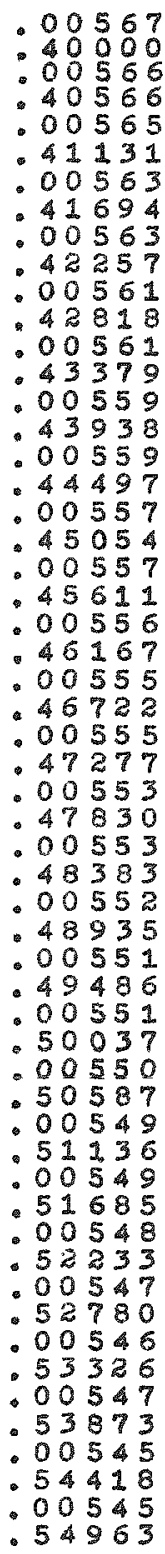 \\
\hline
\end{tabular}

\begin{tabular}{|c|c|c|}
\hline & \multirow{28}{*}{ 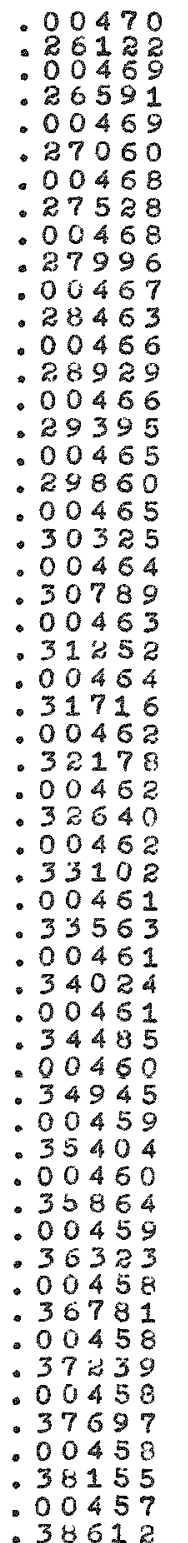 } & \\
\hline .00005 & & .0034 \\
\hline .00005 & & .00350 \\
\hline .00005 & & .00353 \\
\hline .00005 & & .00356 \\
\hline .00005 & & .00359 \\
\hline .00005 & & .00361 \\
\hline .00006 & & .00365 \\
\hline .00005 & & .00367 \\
\hline .00005 & & .00370 \\
\hline .00005 & & .00373 \\
\hline .00005 & & .00375 \\
\hline .00005 & & .00378 \\
\hline .00005 & & .00381 \\
\hline .00006 & & .00384 \\
\hline .00005 & & .00387 \\
\hline .00005 & & .00389 \\
\hline .00005 & & .00392 \\
\hline .00005 & & .00395 \\
\hline .00 & & .00397 \\
\hline .00006 & & .00400 \\
\hline .00006 & & .00403 \\
\hline .00006 & & .00405 \\
\hline .00006 & & .00408 \\
\hline .00006 & & .00410 \\
\hline .00005 & & .00413 \\
\hline .0000 & & .00416 \\
\hline .0000 & & .0 \\
\hline
\end{tabular}

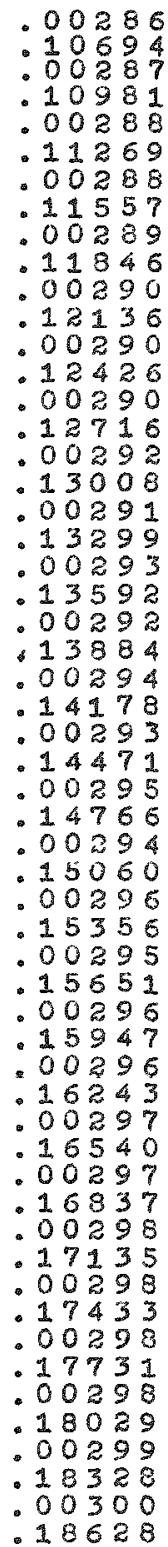

\begin{tabular}{|c|c|c|}
\hline .00142 & 4.93338 & 4.93382 \\
\hline .00145 & 5.03211 & 5.03257 \\
\hline .00147 & 5.13038 & 5.13036 \\
\hline .00149 & 5.22820 & 5.22870 \\
\hline .00152 & 5.32557 & 5.32608 \\
\hline .00155 & 5.42248 & 5.42302 \\
\hline .00157 & 5.51895 & 5.51950 \\
\hline .00159 & 5.61497 & 5.61555 \\
\hline .00162 & 5.71056 & 5.71116 \\
\hline .00164 & 5.80571 & 5.80633 \\
\hline .00166 & 5.90042 & 5.90106 \\
\hline .00168 & 5.99470 & 5.99537 \\
\hline .00171 & 6.08856 & 6.08925 \\
\hline .00173 & 6.18199 & 6.18270 \\
\hline .00175 & 6.27500 & 6.27573 \\
\hline .00177 & 6.38 .759 & 6.36834 \\
\hline .00180 & 6.45976 & 6.46054 \\
\hline .00182 & 6.55151 & 6.552 .32 \\
\hline .00184 & 6.64286 & 6.64369 \\
\hline .00136 & 6.73380 & 6.73465 \\
\hline .00188 & 6.32433 & 6.82521 \\
\hline .00191 & 6.91447 & 6.91537 \\
\hline .00192 & 7.00420 & 7.00513 \\
\hline .00195 & 7.09353 & 7.09449 \\
\hline .00197 & 7.18247 & 7.18345 \\
\hline .00199 & 7.27102 & 7.27203 \\
\hline .00201 & 7.35917 & 7.35021 \\
\hline .00203 & 7.44694 & 7.4480 \\
\hline
\end{tabular}


Toble I (Cont'd)

\begin{tabular}{|c|c|c|c|c|c|c|c|c|}
\hline$T_{p}$ & $T_{n}\left(0^{\circ}\right)$ & $\Delta T_{n}\left(0^{\circ}, 1^{\circ}\right)$ & $T_{n}\left(60^{\circ}\right)$ & $1 / 2 \Delta T_{n}\left(59^{\circ}, 61^{\circ}\right)$ & $T_{n}\left(120^{\circ}\right)$ & $1 / 8 \Delta T_{n}\left(119^{\circ}, 121^{\circ}\right)$ & $z \beta_{2}$ & $2 \beta_{3}$ \\
\hline \multirow{28}{*}{ 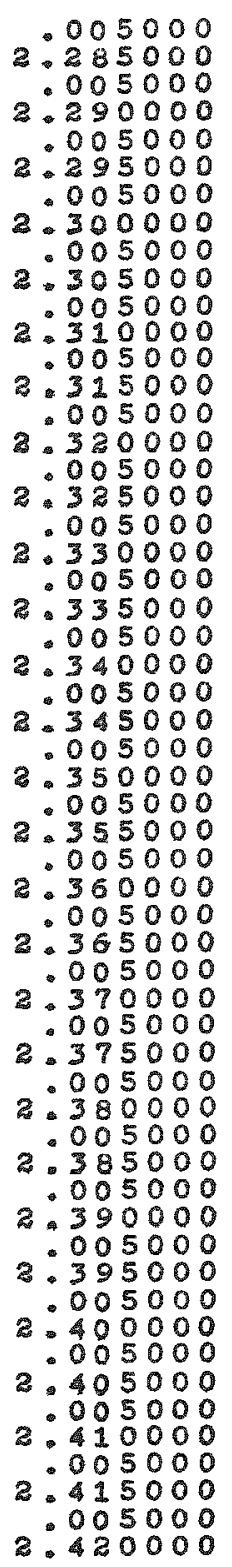 } & \multirow{28}{*}{ 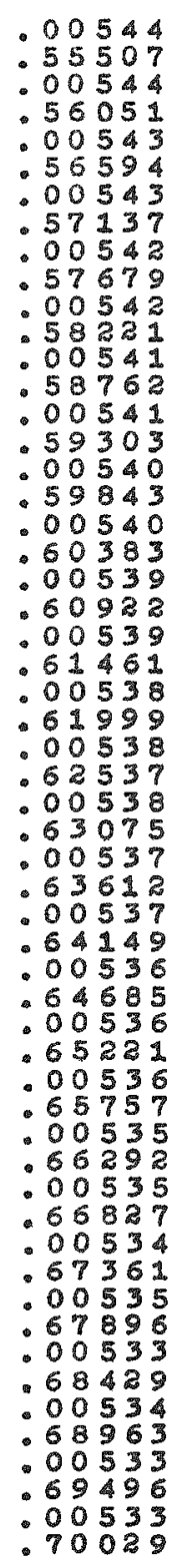 } & .00006 & \multirow{28}{*}{ 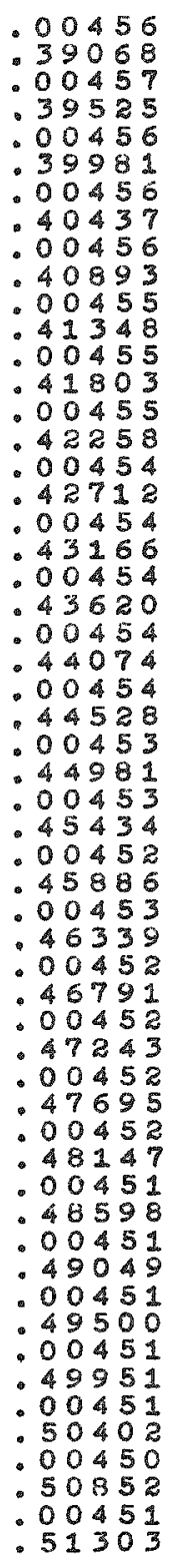 } & .00424 & \multirow{28}{*}{ 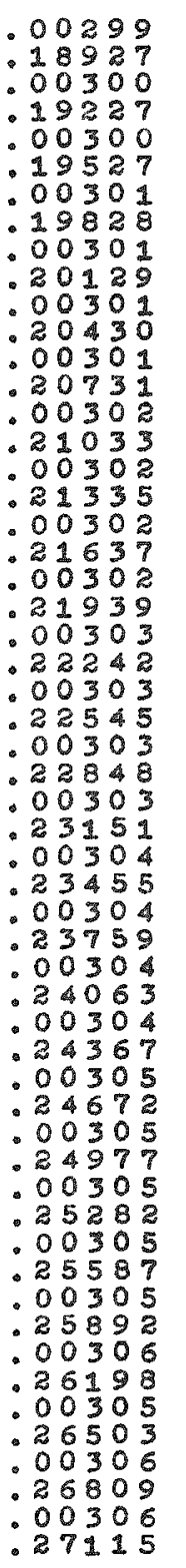 } & .00206 & 7.53433 & 7.53542 \\
\hline & & .00006 & & .00426 & & .00208 & 7.62133 & 7.62245 \\
\hline & & .00006 & & .00429 & & .00210 & 7.70796 & 7.70910 \\
\hline & & .00006 & & .00431 & & .00211 & 7.79420 & 7.79538 \\
\hline & & .00006 & & .00434 & & .00213 & 7.88007 & 7.88128 \\
\hline & & .00006 & & .00436 & & .00215 & 7.96557 & 7.96681 \\
\hline & & .00006 & & .00439 & & .00218 & 8.05070 & 8.05196 \\
\hline & & .00006 & & .00442 & & .00220 & 8.13547 & 8.13676 \\
\hline & & .00006 & & .00444 & & .00222 & 8.21986 & 8.22118 \\
\hline & & .00006 & & .00447 & & .00224 & 8.30390 & 8.30525 \\
\hline & & .00006 & & .00449 & & .00226 & 8.38757 & 8.38895 \\
\hline & & .00006 & & .00451 & & .00228 & 8.47089 & 8.47230 \\
\hline & & .00006 & & .00454 & & .00230 & 8.55385 & 8.55529 \\
\hline & & .00006 & & .00457 & & .00232 & 8.63646 & 0.63793 \\
\hline & & .00006 & & .00459 & & .00234 & 8.71872 & 8.72022 \\
\hline & & .00006 & & .00461 & & .00236 & 8.80062 & 8.80216 \\
\hline & & .00006 & & .00464 & & .00238 & 8.88219 & 8.80375 \\
\hline & & .00006 & & .00466 & & .00240 & 8.96340 & 8.96500 \\
\hline & & .00006 & & .00469 & & .00242 & 9.04428 & 9.04591 \\
\hline & & .00006 & & .00471 & & .00244 & 9.12481 & 9.12648 \\
\hline & & .00006 & & .00474 & & .00246 & 9.20500 & 9.20670 \\
\hline & & .00006 & & .00476 & & .00248 & 9.28487 & 9.28660 \\
\hline & & .00006 & & .00478 & & .00250 & 9.36439 & 9.36616 \\
\hline & & .00007 & & .00481 & & .00252 & 9.44358 & 9.44538 \\
\hline & & .00006 & & .00483 & & .00254 & 9.52245 & 9.52428 \\
\hline & & .00007 & & .00486 & & .00255 & 9.60099 & 9.60285 \\
\hline & & .00007 & & .00488 & & .00257 & 9.67920 & 9.68110 \\
\hline & & .00007 & & .00491 & & .00259 & 9.75708 & 9.75902 \\
\hline
\end{tabular}




\begin{tabular}{|c|}
\hline 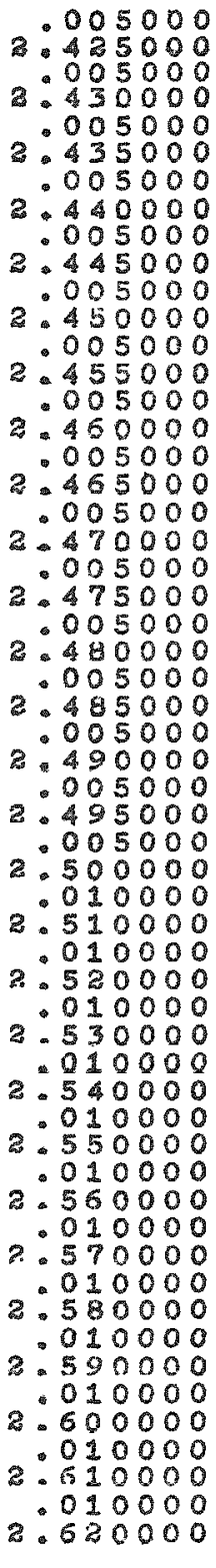 \\
\hline
\end{tabular}

.00006

.00006

.00007

.00006

.00007

.00006

.00007

.00006

.00006

.00007

.00006

.00007

.00007

.00007

.00007

.00007

.00007

.00007

.00007

.00007

.00007

.00007

.00007

.00007

.00008

.00007

.00007

.00007
- 00450 - 51753

- 5220

- 00449

. 52652

.00450

- 53102

.00449

- 53551

. 00449

. 54000

.00450

. 54450

.00448

. 54898

.00449

.55347

. 00449

. 55796

- 00448

$.56 \% 4$

.00448

. 56692

.00448

- 57140

.00448

. 57588

.00448

- 50036

.004a

- 58484

00395

. 59379

.00894

.60273

.00894

- 61167

- 00894

- 62061

002

- 62953

- 00893

- 63846

.00892

64738

- 00891

- 65629

- 00891

- 66520

- 00891

- 67411

- 6830

- 68301

.69191

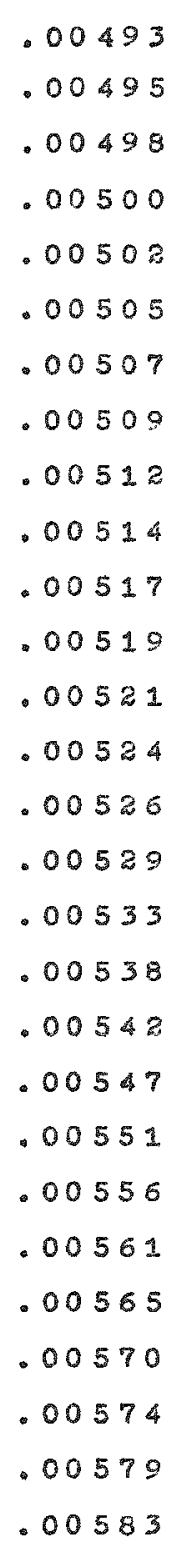

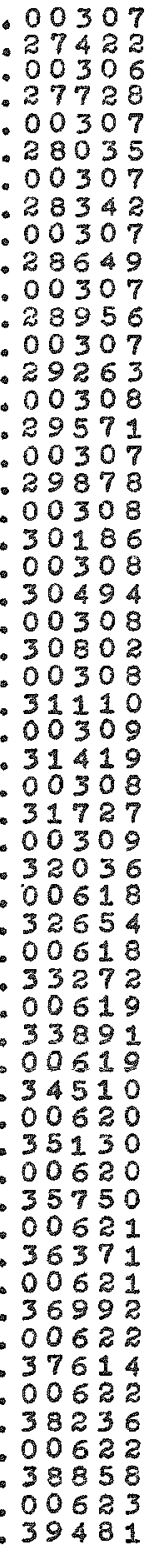

9.83465

9.83602

.00263

9.91190

9.91391

.00265

9.98882

9.99087

.0026710 .06544

10.06751

.0026910 .14174

10.14386

.0027110 .21773

10.31988

$.00273 \quad 10.29341$

10.29559

.0027510 .36877

10.37100

.0027610 .44384

10.44610

.0027810 .51860

10.52090

.0028010 .59305

10.59539

.0028210 .66721

10.65958

.0028410 .74107

10.74348

.0028610 .81463

10.81708

.0028710 .83789

10.89038

.0028910 .96087

10.96339

.0029311 .10594

11.10854

.0029711.24986

11.25254

$.00301 \quad 11.39263$

11.39539

.0030411 .53428

11.53712

.0030811 .67482

11.67775

.0031111 .81427

11.81727

.0031511 .95262

11.95571

.0031912 .03990

12.09307

.0032212 .22612

12.22937

.0032612 .36129

12.36463

.0032912 .49542

12.49885

.0033312 .62853

12.63204 
Table I (Cont'd)

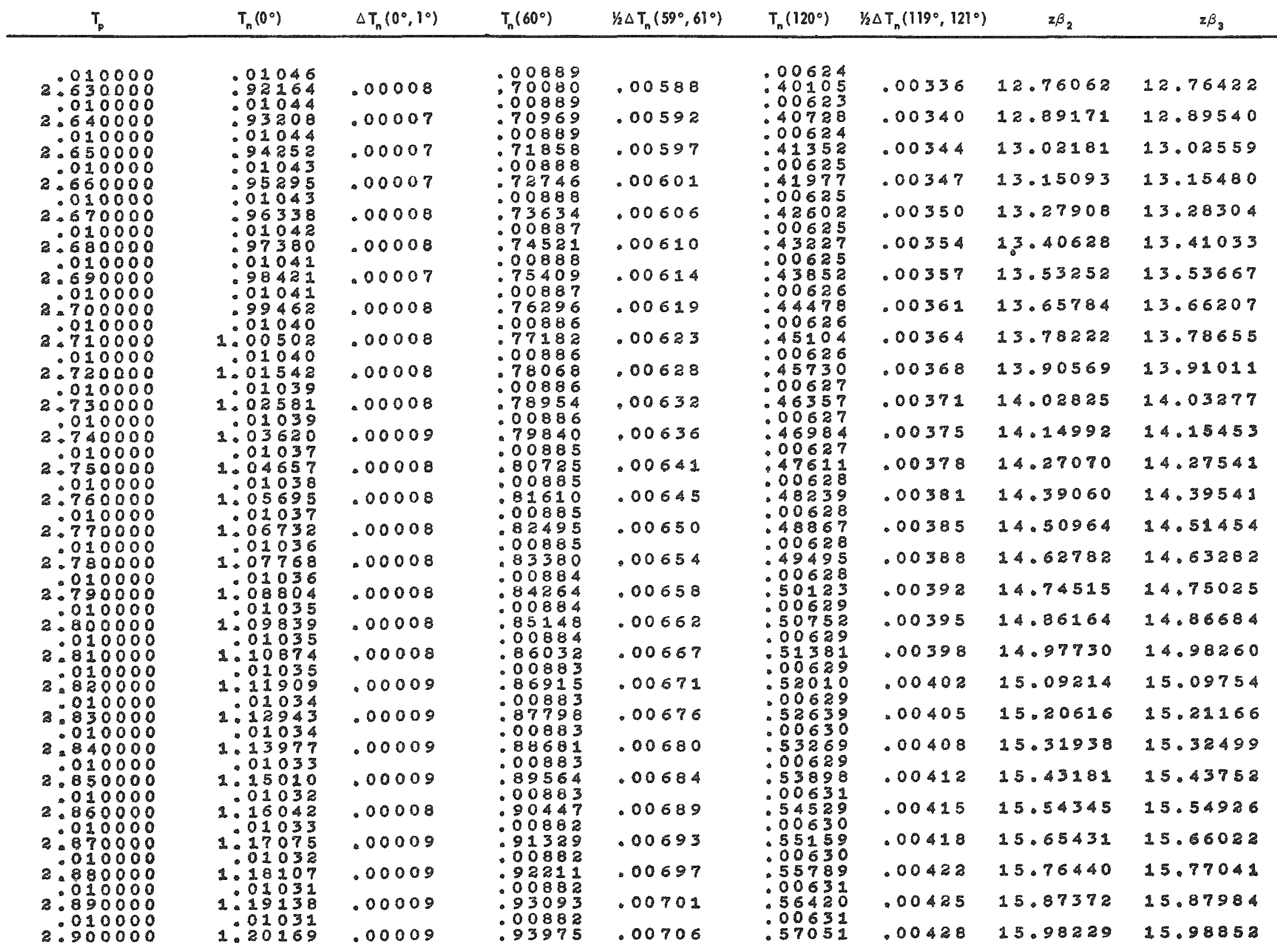




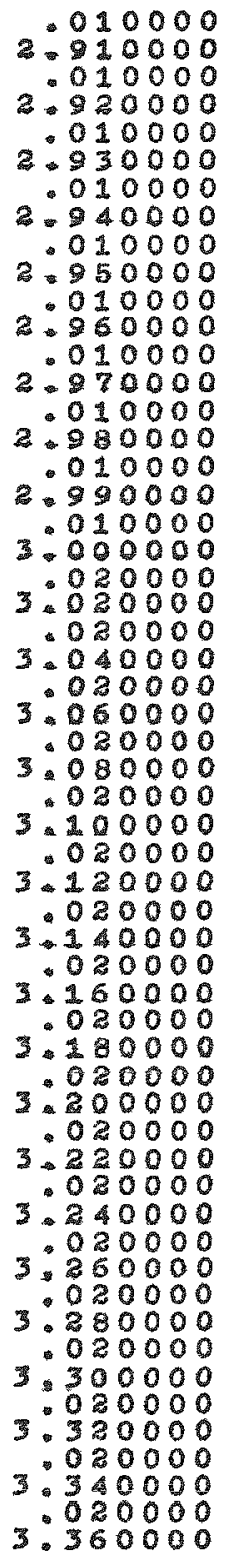

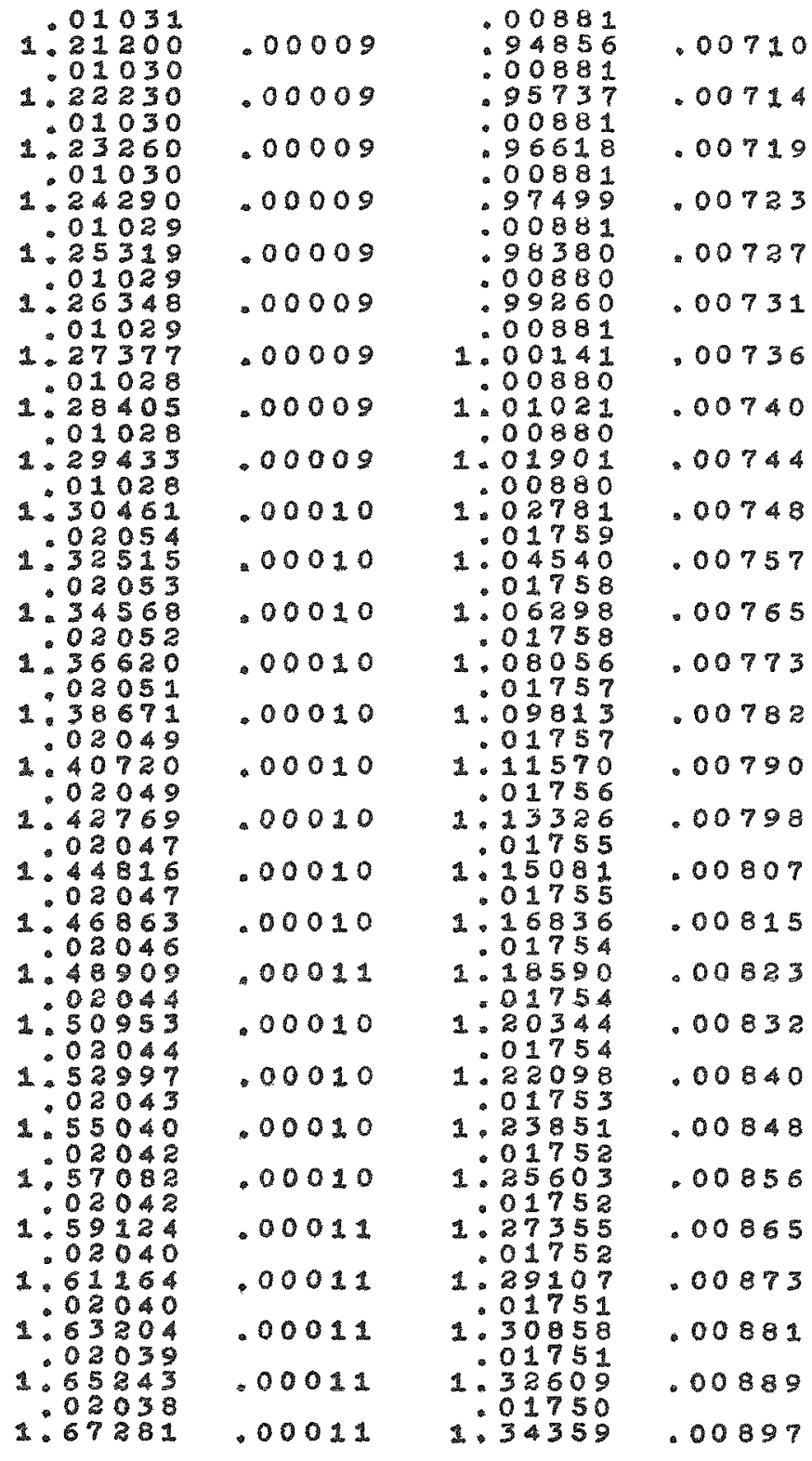

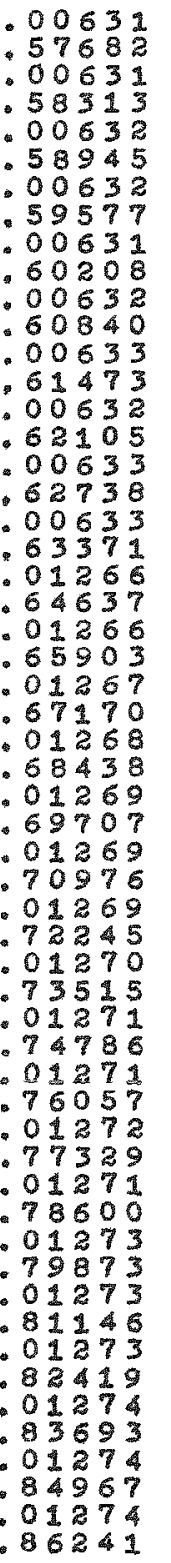

\begin{tabular}{|c|c|c|}
\hline 0431 & 9011 & 16.0964 \\
\hline 00435 & 16.19719 & 16.20363 \\
\hline 00438 & 16.30354 & 16.31009 \\
\hline 00442 & 16.40917 & 164958 \\
\hline 00445 & 16.51408 & 6.5208 \\
\hline 00448 & 16.61827 & 16.6251 \\
\hline 00451 & 16.72177 & 16.7287 \\
\hline 00454 & 16.82457 & 4007 \\
\hline 00458 & 16.92668 & 16.9338 \\
\hline 61 & 17.02 & 17.0 \\
\hline 68 & 17.2 & 17.2 \\
\hline 0 & 3 & 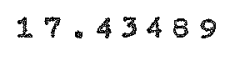 \\
\hline 00481 & 17.62 & $17 \cdot 6$ \\
\hline 487 & 17.81577 & 17.8 \\
\hline & 18.00632 & 1901 \\
\hline & & 18.20 \\
\hline 005 & & 18.3 \\
\hline 00512 & 18.56349 & 18.5726 \\
\hline 00515 & 8.74452 & 18.7539 \\
\hline 00 & 18.92329 & 18.9 \\
\hline 00532 & 09984 & 19.105 \\
\hline .00538 & 19.27419 & 19.2043 \\
\hline .0054 & $19 \cdot 40$ & 19.4567 \\
\hline 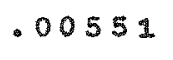 & 19.61652 & $4=000$ \\
\hline 00557 & 78457 & 19.7954 \\
\hline 0 & .95058 & 19.961 \\
\hline 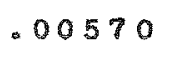 & 20. & $20 . \pm 25$ \\
\hline 00576 & 667 & 2 \\
\hline
\end{tabular}


Table I (Conf'd)

$\Delta T_{n}\left(0^{\circ}, 1^{\circ}\right)$

$T_{n}\left(60^{\circ}\right)$

$1 / 2 \Delta T_{n}\left(59^{\circ}, 61^{\circ}\right)$

$T_{n}\left(120^{\circ}\right)$

$1 / 2 \Delta T_{n}\left(119^{\circ}, 121^{\circ}\right)$

$\mathbf{z} \beta_{2}$

$z \beta_{3}$

.020000

.02038

$.00012 \quad 1.01751$

- 020000

3.400000

- 02036

.00012

$.00011 \quad 1.37859$

.01750

.02037
1.73392

3. 420000

.000121 .39609

- 4000

- 02035

$.00011 \quad .01749$

1. 41358

020000

3.46000

02035

1. 77462

$.00011 \quad 1.43106$

3. 8000

1.79497

. 02033

.000121 .44855

- 500000

1.81530

1. 01748

.00011

1. 46603

- 520000

- 220000

1. 83564

.00012

1. 48350

$\because 02032$

3.540000

- 0253

.00012

- 517098

3. 560000

- 87628

1. 02032

1: 89660

3.580000

- 020000

3.600000

- 020000

3.620000

3.640000

- 020000

3.660000

.020000

3.680000

- 20000

3.700000

- 020000

3.72000

- 020000

3.740000

- 020000

3.760000

- 020000

.020000

3.800000

- 020000

3.820000

- 020000

3.840000

. 020000

3.860000

- 020000

3.810000

- 020000

3.900000

- 020000

- 02031

2. 02030

1. 23721

1.95751

- 02030

1.97781

- 02029

0z 029

2.01839

- 2028

2.03867

2.05895

.02027

2.07922

.02027

.02026

2. 11975

:. 14001

. 02026

2. 16027

2. 13026

- 02025

2.20078

2.22024

.02025

.00012

1. 01747

.00012

1. 51845

1.53592

- 01746

$00012 \quad .01747$

.57046

.00012

1. 58831

.00013

- 017547

.000131 .6232

1.6232

.00013

1.64067

1.01746

.000131 .65813

$.00013 \quad 1.67557$

.00013

1705

1. 69302

.00013

- 01744

:01745

.00013

1.72791

.01743

1.74534

.017278

1.78022

.01743

1.79765

- 817508

.01743

1. 3251

.00905

.01275

.0090

.00914

.81791

.00922

- 01276

00930

- 91342

.00938

.01276

.00946

.00954

.01277

.00963

. 01277

.00970

.00978

97725

99003

.009861 .00281

.01278

1.01559

.00995

.01003

$\therefore 1278$

.01279

.01011

1.05395

.01019

.01027

.01035

.01279
1.06679

.01279

1.07953

.01043

1.01280

.01051

$: 01279$

$.01059 \quad .01200$

1.11792

1.13073

.01067

.01280

.01075

1428

1. 1563

.01280

1.1691

1. 18129

1.19476

-.0128

1.22039

.00582

.00588

20.43681

20.44868

$20.59507 \quad 20.60720$

$.00600 \quad 20.90604 \quad 20.91869$

$.0060721 .05883 \quad 21.07174$

$.00613 \quad 21.20986 \quad 21.22302$

$.0061921 .35915 \quad 21.37258$

$.00625 \quad 21.50675 \quad 21.52043$

$.0063121 .65266 \quad 21.66662$

$.00638 \quad 21.79695 \quad 21.81117$

.0064421 .9396121 .95410

$.00650 \quad 22.08068 \quad 22.09544$

$.00656 \quad 22.22019 \quad 22.23521$

$.00662 \quad 22.35816 \quad 22.37346$

$.00668 \quad 22.49462 \quad 22.51019$

$.00675 \quad 22.62959 \quad 22.64544$

$.00680 \quad 22.76310 \quad 22.77923$

$.00687 \quad 22.89517 \quad 22.91157$

$.0069323 .02583 \quad 23.04250$

$.0069923 .15508 \quad 23.17204$

.0070523 .2829723 .30020

$.0071123 .40951 \quad 23.42702$

$.00717 \quad 23.53472 \quad 23.55251$

$.00723 \quad 23.65862 \quad 23.67669$

$.0072923 .78123 \quad 23.79959$

.0073523 .90258

23.9212

.00741

24.02267

24.04160

.01123

.00747

24.14154

24.16075 


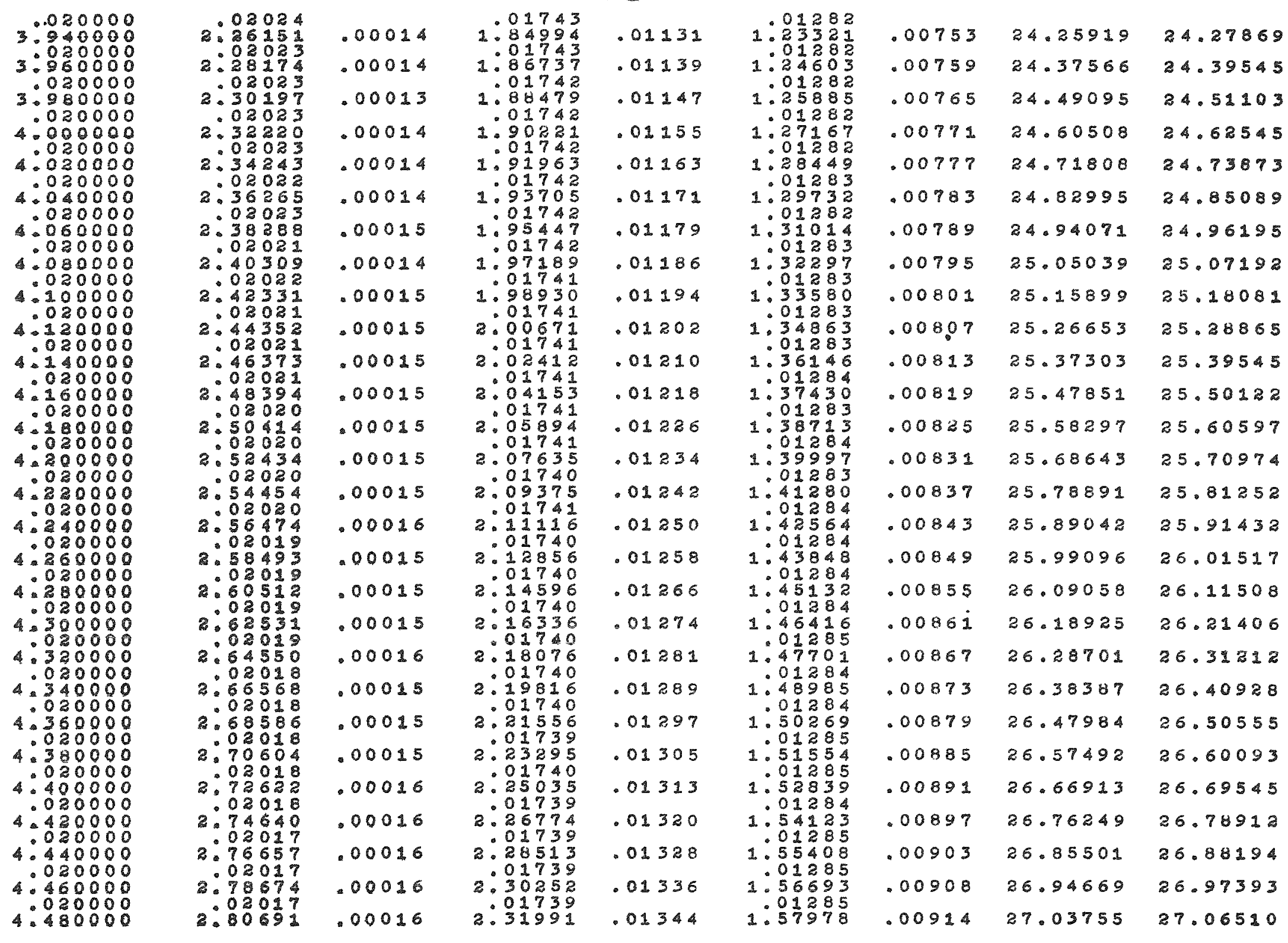


Table I (Cont'd)

\begin{tabular}{|c|c|c|c|c|c|c|c|c|}
\hline$T_{p}$ & $T_{n}\left(0^{\circ}\right)$ & $\Delta T_{n}\left(0^{\circ}, 1^{\circ}\right)$ & $T_{n}\left(60^{\circ}\right)$ & $1 / 2 \Delta T_{n}\left(59^{\circ}, 61^{\circ}\right)$ & $T_{n}\left(120^{\circ}\right)$ & $1 / 2 \Delta T_{n}\left(119^{\circ}, 121^{\circ}\right)$ & $z \beta_{2}$ & $2 \beta_{3}$ \\
\hline & & .00016 & & .01352 & & .00920 & 27.12760 & 27.15545 \\
\hline & & .00017 & & .01360 & $\begin{array}{l}285 \\
549 \\
285\end{array}$ & .00926 & 27.21685 & 27.24502 \\
\hline & & .00016 & & .01368 & $\begin{array}{l}12885 \\
183 \\
1284\end{array}$ & .00932 & 27.30531 & 27.33378 \\
\hline $4: 5$ & & .00016 & & .01375 & $\begin{array}{l}1: 013280 \\
1.63320 \\
013285\end{array}$ & .00938 & 27.39299 & 37.42177 \\
\hline $4: 5$ & & .00017 & & .01384 & & .00944 & 27.47990 & 27.50899 \\
\hline $4: 6$ & $2^{\circ}$ & .00016 & & .01391 & & .00950 & 27.56606 & 27.59546 \\
\hline $4: 6$ & $2: 9$ & .00017 & & .01399 & & .00956 & 27.65146 & 27.68117 \\
\hline & $2:$ & .00017 & & .01407 & 2 & .00962 & 27.73612 & 27.76615 \\
\hline $4: 5$ & $2:$ & .00027 & & .01415 & & .00967 & 27.82006 & 27.85039 \\
\hline $4: 0$ & $3: 0$ & .00017 & 2 & .01423 & 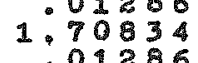 & .00973 & 27.90327 & 27.93392 \\
\hline $4: 7$ & $3: 0$ & .00017 & $\begin{array}{l}38 \\
\frac{1}{3} 4 \\
3\end{array}$ & .01430 & $\begin{array}{l}1260 \\
21206 \\
1286\end{array}$ & .00979 & 27.98578 & 28.01674 \\
\hline $4: 7$ & & .00017 & & .01438 & & .00985 & 28.06757 & 28.09885 \\
\hline $4: 7$ & & .00017 & & .01446 & & .00991 & 28.14868 & 28.18027 \\
\hline $4: 7$ & $3:$ & .00017 & & .01454 & 9 & .00997 & 28.22910 & 28.26100 \\
\hline $4: ?$ & & .00018 & & .01462 & & .01003 & 28.30884 & 28.34106 \\
\hline & & .00017 & & .01470 & & .01009 & 28.38792 & 28.42046 \\
\hline & & .00017 & & .01477 & & .01014 & 28.46634 & 28.49919 \\
\hline & $3: 0$ & .00017 & & .01485 & 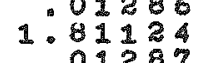 & .01021 & 28.54411 & 28.57728 \\
\hline & & .00018 & & .01493 & & .01026 & 28.62123 & 28.65472 \\
\hline $4: 0$ & $3: 2$ & .00018 & & .01501 & & .01032 & 28.69772 & 28.73152 \\
\hline $4: 0$ & $3:$ & .00019 & 2.68488 & .01509 & $\begin{array}{r}101286 \\
1.84984\end{array}$ & .01038 & 28.77358 & 28.80771 \\
\hline & & .00018 & $2: 70225$ & .01517 & $\begin{array}{l}1: 81287 \\
1.86271 \\
06287\end{array}$ & .01044 & 28.84882 & 28.88326 \\
\hline $4: 9$ & & .00018 & $2:$ & .01524 & $1: 07558$ & .01050 & 28.92345 & 28.95821 \\
\hline & $3: 0$ & .00018 & 2 & .01532 & $1: 88845$ & .01056 & 28.99748 & 29.03256 \\
\hline & $3: 31062$ & .00018 & & .01540 & $1: 90132$ & .01062 & 29.07090 & 29.10630 \\
\hline & & .00018 & & .01548 & $1:$ & .01068 & 29.14374 & 29.17946 \\
\hline & & .00018 & $2:$ & .01567 & & .01082 & 29.32329 & $29.3598 \mathrm{a}$ \\
\hline & & .00019 & & .01587 & 1: & .01097 & 29.49930 & 29.53664 \\
\hline
\end{tabular}




$$
\begin{aligned}
& \begin{array}{r}
050000 \\
5.250000 \\
\hline
\end{array} \\
& \begin{array}{r}
150000 \\
.050000
\end{array} \\
& 5.200000 \\
& \text { - } 050000 \\
& 5.250000 \\
& 5.30000 \\
& 5.300000 \\
& \text { - } 55000 \\
& 5.350000 \\
& 5.50000 \\
& \begin{array}{r}
0.500 \\
050000
\end{array} \\
& \text { - } \\
& \text { - } 45000 \\
& \text { 5:500000 } \\
& .050000 \\
& 5: 550000 \\
& \text { - } 050000 \\
& \text {. } 600000 \\
& \text { 5.650000 } \\
& \text {. } .650000 \\
& \text { 5:700000 } \\
& \text {. } 050000 \\
& 5: 750000 \\
& \text {. } 050000 \\
& 5: 800000 \\
& \text { - } 050000 \\
& \text { 5.850000 } \\
& 5.900000 \\
& \text { - } 90000 \\
& 5.950000 \\
& .050000 \\
& 6.000000 \\
& .0500000 \\
& \text { - } 050000 \\
& \text { - } 050000 \\
& \text { 6.100000 } \\
& 6.150000 \\
& \text { - } 20000 \\
& \text { * } 5000 \\
& \text { - } 050000 \\
& \text { 6.25000 } \\
& \text { - } 300000 \\
& \text { - } 300000 \\
& \text { - } 350000 \\
& \text {. } 050000 \\
& \text { 6.400000 } \\
& .050000 \\
& \text { 6. } 50000 \\
& .050000 \\
& \text { 6.500000 }
\end{aligned}
$$

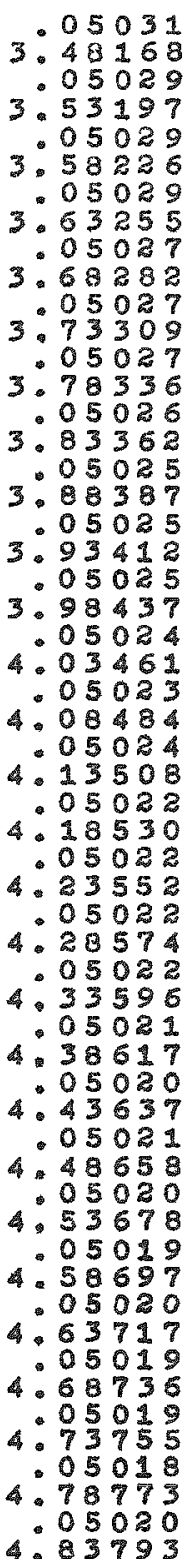

.00020

.00019

.04341 2.90196 2.94536

2.94536 2.98876

2.9887

3:03215

.00012

.00020

- 04339

.00020

.07554

3. 11893

- 04339

.00020

.00021

. 1623

3.20570

. 04338

34908
.04337

3.29245

- 04338

.00020

.00021

.00022

3.33583

3. 37920

.04336

3.42256
.04337

3. 46593

. 04336

3.50929

. 04336

3.55265

3.59601

- 0335

3.63935

3.68271

. 0435

.0435

3.76941

3.81276

.0433

3.85610

.04334

3.8994

.04334

. 94278

3.98612

0433
4.02945

.04330

4.07275
25

.01606
.01625
.01645
.01664
.01684
.01703
.01723
.01742
.01762
.01761
.01800
.01820
.01839
.01858
.01878
.01897
.01916
.01936
.01955
.01975
.01994
.02013
.02032
.02052
.02071
.02091
.02110
.02129

(⿸丆口
.01073 2.04292 .03219 .07511 0.073 . 2.13950 0.172169 2.03230

0.03221

26830

.03221

0.33272

- 03221

- 323

.39715

.03221

0.42936

3.46158

- 03222

.49380

- 52602

03aza

.55824

2.59046

. 3 az

.62269

0.03222

2.65491

2: 68714

.03223

$.7 \frac{1}{3} 327$

2.75160

.03223

2.78383

$2: 81606$

.03223

2.84829

2.88042
01126

.01141

.01155

.01257

.01271

01301

.01315

.01329

.01344

.01359

.01373

.01388

.01402

.01416

.01431

.01445

.01460

.01474

.01488

.01503
29.67188

29.84113

30.00713

30.16997

30.32976

30.48657

30.64049

30.79159

30.93996

31.08565

31.22875

31.36932

31.50744

31.64315

31.77654

31.90764

32.03652

$32 \cdot 16324$

32.28785

$32 \cdot 41040$

32.53094

32.64953

32.76620

32.88101

32.99399

33.10519

33.21465

33.31711
29.71002

29.88008

30.04689

30.21056

30.37116

30.52879

30.66354

30.83546

30.98465

31.13118

31.27511

31.41651

31.55546

31.69201

31.82623

31.95818

32.08790

32.21547

32.34092

32.46432

32.58571

32.70514

32.82266

32.93833

33.05216

33.16422

33.27454

33.37783 
Toble I (Conf'd)

\begin{tabular}{|c|c|c|c|c|c|c|c|c|}
\hline$T_{p}$ & $T_{n}\left(0^{\circ}\right)$ & $\Delta T_{n}\left(0^{\circ}, 1^{\circ}\right)$ & $T_{n}\left(60^{\circ}\right)$ & $1 / 2 \Delta T_{n}\left(59^{\circ}, 61^{\circ}\right)$ & $T_{n}\left(120^{\circ}\right)$ & $1 / 2 \Delta T_{n}\left(119^{\circ}, 121^{\circ}\right)$ & $z \beta_{2}$ & $z \beta_{3}$ \\
\hline \multirow{28}{*}{ 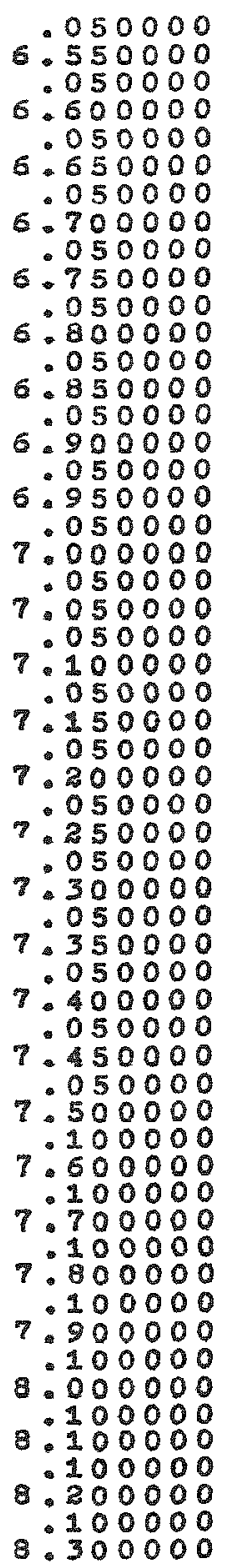 } & \multirow{28}{*}{ 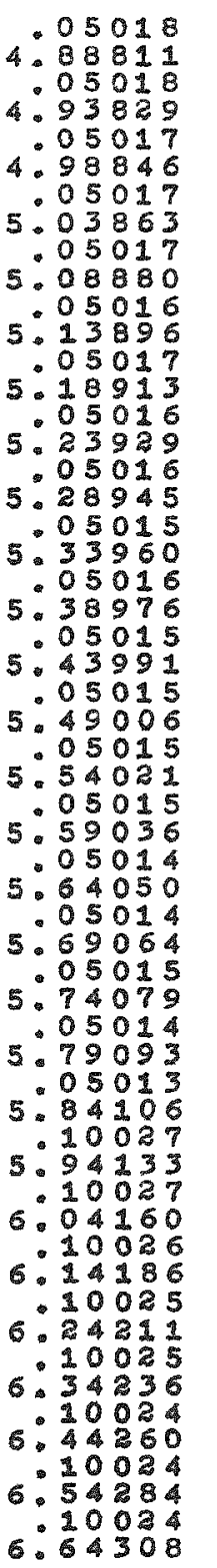 } & .00025 & \multirow{28}{*}{ 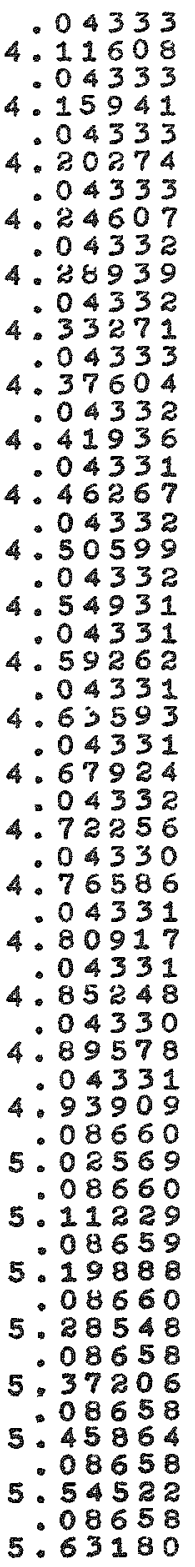 } & .02148 & \multirow{28}{*}{ 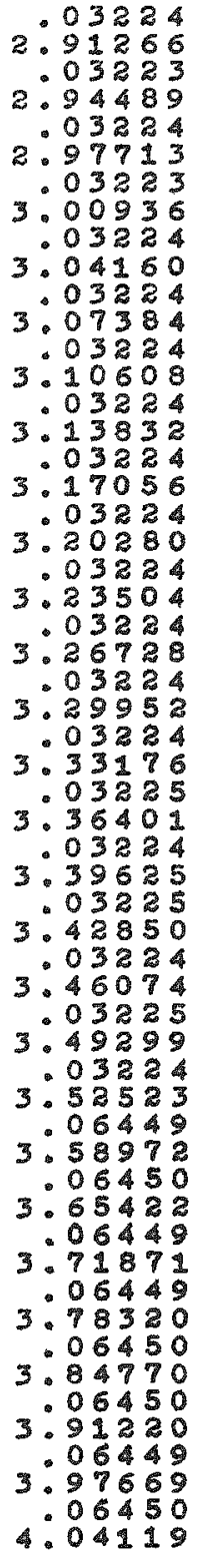 } & .01518 & 33.42320 & 33.48478 \\
\hline & & .00026 & & .02168 & & .01532 & 33.52767 & 33.59011 \\
\hline & & .00026 & & .02187 & & .01547 & 33.63055 & 33.69385 \\
\hline & & .00026 & & .02206 & & .01561 & 33.73188 & 33.79605 \\
\hline & & .00027 & & .02226 & & .01575 & 33.83170 & 33.89673 \\
\hline & & .00026 & & .02245 & & .01589 & 33.93003 & 33.99593 \\
\hline & & .00027 & & .02264 & & .01604 & 34.02692 & 34.09368 \\
\hline & & .00027 & & .02284 & & .01618 & 34.12239 & 34.19001 \\
\hline & & .00028 & & .02303 & & .01633 & 34.21647 & 34.28496 \\
\hline & & .00027 & & .02322 & & .01647 & $34 \cdot 30920$ & 34.37856 \\
\hline & & .00028 & & .02341 & & .01662 & 34.40059 & 34.47082 \\
\hline & & .00028 & & .02360 & & .01676 & 34.49069 & 34.56178 \\
\hline & & .00028 & & .02380 & & .01690 & 34.57951 & 34.65148 \\
\hline & & .00028 & & .02399 & & .01705 & 34.66709 & 34.73993 \\
\hline & & .00029 & & .02418 & & .01719 & 34.75344 & 34.82715 \\
\hline & & .00029 & & .02437 & & .01734 & 34.83860 & 34.91318 \\
\hline & & .00029 & & .02457 & & .01748 & 34.92258 & 34.99005 \\
\hline & & .00030 & & .02476 & & .01762 & 35.00543 & 35.08176 \\
\hline & & .00030 & & .02495 & & .01777 & 35.08714 & 35.16435 \\
\hline & & .00029 & & .02515 & & .01791 & 35.16776 & 35.24585 \\
\hline & & .00030 & & .02553 & & .01820 & 35.32577 & 35.40561 \\
\hline & & .00031 & & .02592 & & .01848 & 35.47962 & 35.56122 \\
\hline & & .00031 & & .02630 & & .01877 & 35.62948 & 35.71285 \\
\hline & & .00031 & & .02669 & & .01906 & 35.77550 & 35.85063 \\
\hline & & .00032 & & .02707 & & .01934 & 35.91782 & 36.00472 \\
\hline & & .00032 & & .02746 & & .01963 & 36.05659 & 36.14525 \\
\hline & & .00032 & & .02784 & & .01992 & 36.19192 & 36.28236 \\
\hline & & .00033 & & .02823 & & .02021 & 36.32395 & 36.41616 \\
\hline
\end{tabular}




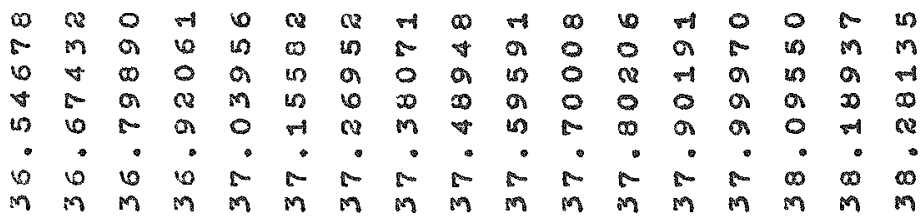

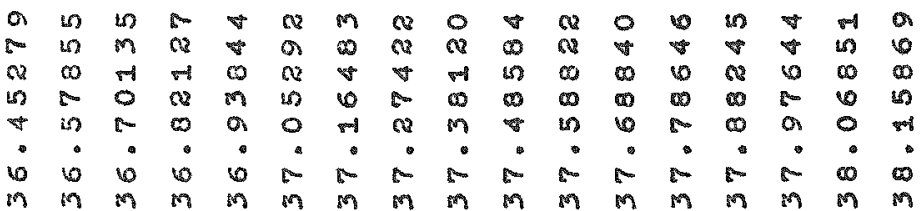

\begin{tabular}{|c|c|c|c|c|c|c|c|c|c|c|c|c|c|c|c|}
\hline$a$ & $\infty$ & 0 & $n$ & 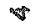 & ces & का & on & $\infty$ & $\infty$ & in & $m$ & $\mathbb{Q}$ & هి & 0 & $\infty$ \\
\hline 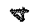 & 2 & 0 & $m$ & $\omega$ & $a$ & $a$ & $\nabla$ & 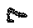 & 0 & $m$ & 6 & $a$ & $\alpha$ & $n$ & 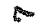 \\
\hline 0 & 0 & $\pi$ & $\omega$ & $\$ 1$ & Fl & 0 & os & $\alpha$ & $\mathrm{m}$ & $m$ & $m$ & $m$ & $\forall$ & 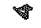 & 搂 \\
\hline$\alpha$ & $w$ & ใะ & $\mathbb{Q}$ & $Q$ & 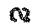 & $\mathfrak{N}$ & $\mathrm{N}$ & $\mathbb{N}$ & 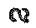 & $\alpha$ & 0 & $\mathbb{Q}$ & $\mathbb{Q}$ & 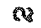 & $\mathbf{Q}$ \\
\hline 6 & 0 & 0 & 0 & 0 & 0 & 0 & 0 & 0 & 0 & 0 & 0 & 0 & 0 & 0 & 0 \\
\hline
\end{tabular}

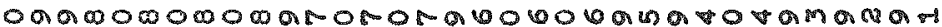
10 10 t

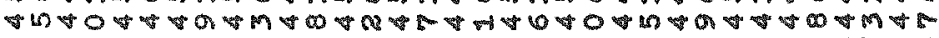
1005 OHO-100000m0 0

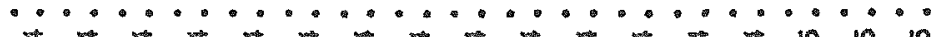

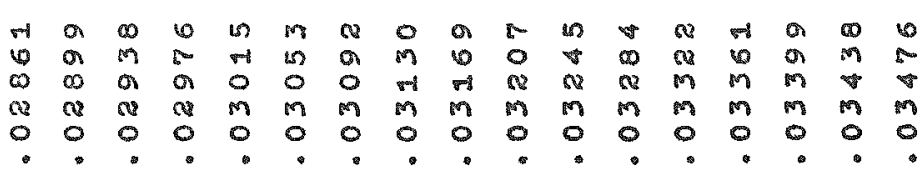

C-

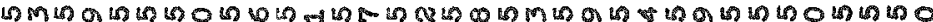

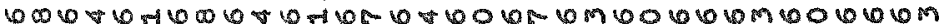

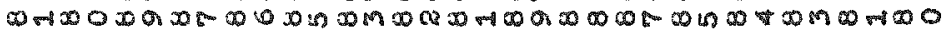

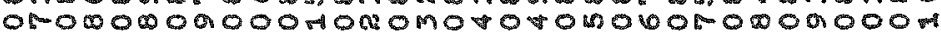

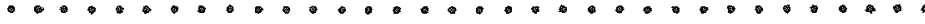

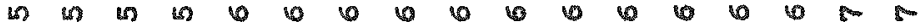

$$
\begin{array}{lllllllllllllllll}
4 & m & n & n & 0 & 0 & \cdots & 0 & \cdots & \cdots & 0 & 0 & 0 & 0 & 0 & 0 & 0 \\
0 & 0 & 0 & 0 & 0 & 0 & 0 & 0 & 0 & 0 & 0 & 0 & 0 & 0 & 0 & 0 & 0 \\
0 & 0 & 0 & 0 & 0 & 0 & 0 & 0 & 0 & 0 & 0 & 0 & 0 & 0 & 0 & 0 & 0 \\
0 & 0 & 0 & 0 & 0 & 0 & 0 & 0 & 0 & 0 & 0 & 0 & 0 & 0 & 0 & 0 & 0
\end{array}
$$

M Q Mล म०

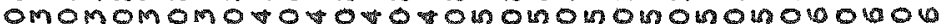

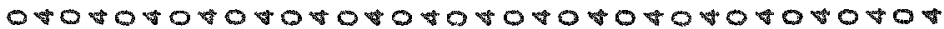

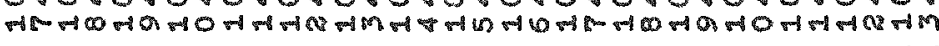

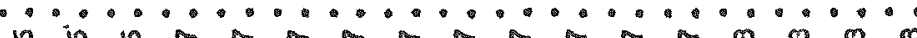

0000000000000000000000000000000000 0000000000000000000000000000000000 0000000000000000000000000000000000 0000000000000000000000000060000000 0000000000000000000000000000000000 स W

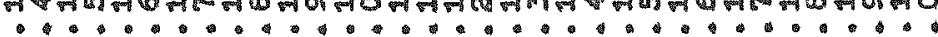

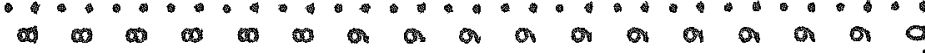


Toble II

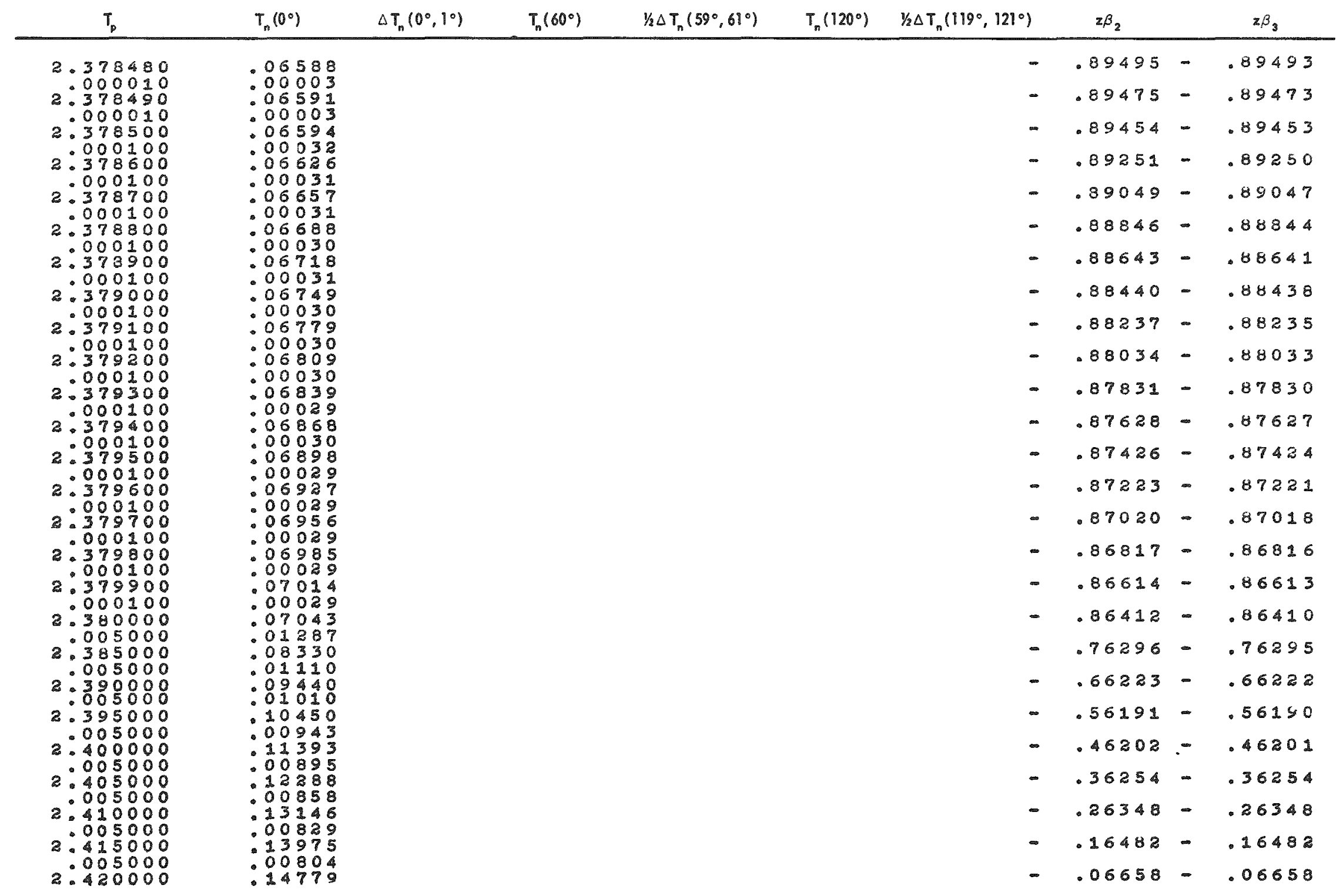




\begin{tabular}{|c|c|}
\hline 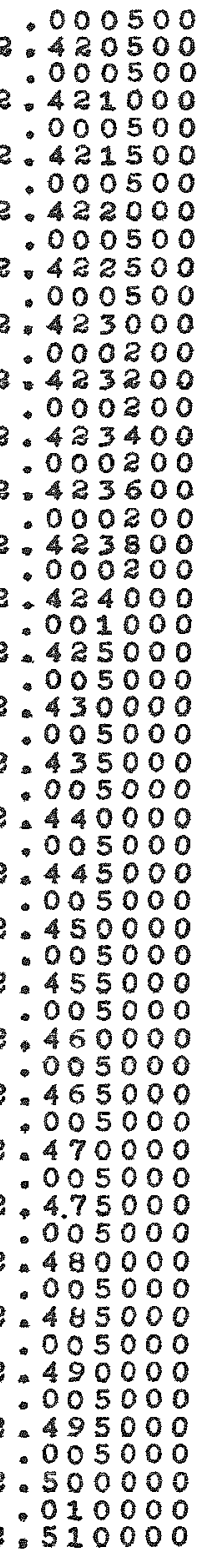 & 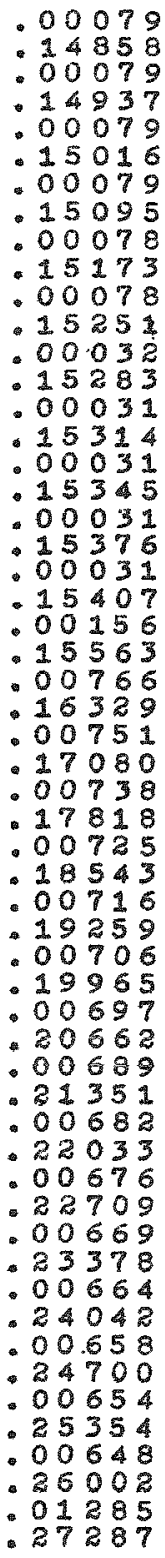 \\
\hline
\end{tabular}

\begin{tabular}{|c|}
\hline 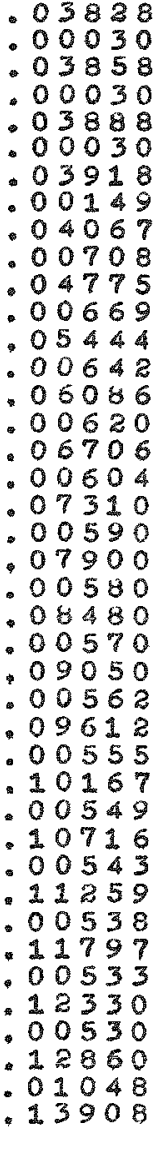 \\
\hline
\end{tabular}

\begin{tabular}{|c|c|c|}
\hline .05677 & - & .05677 \\
\hline .04697 & - & .04697 \\
\hline .03718 & - & .03718 \\
\hline .02739 & - & .02739 \\
\hline .01760 & - & .02760 \\
\hline .00782 & - & .0078 \\
\hline .00391 & - & .00391 \\
\hline .00000 & & .00000 \\
\hline .00391 & & .00391 \\
\hline .00782 & & .00782 \\
\hline .01173 & & .01173 \\
\hline .03127 & & .03127 \\
\hline .12870 & & .12870 \\
\hline .22574 & & .22574 \\
\hline .32238 & & .32238 \\
\hline . 41862 & & .41863 \\
\hline .51447 & & .51448 \\
\hline .60993 & & .60994 \\
\hline .70500 & & .70501 \\
\hline .79969 & & .79970 \\
\hline .89399 & & .89401 \\
\hline .98791 & & .96793 \\
\hline 1.08145 & & 1.08147 \\
\hline 1.17 & & 1.17464 \\
\hline 1.26740 & & 1.26744 \\
\hline 1.35982 & & 1.35986 \\
\hline 1.45187 & & 1.45191 \\
\hline 1. & & 1.6349 \\
\hline
\end{tabular}


Table II (Cont'd)

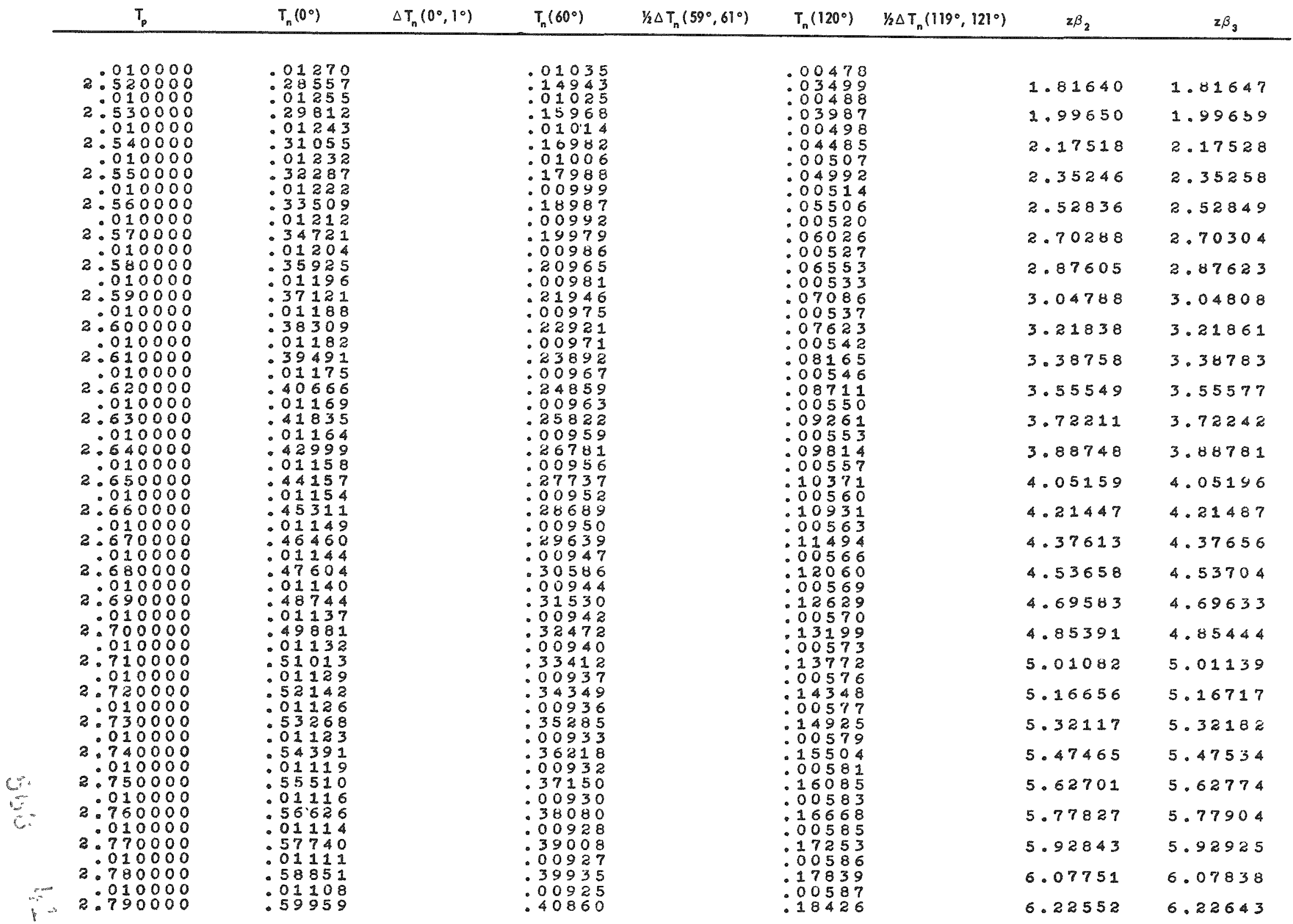




\begin{tabular}{|c|c|}
\hline 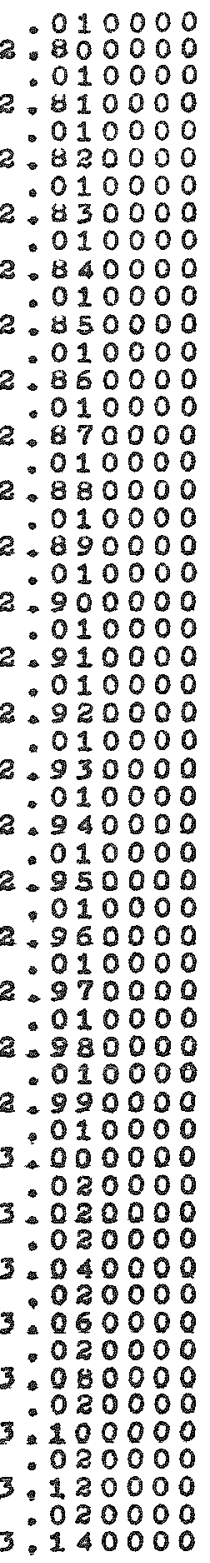 & 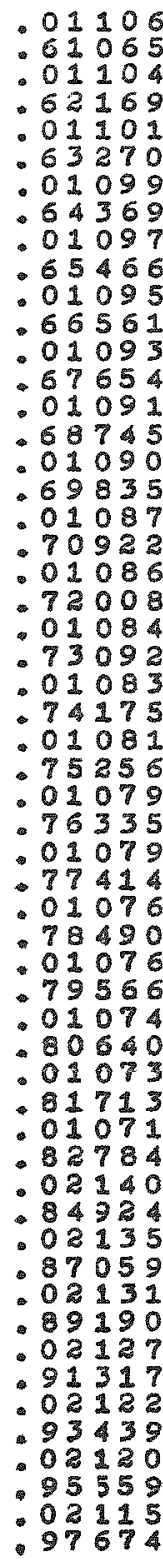 \\
\hline
\end{tabular}

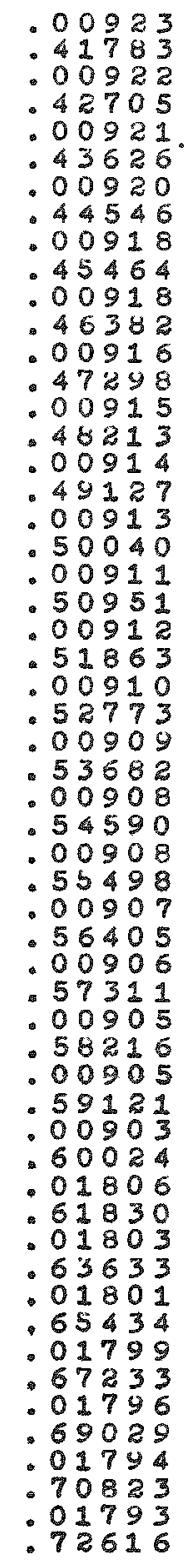

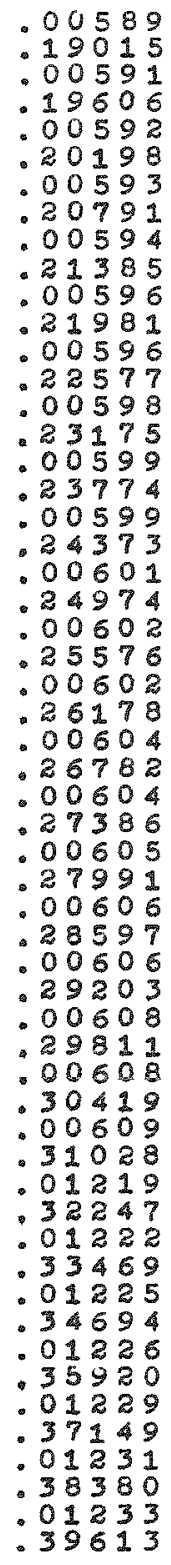

$\begin{array}{ll}6.37247 & 6.37343 \\ 6.51838 & 6.51938 \\ 6.66325 & 6.66430 \\ 6.80709 & 6.80819 \\ 6.94992 & 6.95107 \\ 7.09175 & 7.09295 \\ 7.23258 & 7.23383 \\ 7.37243 & 7.37374 \\ 7.51131 & 7.51267 \\ 7.64922 & 7.65064 \\ 7.78618 & 7.78766 \\ 7.92220 & 7.92374 \\ 8.05729 & 8.05088 \\ 8.19145 & 8.19310 \\ 8.32470 & 8.32641 \\ 8.45705 & 8.45882 \\ 8.58850 & 8.59033 \\ 8.71906 & 8.72096 \\ 8.84874 & 8.85070 \\ 8.97756 & 8.97958 \\ 9.10552 & 9.10761 \\ 9.35888 & 9.36111 \\ 9.60891 & 9.61127 \\ 9.85567 & 9.85817 \\ 0.09921 & 10.10185 \\ 0.33961 & 10.34240 \\ 0.57692 & 10.57986 \\ 0.81121 & 10.81429\end{array}$




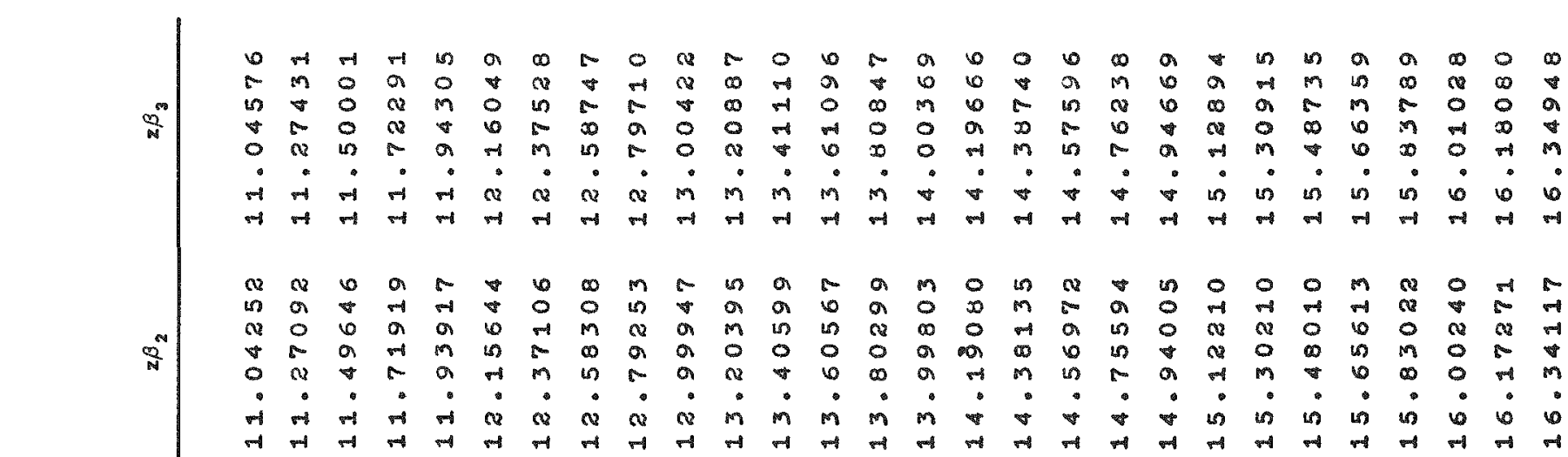

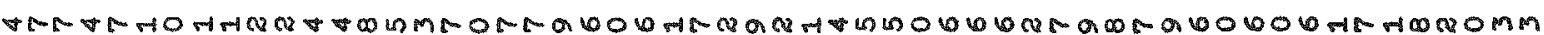

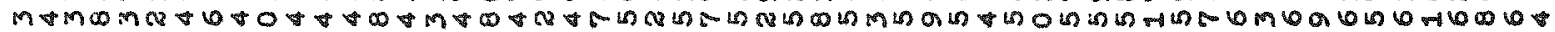

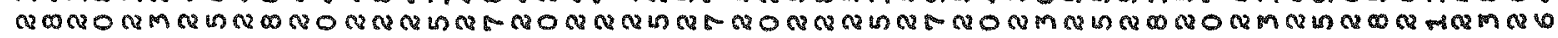

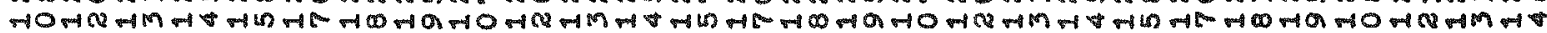

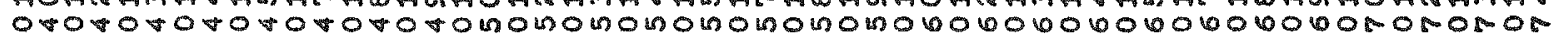

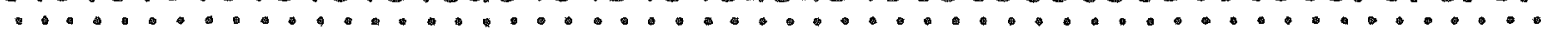

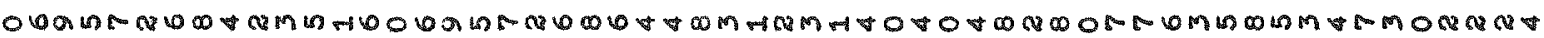

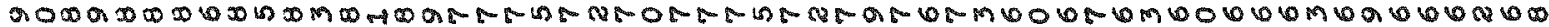

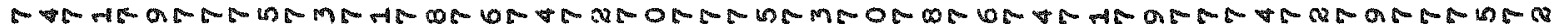

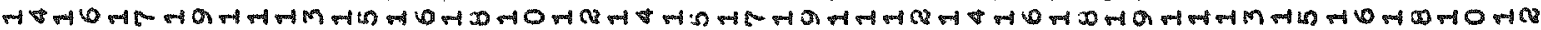

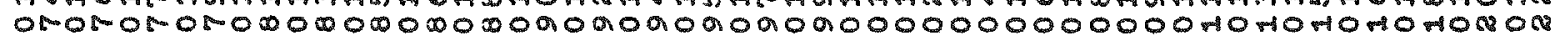

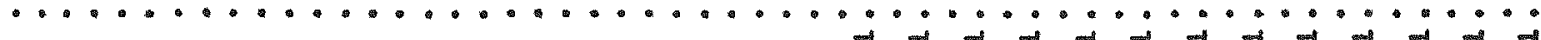$$
\text { ता }
$$

MHOW

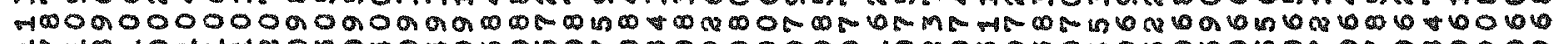

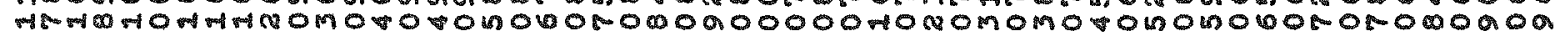

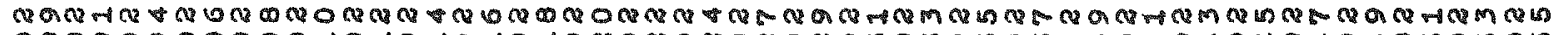

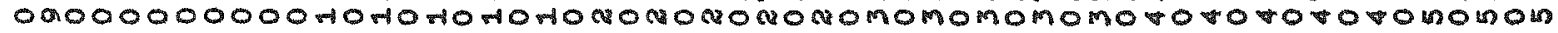

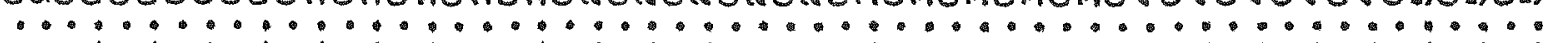

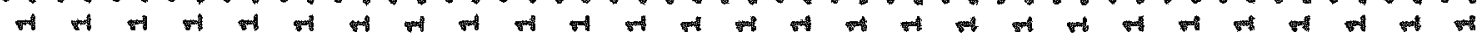

09000000000009000000000000000000000000000000000000000000 00000000000000000000000000000000000000000000000000000000 00000000000000000000000000000000000000000000000000000000 00000000000000000000000000000000000000000000000000000000

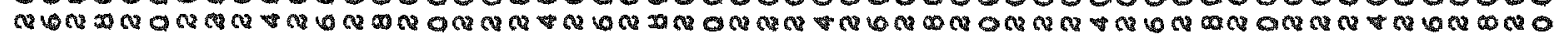

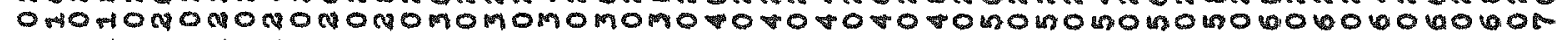

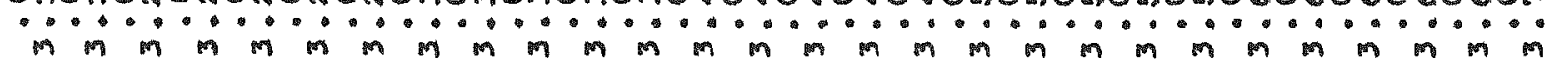




\begin{tabular}{|c|c|}
\hline 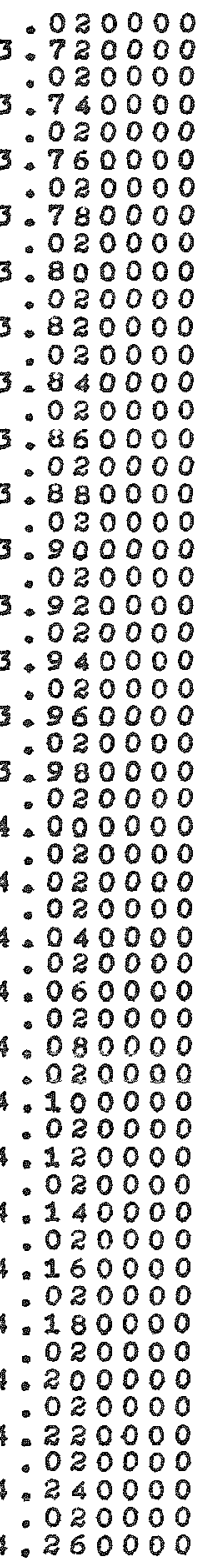 & 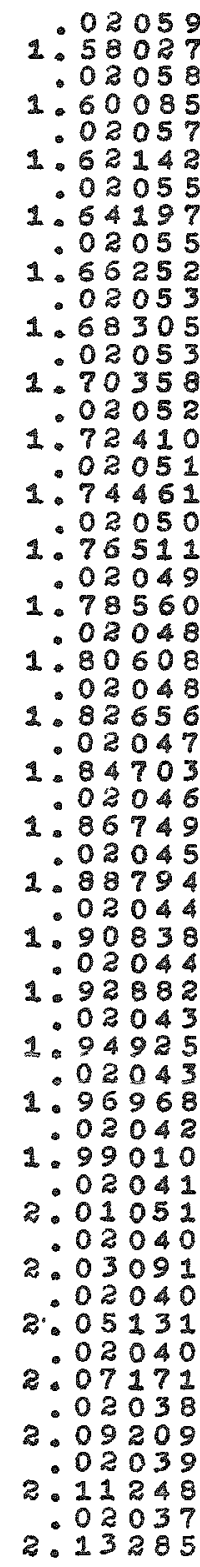 \\
\hline
\end{tabular}

\begin{tabular}{|c|c|}
\hline 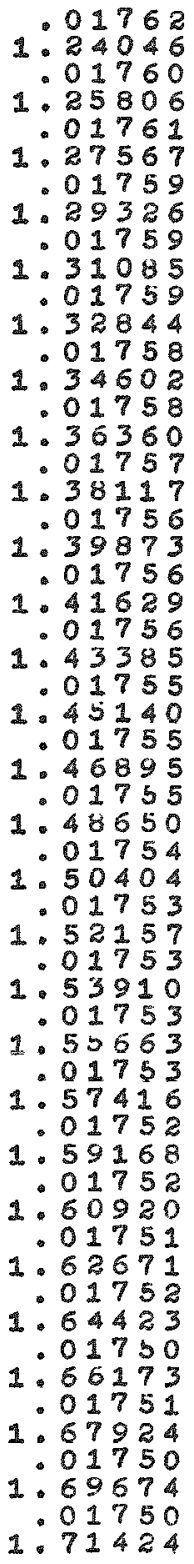 & 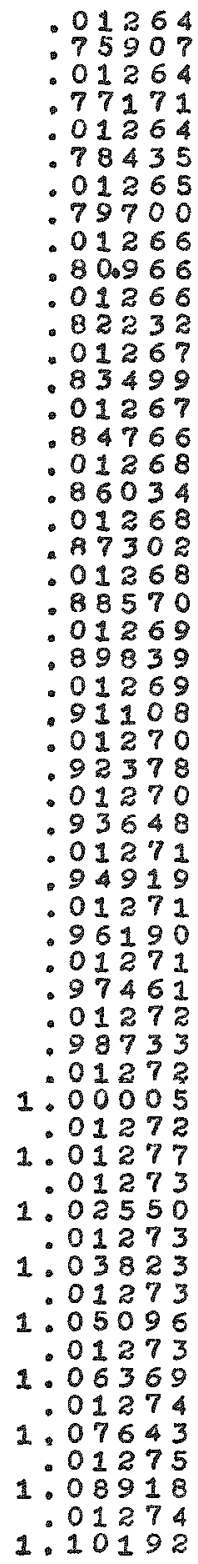 \\
\hline
\end{tabular}

\begin{tabular}{|c|c|}
\hline 16.50782 & 16.51635 \\
\hline 16.67268 & 16.6814 \\
\hline 16.83578 & 16.8447 \\
\hline 16.99716 & 17.00634 \\
\hline 17.15683 & 17.16624 \\
\hline 17.31482 & 17.32445 \\
\hline 17.47117 & 17.4810 \\
\hline 17.62589 & 17.63597 \\
\hline 17.77901 & 17.78933 \\
\hline 17.93056 & 17.94110 \\
\hline 18.08055 & 18.09133 \\
\hline 18.22903 & 18.24004 \\
\hline 18.37599 & 18.38724 \\
\hline 18.52148 & $18.5=$ \\
\hline 18.66551 & 18.67 \\
\hline 18.80810 & 100 \\
\hline 18.94927 & 18.9614 \\
\hline 19.08905 & 19.1014 \\
\hline 19.22746 & 19.24014 \\
\hline 19.36451 & 19.37744 \\
\hline 19.50023 & 19.51341 \\
\hline 19.63464 & 19.64806 \\
\hline 19.76774 & 19.78141 \\
\hline 19.89957 & 19.91349 \\
\hline 20.03014 & 20.04431 \\
\hline 20.15947 & 20.1739 \\
\hline 20.28758 & 20.3022 \\
\hline 20.4144 & 20.429 \\
\hline
\end{tabular}


Table II (Cons'd)

\begin{tabular}{|c|c|c|c|c|c|c|}
\hline$T_{p}$ & $T_{0}\left(0^{\circ}\right)$ & $\Delta T_{n}\left(0^{\circ}, 1^{\circ}\right)$ & $T_{m}\left(60^{\circ}\right)$ & $1 / 2 \Delta T_{n}\left(59^{\circ}, 61^{\circ}\right)$ & $1 / 2 \Delta T_{n}\left(119^{\circ}, 121^{\circ}\right)$ & $2 \beta_{3}$ \\
\hline 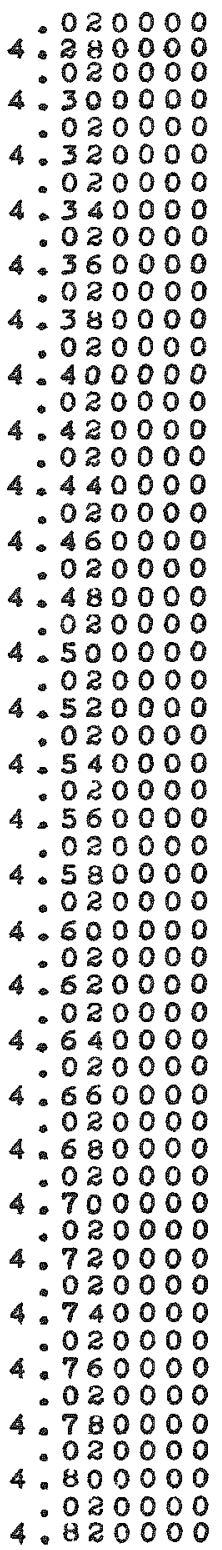 & 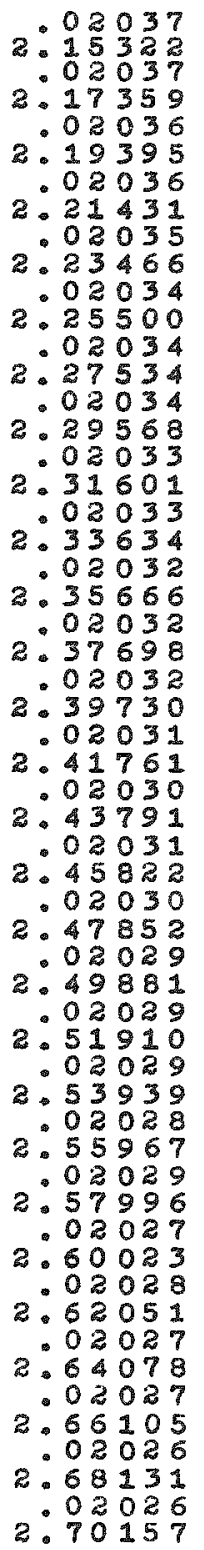 & & 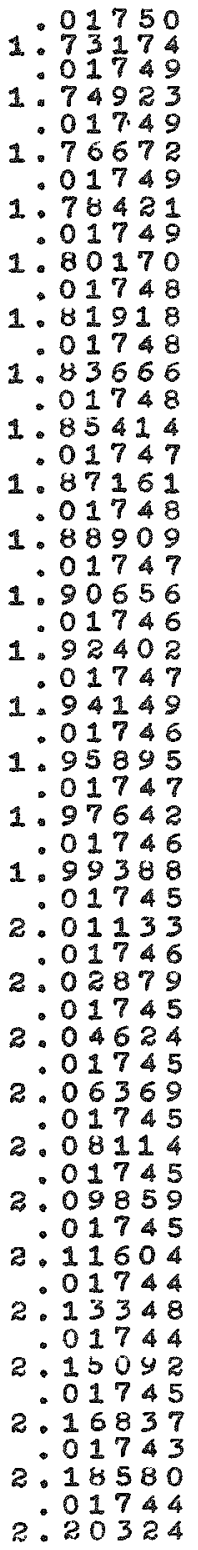 & 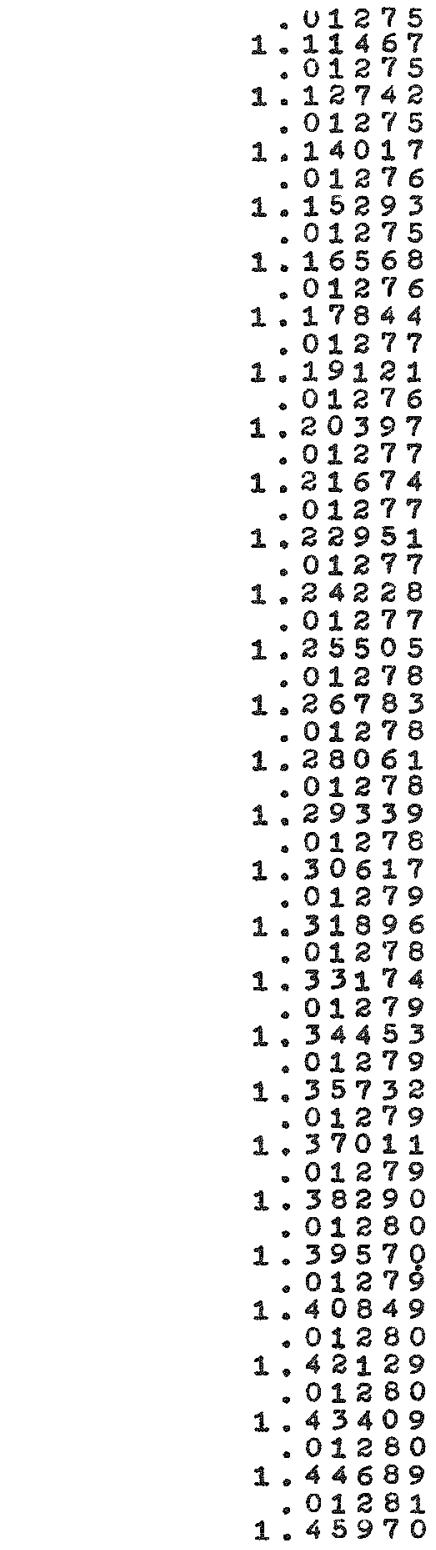 & $\begin{array}{l}20.54019 \\
20.66472 \\
20.78811 \\
20.91035 \\
21.03146 \\
21.15147 \\
21.27038 \\
21.38821 \\
21.50498 \\
21.62069 \\
21.73537 \\
21.84903 \\
21.96168 \\
22.07333 \\
22.18400 \\
22.29370 \\
22.40244 \\
22.51024 \\
22.61710 \\
22.72305 \\
22.82808 \\
22.93222 \\
23.03547 \\
23.13785 \\
23.23937 \\
23.34003 \\
23.43985 \\
23.53884\end{array}$ & $\begin{array}{l}20.55537 \\
20.68017 \\
20.80381 \\
20.92631 \\
21.04768 \\
21.16795 \\
21.28712 \\
21.40522 \\
21.52225 \\
21.63823 \\
21.75317 \\
21.86710 \\
21.98002 \\
22.09193 \\
22.20287 \\
22.31285 \\
22.42186 \\
22.52993 \\
22.63707 \\
22.74329 \\
22.84860 \\
22.95301 \\
23.05654 \\
23.15920 \\
23.26099 \\
23.36193 \\
23.46203 \\
23.56130\end{array}$ \\
\hline
\end{tabular}




\begin{tabular}{|c|c|}
\hline 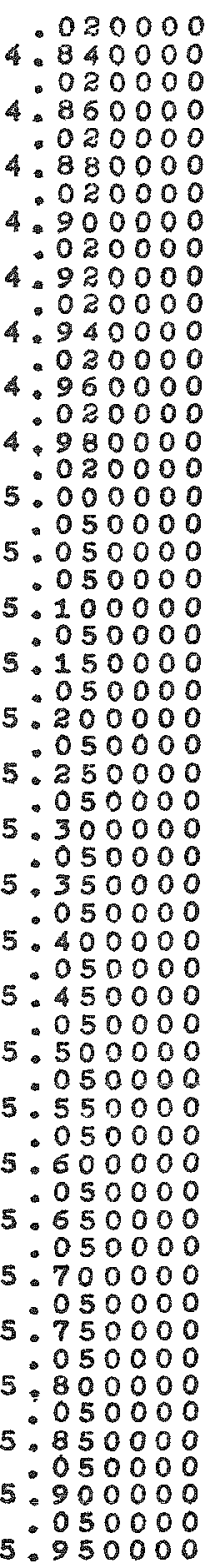 & 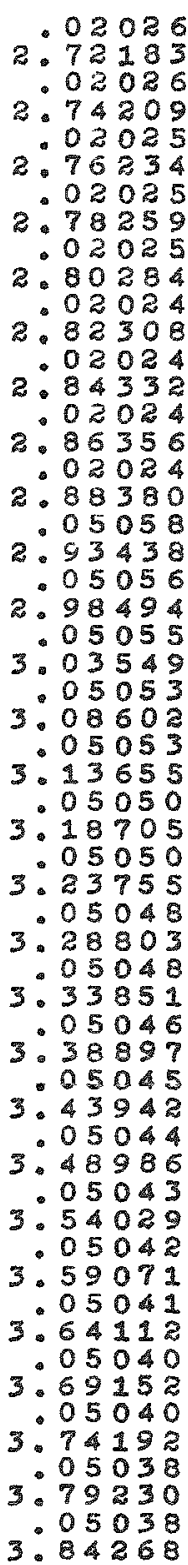 \\
\hline
\end{tabular}

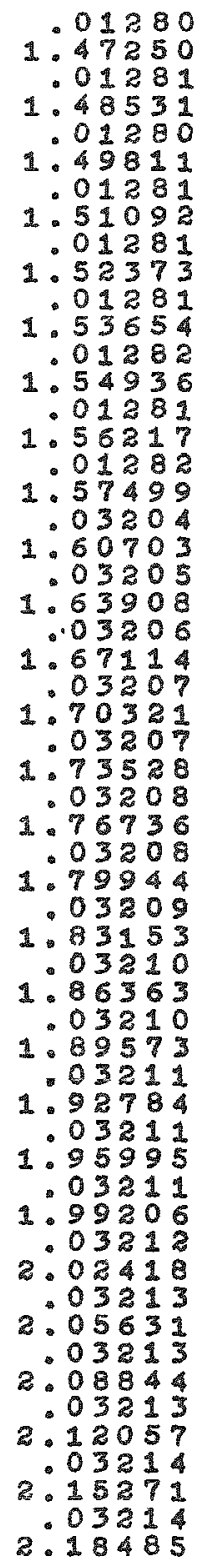

23.63701

23.65975

2.22068

2:23811

- 01743

2.25554

2.27298

- 01743

. 2.

2:30785

- 01743

.01742

2. 34268

2. $3601 \frac{1}{5}$

2. 40366

- 04355

.04351

2. 49074

04353
.53427

2. 57352

. 04352

2. 62131

2. 65481

- 04350

2.70831

.75181

. 04349

.79530

- 034

.04347

.88225

- 04347

.04347

2.96919

.04346

3:05611

3.04345

. 09956

$3: 14300$

3.1864

$\begin{array}{ll}23.73436 & 23.75739 \\ 23.83092 & 23.05423 \\ 23.92668 & 23.95028 \\ 24.02166 & 24.04555 \\ 24.11588 & 24.14004 \\ 24.20933 & 24.23378 \\ 24.30202 & 24.32676 \\ 24.39397 & 24.41900 \\ 24.62064 & 24.64639 \\ 24.84285 & 24.86933 \\ 25.06073 & 25.08794 \\ 25.27440 & 25.30234 \\ 25.48399 & 25.51267 \\ 25.68959 & 25.71902 \\ 25.89134 & 25.92151 \\ 26.08934 & 26.12026 \\ 26.28368 & 26.31536 \\ 26.47448 & 26.50691 \\ 26.66182 & 26.69501 \\ 26.84580 & 26.87975 \\ 27.02650 & 27.06122 \\ 27.20402 & 27.23951 \\ 27.37844 & 27.41470 \\ 27.54983 & 27.58686 \\ 27.71828 & 27.75609 \\ 27.88385 & 27.92244 \\ 28.04663 & 28.08600\end{array}$


Table II (Conf'd)

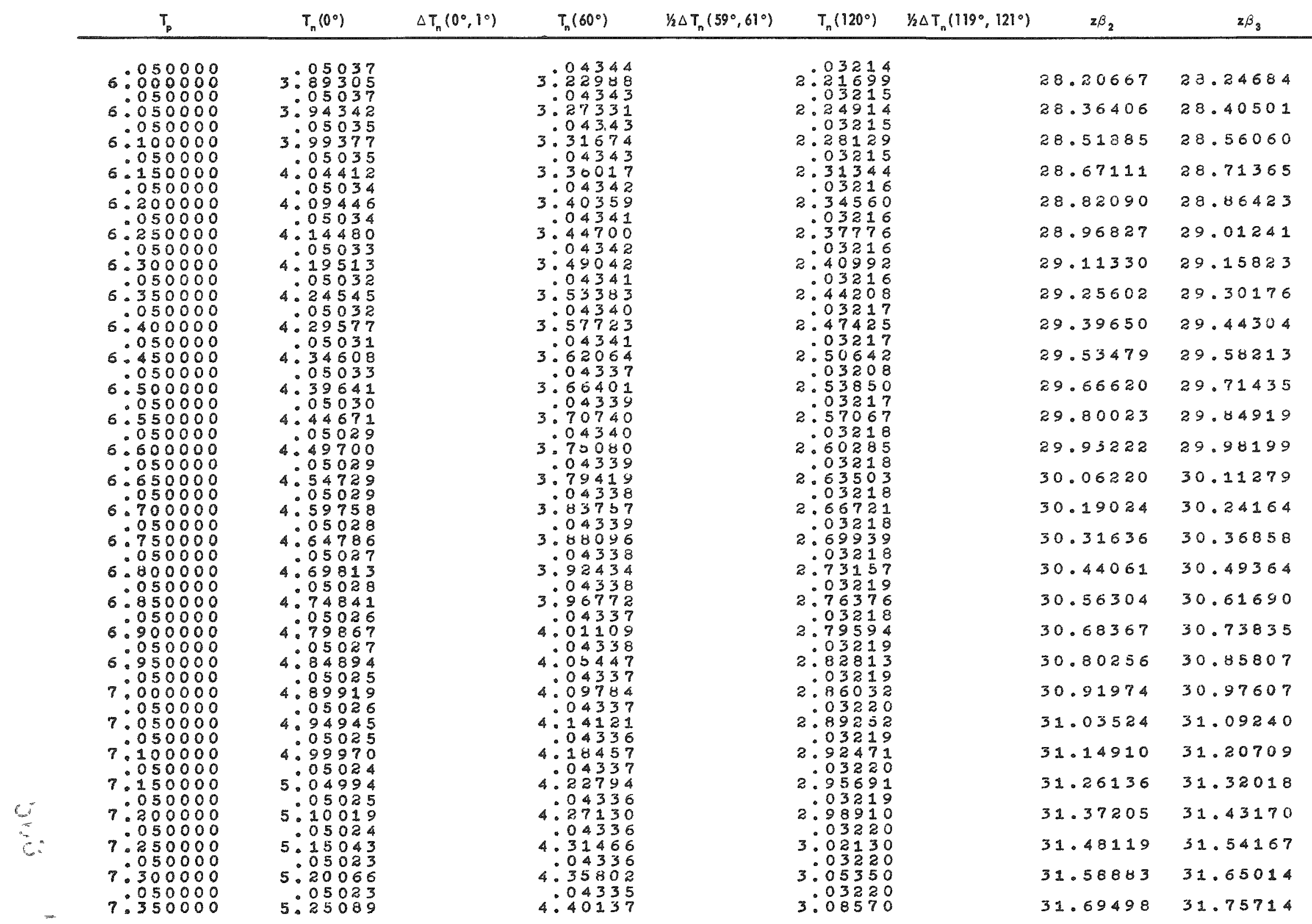




\begin{tabular}{|c|c|c|c|c|c|c|c|c|c|c|c|c|c|c|c|c|c|c|c|c|c|c|c|c|c|c|}
\hline$a$ & 08 & $D$ & 0 & 0 & $\infty$ & 0 & 5 & 6 & $\mathrm{QB}$ & $\mathrm{CQ}$ & $H$ & $x-1$ & $\infty$ & $\nabla$ & $s$ & +1 & 10 & त & or & 9 & 02 & a & o & $\infty$ & $\sigma$ & 02 \\
\hline 10 & $\infty$ & 12 & 0 & $\alpha$ & $n$ & 5 & $n$ & 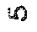 & $\notin$ & $H$ & $\infty$ & 10 & 0 & -1 & H & $\infty$ & 0 & 0 & $m$ & $S$ & $\pi$ & $\forall$ & $m$ & 10 & सै & $\infty$ \\
\hline$a$ & 10 & a & $H$ & 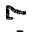 & $\infty$ & 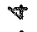 & $\infty$ & $m$ & 10 & 12 & on & 0 & $r$ & $H$ & -1 & $\infty$ & 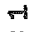 & $5-1$ & $\omega$ & 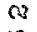 & $m$ & $\alpha$ & $\infty$ & -1 & $\mathbb{Q}$ & 8 \\
\hline 10 & 0 & $\omega$ & $s$ & 6 & 10 & $\$$ & $\mathbf{Q}$ & 0 & $\infty$ & $\forall$ & 0 & $\infty$ & 0 & $\$$ & $n$ & 5 & $\infty$ & $: 0$ & or & 9 & $\omega$ & $a$ & 84 & 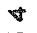 & 0 & 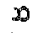 \\
\hline$\infty$ & $a$ & 0 & $\otimes$ & $\forall$ & 6 & $\infty$ & 0 & 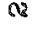 & $m$ & 40 & $\infty$ & $x$ & 0 & 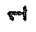 & $n$ & $\forall$ & 10 & $\infty$ & $\infty$ & 0 & $H$ & $\mathbf{0}$ & 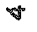 & in & 10 & $p \rightarrow$ \\
\hline - & - & - & - & - & - & - & - & - & - & - & - & - & - & - & - & - & - & - & - & • & 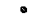 & - & - & . & - & - \\
\hline 4 & HI & $\alpha$ & $Q ?$ & నo & $\alpha$ & N & $n$ & $m$ & $m$ & $m$ & $m$ & $m$ & 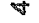 & $\forall$ & $*$ & 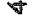 & $v$ & 8 & $\checkmark$ & 18 & 0 & 40 & 10 & in & $\Omega$ & 10 \\
\hline 7 & $m$ & $m$ & $m$ & $M$ & $m$ & $m$ & $m$ & $m$ & $m$ & $m$ & $m$ & $m$ & $m$ & $m$ & $m$ & $m$ & $m$ & $m$ & $m$ & $m$ & $m$ & $m$ & $m$ & $m$ & $n$ & 9 \\
\hline
\end{tabular}

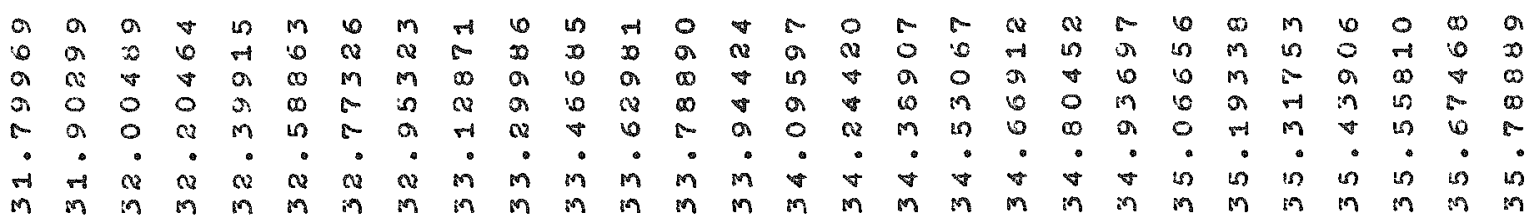

OOFWOF HNO

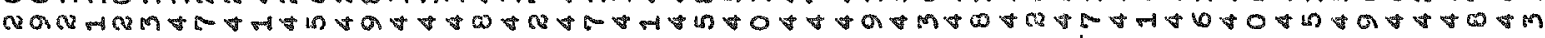
QR

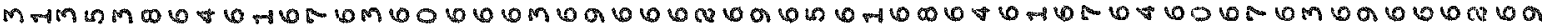

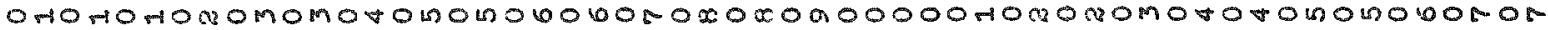

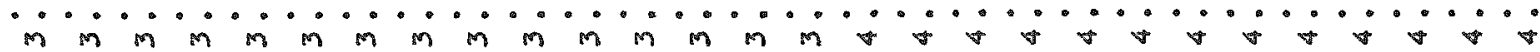

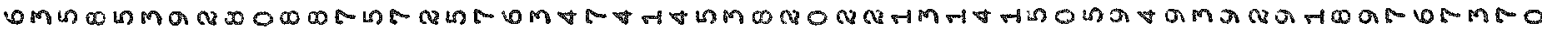
MAMOM W MMcommlo ow

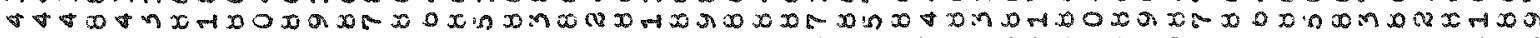

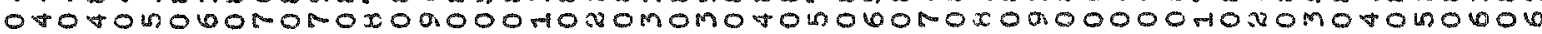

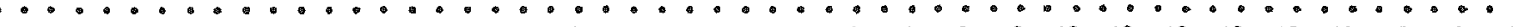

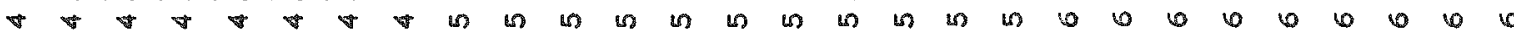

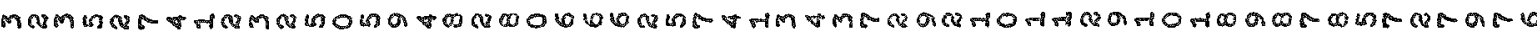
QHWMRL

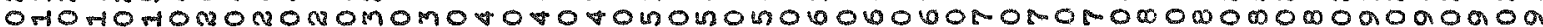
nown no00000000000000000000000000000000000000000000000000

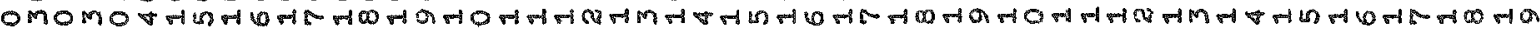

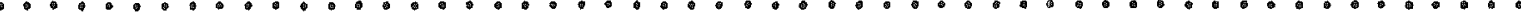

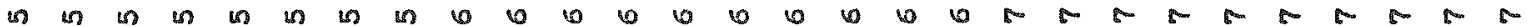

00000000000000000000000000000000000000000000000000000000 00000000000000000000000000000000000000000000000000000000 00000000000000000000000000000000000000000000000000000000 00000000000000000000000000000000000000000000000000000000 noth n th 000000000000000000000000000000000000000000000000000

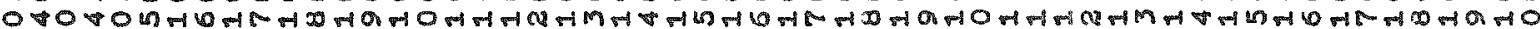

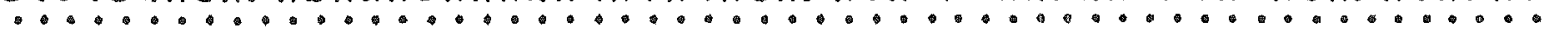

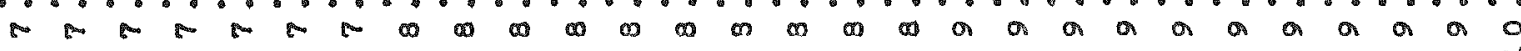

